University of Louisville

ThinkIR: The University of Louisville's Institutional Repository

Electronic Theses and Dissertations

7-1981

\title{
A new assessment of the archaeological significance of the Ashworth site (15Bu236).
}

Philip James DiBlasi 1954-

University of Louisville

Follow this and additional works at: https://ir.library.louisville.edu/etd

\section{Recommended Citation}

DiBlasi, Philip James 1954-, "A new assessment of the archaeological significance of the Ashworth site (15Bu236)." (1981). Electronic Theses and Dissertations. Paper 342.

https://doi.org/10.18297/etd/342

This Master's Thesis is brought to you for free and open access by ThinkIR: The University of Louisville's Institutional Repository. It has been accepted for inclusion in Electronic Theses and Dissertations by an authorized administrator of ThinkIR: The University of Louisville's Institutional Repository. This title appears here courtesy of the author, who has retained all other copyrights. For more information, please contact thinkir@louisville.edu. 
A NEW ASSESSMENT OF THE ARCHAEOLOGICAL SIGNIFICANCE

OF THE ASHWORTH SITE (15BU236)

A Study of the Dynamics of Archaeological Investigation in Cultural Resource Management

By

Philip James DiBlasi

B.A., University of Louisvi17e, 1976

\author{
A Thesis \\ Submitted to the Faculty of the \\ Graduate School of the University of Louisville \\ in Partial Fulfillment of the Requirements \\ for the Degree of
}

Master of Science

Interdisciplinary Studies

University of Louisville

Louisville, Kentucky

JuTy 1981 
A NEW ASSESSMENT OF THE ARCHAEOLOGICAL SIGNIFICANCE OF THE ASHWORTH SITE (15Bu236)

A Study of the Dynamics of Archaeological Investigation in Cultural Resource Management

By

Philip James DiBlasi

B.A., University of Louisville, 1976

A Thesis Approved on

August 4, 1981

by the following Reading Committee:

Thesis Director

Stuart E. Neff 


\section{ABSTRACT}

Reinvestigation of a National Register property, the Ashworth Rockshelter (15BU236), northeast of Shepardsville, Bullitt Co., Kentucky, revealed stratified Early Archaic through Mississippian components (ca. 7900 B.C. -1500 A.D.). Primary occupation occurred under the shelter and eight meters (horizontally) of talus were located. The depth of the deposit is two meters, the lowest third representing the Early Archaic period. Forty-five culturaliy-diagnostic projectile points delineated the strata.

Seven well-preserved burials indicate early mortality, severe physical conditions, and a preference to bury under the shelter. Wellpreserved mollusks and vertebrate remains indicate a subsistence shift from aquatic to forest-edge communities from Early to Late Archaic periods.

Federal legislation relevant to the significance statement must be observed if sites such as Ashworth are to be fully assessed and their priority determined in an archaeological planning design for the region. 


\section{ACKNOWLEDGEMENTS}

The author gratefully acknowledges the financial assistance of the University of Louisville's Archaeological Survey and the Dean's Office of the Graduate School. The author also wishes to express his thanks to the following persons whose assistance has made this work possible: Ronald C. Wilson, Paul W. Parmalee, and John E. Guilday for their identification of the vertebrate remains; William $\mathrm{F}$. Clench, Stuart E. Neff, James L. Conkin, and Paul D. Barker for their identification of the mollusks recovered, Philip A. DiBlasi and Stuart E. Neff for their assistance with burial four; Joseph E. Granger for his overall guidance (and library) and finally the Ashworth family for allowing me to excavate on their property. 


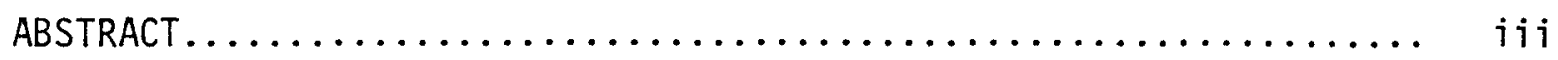

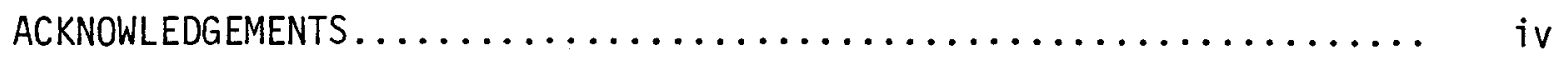

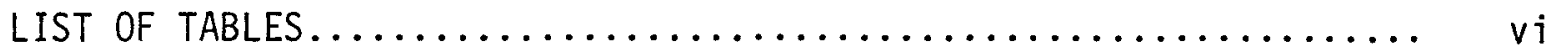

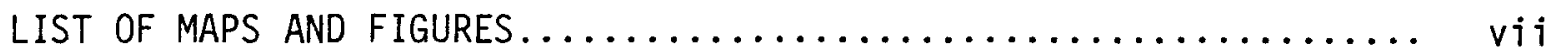

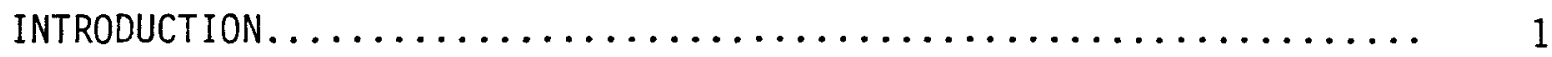

NATURAL HISTORY OF SITE AREA............................. 4

Geology-Pedology................................. 4

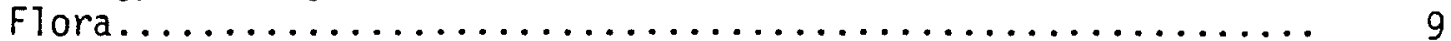

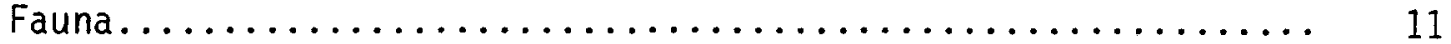

Proximity and Availability of Salt..................... 14

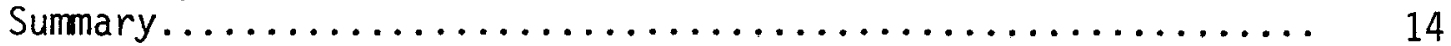

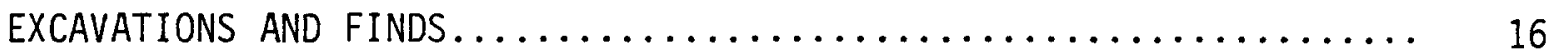

Excavations...................................... 16

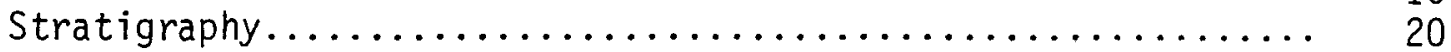

Features..................................... 22

Culturally-diagnostic objects....................... 26

Diagnostic Projectiles........................... 30

Non-diagnostic Projectiles and Fragments................. 54

Ceramics and Fired Clay.............................. 57

Burials and Human Remains.......................... 66

Faunal Remains................................. 80

Vertebrates............................... 80

Mollusca..................................... 84

Radiocarbon Determinations.......................... 88

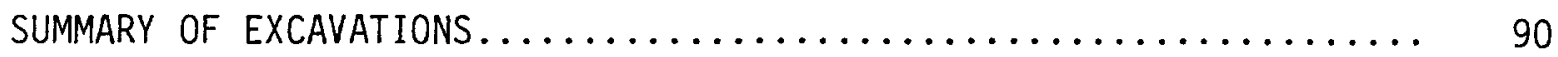

CULTURAL RESOURCE MANAGEMENT OVERVIEW..................... 93

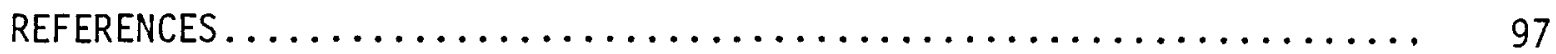

APPENDIX A: BURIAL DATA............................. 102

APPENDIX B: FAUNAL REMAINS.......................... 109

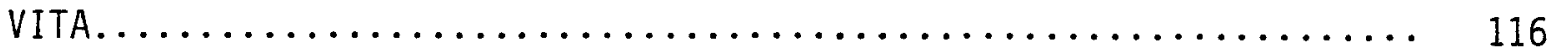




\section{LIST OF TABLES}

Page

TABLE 1. Late Archaic Stemmed Projectiles................... 39

TABLE 2. Salt River Side Notched Projectiles................ 43

TABLE 3. Ashworth Corner Notched Projectiles................ 52

TABLE 4. Nondiagnostic Material Culture................... 63

TABLE 5. Nondiagnostic Material Culture - NOW2

(Profile Control Unit)........................ 65

TABLE 6. The Ten Most Common Vertebrates from Occupied Strata............................. 82

TABLE 7. Percentages of Class of Animals from a11 Identified Bone............................. 82

TABLE 8. Molluscs Identified from NOW10.................. 85 


\section{LIST OF MAPS AND FIGURES}

Page

MAP 1. Location of the Ashworth Site, Brooks and

Shepardsville, Kentucky $7.5^{\prime}$ U.S.G.S............... 5

FIGURE 1. Plan of the Ashworth Site and excavated units........ 6

FIGURE 2. South wall profile of excavation units........... 8

FIGURE 3. The stratigraphy at the Ashworth Site........... 21

FIGURE 4. Feature locations at the Ashworth Site........... 23

FIGURE 5. Woodland and Late Archaic features.............. 24

FIGURE 6. Early Archaic features................... 27

FIGURE 7. Temporal and stratigraphic position of projectile points at the Ashworth Site.................... 29

FIGURE 8. Woodland projectile points recovered from

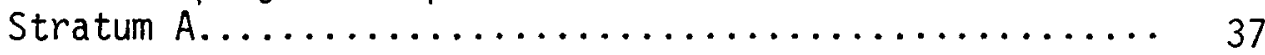

FIGURE 9. Late Archaic stemmed projectile points recovered from Stratum $B \ldots \ldots \ldots \ldots \ldots \ldots \ldots \ldots \ldots \ldots$

FIGURE 10. Salt River Side Notched projectile points recovered from Stratum B.................... 41

FIGURE 11. Middle and late Early Archaic projectile points recovered from Stratum B................ 44

FIGURE 12. Ashworth Corner Notched projectile points recovered from Stratum C.................... 49

FIGURE 13. Ashworth Corner Notched projectile points recovered from Stratum C................... 50

FIGURE 14. Non-diagnostic projectile points and fragments...... 55

FIGURE 15. Burial locations..................... 67 


\section{INTRODUCTION}

The Ashworth site (15Bu236) located in Bullitt County, Kentucky, was first discovered in 1974 as part of an environmental assessment for the relocation and expansion of the Kentucky Turnpike (Interstate 65). This reconnaissance found eleven archaeological sites. In an effort to assess the significance of these resources, the principal investigator, Betty J. McGraw, tested five of the sites (McGraw 1977:88). These test excavations revealed that only the Ashworth site was possibly eligible for inclusion in the National Register of Historic Places. The State Historic Preservation Officer certified that the site had been evaluated and forwarded the nomination on 14 July, 1975, and the site was entered in the National Register on 11 September, 1975.

The draft environmental impact assessment, prepared by the Kentucky Department of Transportation (KYDOT), was circulated for comment in 1977. Comments discussed in a number of public meetings were a]so considered. Both the Office of State Archaeology (OSA) and the University of Louisville Archaeological Survey (ULAS) raised questions concerning the thoroughness and the legality of the archaeology that B. J. McGraw had carried out. The OSA comments also commented on the archaeological impact assessment, stating that it did not: 1) provide adequate treatment of the resources, 2) comply with federal law and regulation, 3) made erroneous statements concerning impacts, 4) significance of several of the sites had not yet been determined, and 5) a mitigation plan (for sites that might be determined significant) needed to be proposed. 
The University of Louisville Archaeological Survey raised questions that dealt specifically with the Ashworth site. Collectively, the specific points addressed were concerned with the questionable sampling methods that led to an incomplete testing of the site and, as a result, an incomplete statement of its significance. Neither existing and possible impacts nor specific mitigation alternatives were discussed.

The Kentucky Department of Transportation (KYDOT 1978) treated these reviewers' comments in a perfunctory manner in the final environmental impact assessment. Rather than comply with federal law and regulation by requesting additional field work and analysis to correct the technical errors or to deal with the sites in a thorough manner, KYDOT chose to defend the principal investigator and thereby circumvented the issues raised by the reviewers.

Concurrently, ULAS developed a research design for the management of the cultural resources of the Falls of the Ohio region. Since B. J. McGraw did not discuss the Ashworth site as a resource in terms of that regional design, the present writer decided to re-examine the site. The work that I undertook was concerned with determining the significance of this resource to the cultural history of the Floyd's Fork drainage system.

The results of my investigations demonstrate that the Ashworth site is a significant resource to the Falls region and possibly to the eastern United States. This statement of significance is based upon:

1) the variety (Early Archaic-Mississippian) of cultures and materials present;

2) the quantity of faunal, cultural and anthropological materials; 
3) the depth of the deposits and their distinctiveness;

4) the degree of preservation and undisturbed nature of the deposits; and

5) the environmental context of the site's materials.

These properties will be discussed below relative to existing research designs and specific research strategies that have been developed to deal with the findings. 
The Ashworth site (15Bu236 Rockshelter \#7) is located at $85^{\circ}$ $50^{\prime} 40^{\prime \prime}$ west longitude and $38^{\circ} 00^{\prime} 57^{\prime \prime}$ north latitude in Bullitt County, Kentucky. The Universal Transverse Mercator grid reference is taken from the Brooks, Kentucky 7.5' United States Geologic Survey quadrangle, 1959 edition (Photorevision 1971). The U.T.M. reference is Zone 16: 4,208,040 meters North and 614,530 meters East (Map 1). The shelter has formed in Louisville Limestone at the foot of MacDonald Knob in the Floyd's Fork stream valley.

The overhang of the rockshelter is 23 meters wide (north-south) and three meters deep (east-west). The height of the overhang, measured from the modern floor, averages 1.5 meters. There has been a considerable amount of talus built up since the initial occupation. Measured horizontaily from the drip line to the foot of the slope, it averages 6.5 meters (Figure 1). The shelter faces east.

\section{Geology-Pedology}

Floyd's Fork has played a major role in the formation and prehistory of the Ashworth site. When the Floyd's Fork valiey was formed is not clearly known. It is known that the valley predates the Illinoian glacial advance, due to the presence of Illinoian Age lacusterine deposits on the valley floor (Kepferle 1972). The Iacusterine deposits were formed during the Illinoian advance when the valleys of the Licking and Kentucky rivers were blocked by ice. The lakes thus formed spiiled over the divide into the Salt River valley (Walker 1957:11). 
Map 1. Location of the Ashworth Site, Brooks and Shepardsville, Kentucky $7.5^{\prime}$ U.S.G.S. 





Figure 1. Plan of the Ashworth Site and excavated units. 


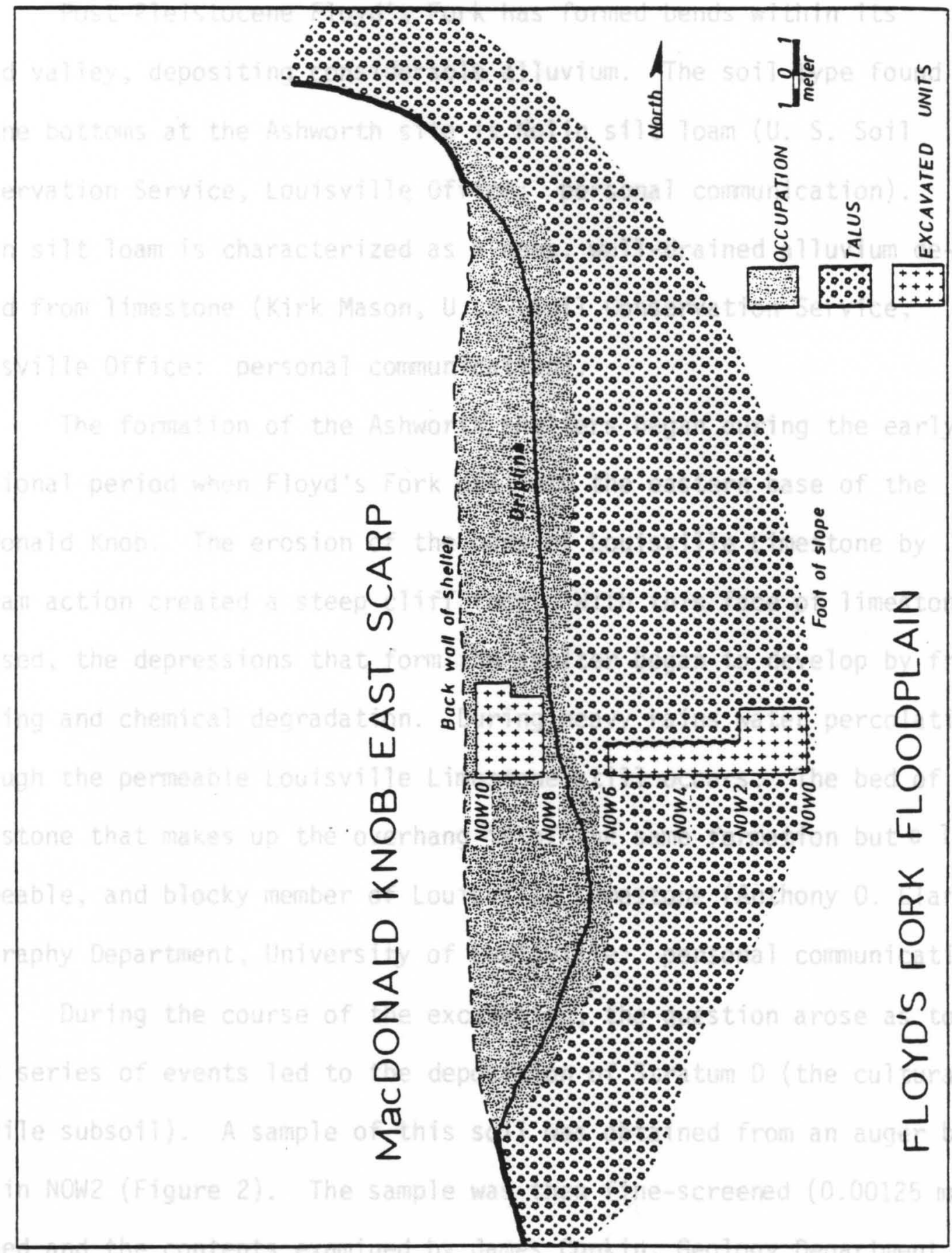


Concurrently, the Salt River was partially blocked at its mouth. The ponding of the Salt River vailey then backed up the vailey of Floyd's Fork for a distance of approximately 25 kilometers (Kepferle 1972).

Post-Pleistocene Floyd's Fork has formed bends within its broad valiey, depositing considerable alluvium. The soil type found in the bottoms at the Ashworth site is Nolin silt loam (U. S. Soil Conservation Service, Louisvilie office: personal communication). Nol in silt loam is characterized as a deep, we1l-drained alluvium derived from limestone (Kirk Mason, U. S. Soil Conservation Service, Louisville Office: personal communication).

The formation of the Ashworth shelters began during the early erosional period when Floyd's Fork cut into the eastern base of the Macionald Knob. The erosion of the beds of Louisville Limestone by stream action created a steep cliff face. With this face of iimestone exposed, the depressions that form the shelter began to develop by frost wedging and chemical degradation. During heavy rains water percolation through the permeable Louisville Limestone still occurs. The bed of limestone that makes up the overhang is of the same formation but a less permeable, and blocky member of Louisville Limestone (Anthony 0. Clarke, Geography Department, University of Louisville: personal communication). During the course of the excavation, the question arose as to what series of events led to the deposition of Stratum $D$ (the culturallysterile subsoi1). A sample of this soil was obtained from an auger boring in NOW2 (Figure 2). The sample was then fine-screened $(0.00125 \mathrm{~mm}$ ) washed and the contents examined by James Conkin, Geology Department, University of Louisville. His conclusion was that this stratum was not the result of lacusterine deposition. The formation of Stratum $D$ was 
Figure 2. South wall profile of excavation units. 


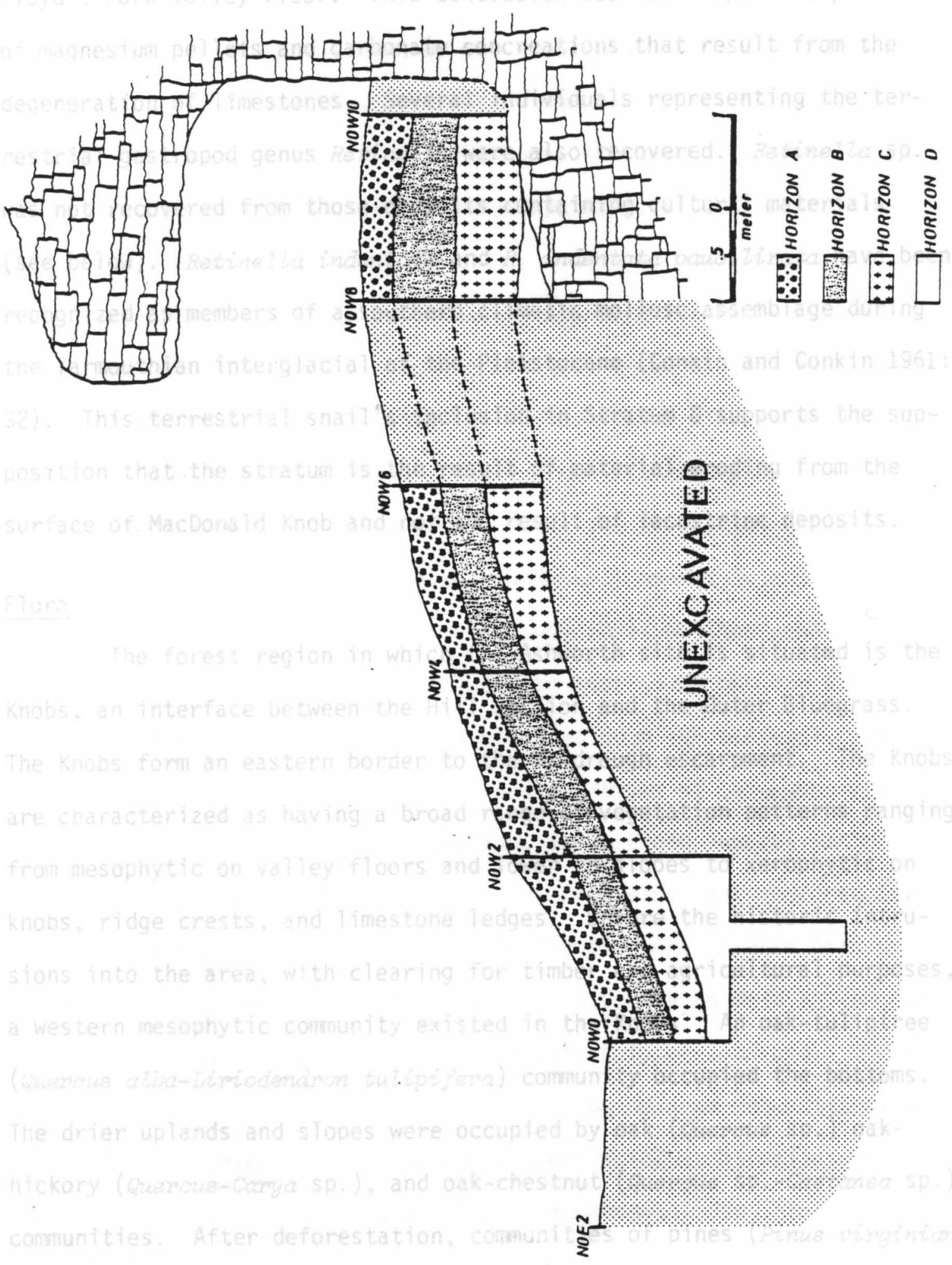


a result of material sloughing off MacDonald Knob and deposited within Floyd's Fork valley floor. This conclusion was based upon the presence of magnesium pellets and carbonate concreations that result from the degeneration of $\mathrm{i}$ imestones. Several individuais representing the terrestrial gastropod genus Retinelza were also recovered. Retinelza sp. was not recovered from those deposits containing cultural materials (see beĩow). Retinella indentata and $R$. indentata paucilirata have been recognized as members of a southern climatic mollusc assemblage during the Yarmouthian interglacial of the Pleistocene (Conkin and Conkin 1961: 32). This terrestrial snail's inclusion in Stratum D supports the supposition that the stratum is the result of material eroding from the surface of MacDonald Knob and not the result of lacustrine deposits.

Flora

The forest region in which the Ashworth site is situated is the Knobs, an interface between the Hill Section and the Outer Bluegrass. The Knobs form an eastern border to the Muldraugh escarpment. The Knobs are characterized as having a broad range of vegetation patterns ranging from mesophytic on valley floors and lower to slopes to xerophytic on knobs, ridge crests, and limestone ledges. Before the historic intrusions into the area, with clearing for timber and agricultural purposes, a western mesophytic community existed in the Knobs. An oak-tuliptree (Quercus alba-Liriodendron tulipifera) community occupied the bottoms. The drier uplands and slopes were occupied by oak (Quercus sp.) oakhickory (Quercus-Carya sp.), and oak-chestnut (Quercus sp.-Castanea sp.) communities. After deforestation, communities of pines (Pinus virginiana) and red cedar (Juniperus virginiana) developed as secondary stands, with red cedar in drier areas (Braun 1972:137-138). 
Field observations and landowner interviews in the immediate vicinity of the site indicate that the east bank of Floyd's Fork had been timbered in the early part of the twentieth century. Approximately sixty meters northwest of rockshelter seven a large stand of red cedar exists. In areas of the botioms near the edges of Floyd's Fork and other minor tributaries, iarge sycamores (Platanus occiäentaits; still grow.

As part of a 1980 planning study of Floyd's Fork by Miller, Winrey and Lee Incorporated, the flora was observed to contain three forest cover types. On the banks and floodpiains a silver maple-syacmore-box elder (Acer saccharinum-Platanus occidentalis-Acer negundo) forest type is found. On side slopes above the floodplain a sugar mapleash-elm (Acer saccharmm-Eraxinus sp.-Ulmus sp.) forest type was found that differed from the dry side slopes and ridgetops that contained an oak-hickory forest type. Also included in this study was the characterization of floral patterns that have resulted from agricultural, residential, and right-of-way land uses. Among the types of land uses are cropland/pasture, old fields, grassland, and wetland vegetation (Miller, Wihrey, and Lee 1980:II-51-61). However, this study was confined to Jefferson County where land use is considerabiy more intense than in Bullitt County. The low relief of Jefferson County as well as the popuiation density are major factors in the intensity of land use. Currently in Buriitt County most of the bottomland is being used for pasturage. The valley of Floyd's Fork is somewhat constricted as it passes through the Knobs, in Bullitt County, making it uneconomical for large-scale agriculturai use. 
Fauna

The valley of Floyd's Fork and the Knobs region contains a diverse species inventory as well as a relative abundance of the individual species, many of which could have supplied the prehistoric populations with meat. While in the field the crew observed or collected road kiils for the University of Louisville's Archaeological Survey's comparative skeletal collection consisting of the foliowing species of mammals: Sciums carolinensis (grey squirrel), S. niger (fox squirrel), odocoileus virginionus (white-tailed deer), Vulpes fulva (red fox), Peromyscus Zeucopus (white-footed mouse), Mephitis mephitis (striped skunk), Didelphis marsupialis (opossum), Sylvilagus floridanus (eastern cottontail), Marmota monax (groundhog), and Tamias striatus (chipmunk). In addition to the ten species listed above, approximately thirty-five additional species of mammals have been observed or are known to have ranges within the region (Miller, Wihery, and Lee 1980; Burt and Grossenheider 1976). Few oí the additional species of mammals present are large enough or found in sufficient number to provide a major resource in the prehistoric diet. Some of these include Ondatra zibethicus (muskrat), Procyon Lotor (raccoon), and Mustela frenata (long-tailed wease 1).

There are also a large number of species of amphibians and reptiles known to live within the knobs region, many of which are known to have been utilized by the prehistoric inhabitants of the Ashworth site (see Faunal Analysis). An estimated twenty-five species of amphibians are believed to inhabit the area. They consist primarily of various species of frog (Rana catesbeiana, $R$. sphenocephala, R. clamitans, Acris crepitans, Hyla crucifer, and Pseudacris triseriata), toad 
(Bufo comericanus, B. woodhousei fowleri), and a large number of salamanders. An estimated thirty-two species of reptiles are present within Floyd's Fork valley and its environs. Two potentially dangerous species present are Crotalus horridus (timber rattiesnake) and Agkistroden contortrix (copperhead), as well as a number of non-venomous snakes. Turtles are common to the area including Trionyx spinifer (eastern spiny softshell), Chrysemys picta (painted), C. scripta (red-eared), and Terrapene carolina (box turtle) (Barbour 1971; Miller, Wihery, and Lee i980). Turites are by far the most frequently utilized amphibian by the prehistoric populations.

Birds represent the most diverse class of animals present in the region with approximately 296 species present (Miller, Wihrey, and Lee 1980). Of these, approximately 56 percent are considered transients (Monroe 1976). Twelve species were observed in the immediate vicinity of the site by the field crew. One species otus asio (screech owl) was collected as a road-kill. The other eleven species observed were: $A i x$ sponsa (woodduck), Zenaidura macroura (mourning dove), Megaceryle alcyon (beited kingfisher), Centurus carolinus (redbeilied woodpecker), Melanerpes erythrocephalus (redheaded woodpecker), Dendrocopos pubescens (downy woodpecker), Himindo rustica (barn swallow), Cycnocitta cristata (bluejay), Corvus brachyrhynchos (crow), Turdus migratorius (robin), and Cardinalis cardinalis (cardinal). According to Monroe the species observed by the field crew are considered common to the area.

Few studies of the mollusca of the area have been undertaken. Those published have been primarily concerned with the nearby Salt River. The only study published to date dealing with Floyd's Fork has been Taylor (1980). In his study, Taylor discusses the presence of twenty-five 
species of mussels that currentiy inhabit Floyd's Fork. One species, the Asian clam, Corbicula manilensis (also known as C. mulleri, C. Leana, and $C$. fulminea) has been introduced in this country within the historic past. Taylor described Floyd's Fork as "...a stream of rather high water quality and a bivalve population that is both stable and healthy." This type of stream would have been ideal for the prehistoric population providing both fresh water as weil as a broad spectrum of aquatic faunal material. A more specific discussion of the mollusks present in the Salt River and Floyd's Fork is presented in a later section.

Studies of fish populations within the region have, again, been primarily concerned with the Salt River. However, in Miller, Wihrey, and Lee 1980 management plan study, a list of species has been published for Floyd's Fork. This species list was obtained from the Kentucky Department of Fish and Wildlife Resources, but has yet to be published by that office. KDFWR reports fifteen species plus "several species of darters" (Miller, Wihrey, and Lee 1980:II-70:71). However, a 1969 through 1972 study of areas of the Salt River, the Beech Fork, and the Chaplin has produced sixty-five species of fishes and five hybrid species (Hoyt, et al. 1979). Oniy one species, Esox comericanus vermiculatus (grass pickerel) was noted in Floyd's Fork but not in the Salt River. It is reasonable to assume that due to the similarity between the Salt River and Floyd's Fork that a complete species list for Fioyd's Fork would very closely approximate that of the Salt River.

The most common species reported for Floyd's Fork are bass (Micropterus punctulatus, M. dolomieui, M. salmoides), catfish (Ictalums punctatus, I. natalis, I. melas), bream (Lepomis megalotis, L. cyanelzus, L. macrochirus), pickerel (Esox americanus vermiculatus), 
sucker (Catostomus commersoni and Moxostoma erthrumu), shad (Dorosoma cepedianum), stoneroller (Campostoma conomalum), chub (Semotilus atromaculatus), and darter (Etheostoma sp.) (Miller, Wihry, and Lee 1980: II :70-71).

\section{Proximity and Availability of Salt}

The area around Shepardsville has been known historically for the presence of salt licks and saline springs. Early historic accounts of Kentucky describe these springs, the most prominent being Bullitt's Lick. These springs were also well known to the native population. Apparently there was sufficient confict over "rights" to the springs that Europeans had to establish a fort (Brashear's Fort), as a refuge from marauding Indians, while panning for salt. Brashear's Fort was jocated on the west side of Floyd's Fork and north of the Salt River (Fiison 1962). Prehistorically these salt licks and saline springs may have played an important role in drawing animal as weil as human populations to the area.

\section{Summary}

The Ashworth site, in both its physical setting as well as the area around it, provided an opitimum situation for prehistoric settlement. within a twenty square-kilometer setting almost all of the available resources required by a hunting and gathering subsistence economy can be found. Floyd's Fork provides water and a diverse number of organisms easily gathered, trapped, or hunted. Edible floral resources found within a mixed mesophytic forest are sufficient to provide mast, green vegetables, and carbohydrates to supplement a diet. Salt is found within close proximity for human consumption and the animals drawn to the salt 
were also available. The shelter provided by the rock overhang also must have played an important role in choice of habitation area. The overhang provides considerable protection from the elements. In the summer the shelter is cooler than the surrounding area. In the winter, with no leaves on the trees, the east-facing shelter warms rather quickly and retains that warmth into the evening. 


\section{EXCAVATIONS AND FINDS}

\section{Excavations}

The test excavation methods I employed at the Ashworth site (15Bu236 Rockshelter \#7) were directed at determining several categories of data:

1) Determine the site's significance and potential for further study.

2) Establish a chronology of the occupations based upon artifact associations supplemented by radiocarbon determinations.

3) Determine the size of the occupations during the sequence of culture periods (delineated in 2 above).

4) Obtain an understanding of the resources utilized, environmental conditions, and intra-site utilization.

In an effort to achieve those goals described above, a single trench was laid out from the toe of the talus to the back wall of the shelter (Figure 1). The floodplain was also tested through the excavation of two units ( 1 by 2 meters), NOE7 and NOE16. The units excavated on the floodplain revealed that no prehistoric occupations were present.

The initial test unit opened was NOW2 (southwest corner of the unit). This unit was excavated in 10-centimeter levels that were kept horizontal. The horizontal levels were maintained through the use of a Berger Model $110 \mathrm{C}$ optical level and stadia rod. All elevations were correlated to a permanently-established datum. A11 artifacts recovered were triangulated to the southern corners of the test unit (NOWO and NOW2). Once the natural stratigraphy was determined and culturally- 
sterile deposits were encountered and excavated one-half meter by hand, an auger was used to penetrate an additional 1.5 meters. The auger produced a boring 25.4 centimeters in diameter that was profiled and flotation samples were taken.

The next units to be excavated were NOW4 and NOW6. In these two units the stratigraphy was used as the level of excavation rather than the horizontal levels used for the strata cut (NOW2). During the excavation of these units, elevations were recorded at the beginning and ending of each day as well as when artifacts were found.

The final unit excavated was NOW10. This unit is composed of a single 2 by 2 meter square with an additional meter square extending to the north. A one by one-half meter unit was also excavated adjacent to NOW10, north and east of NOW10. The latter unit was to be a full meter square but was reduced to half its size to avoid the removal of a tree. The unusual size and dimensions of this unit are the result of this investigator's attempt to relocate the unit of a previous investigator.

The total area excavated on the talus was 8.0 square meters (4.65 percent) of the estimated 172 square meters of talus. The area under the shelter that was excavated was 5.5 square meters (5.29 percent) of the estimated 104 square meters under sheiter. The entire site area is estimated at 276 square meters of which 13.5 square meters (4.89 percent) was excavated. The total volume of earth excavated was 23.63 cubic meters.

All of the test units were excavated into the sterile subsoil and in the case of NOW10 to bedrock. Excavation was carried out by shovel skinning or by troweling the floors. All of the soil that was 
removed was dry screened through 0.125 -inch (32 millimeter) mesh. Artifacts recovered during the skinning or troweling process were triangulated and an elevation taken in situ. Diagnostic artifacts were photographed in situ. Once artifact locations were recorded the object and an artifact data card were sealed in a smali plastic bag. Then the artifacts were placed in the unit bag. Each unit bag corresponded with elevations taken for each level removed. All unal tered limestone recovered was weighed by unit level and recorded. Soil samples were taken from all levels in all units and from the interiors of all features and burials. Soil samples were taken for several reasons: to determine color, texture, and $\mathrm{pH}$ of soil; to recover floral and faunal material that might otherwise be lost if dry screened; and, in the case of burial pits, to recover epiphyses and smaller elements. In several instances (Features 2 and 3 ) the entire contents of features were taken. However, in general practice approximately 25 percent of features and burial fill were taken as a sample. To recover soil samples from all levels, 10 by 10 centimeter balks were left at N2W2, NOW4, N2W4, NOW8, N2W8, NOW10, and N2W10, and removed in 10-centimeter levels (within each stratum) upon completion of each unit. The balks were removed and placed in plastic soil sample bags with an interior and exterior provenience label.

Carbon samples were taken from the interior of every feature that contained sufficient quantities to be removed by trowe1. The fragments thus removed were placed on a sheet of aluminium foil and sealed in an airtight metai container. Limited funds have permitted only three radiocarbon determinations, however, the samples are being stored and will be assayed when funding is obtained. All carbon samples taken 
consisted of carbonized wood or nuts, no burned molluscs were taken for carbon assay.

Laboratory analysis of all material took place during those periods when field work was impractical. All material was stored in labeled plastic bags until washing, separation, and boxing could be accomplished. Any artifacts not recognized during the field work (primarily small bifaces and worked bone fragments) were separated.

All of the material recovered was catalogued into the University of Louisville Archaeological Survey's collections. However, ali materials are property of the landowner until actual donation to the State.

Materials were divided, during the separation process, on the basis of material such as faunal, floral, human remains, chipped lithic, groundstone, etc. Individual artifacts, no matter at what point they were found in the recovery process, are catalogued individually. Groups of material such as detritus, shell, and bone are given a single acquisition and are labeled by lot. Each object within the lot is iabeled with indelible ink. Flotation samples and burials are given an alpha character code in the denominator (Burial \#4 - 78.4/B4, flotation sample 36-78.4/F36). Catalogue cards are filled out on each object or lot of material listing the provenience, object, acquisition number, date of recovery, and a description of the objects (including metrics and a drawing).

Provenience has been maintained on all material recovered to specific level within the strata by excavated unit. However, for the purposes of this paper, the materials are reported by strata and unit only (see Diagnostic and Non-diagnostic Material sections). 
The materials recovered were catalogued into the collections at the Archaeological Survey. The aquisition numbers consist of a fraction that contains specific information. The numerator represents the year of collection and the site. In coliections aquired before 31 December 1978 the denominator represented a total of materials in the entire collection. After that date the denominator represented the totai from the individual site. Ashworth aquisition numbers are: $74.119 / 19804-74.119 / 19875$ and $78.4 / 1-78.4 / 307$.

\section{Stratigraphy}

The profile control unit (NOW2) revealed three distinct strata that contained cultural material and a fourth stratum that was found to be devoid of cultural material or sterile (see figure 3 ). The individual strata that contained cultural material varied from 50 to 60 centimeters in thickness, these were labeled A through $C$. The sterile stratum D continued beyond 2 meters of penetration to an unknown depth. Stratum A consisted of a black (5YR 2.5/1) soil that was composed of large loose granular particules. Stratum B was a dark reddish-browh (5YR 3/2) soil of very much the same consistency as Stratum A. Stratum C was a dark brown (7.5YR $3 / 2$ ) soil that contained much more silt than the upper stratum. All of the strata mentioned above contained fragments of 1 imestone. Stratum D was a yellow (10YR 8/8) silt. This silt was highly compacted and contained manganese pellets as well as several snails, discussed below.

The strata under the shelter consisted of very different soil colors and textures than those on the talus. The thicknesses were somewhat greater, 60 to 75 centimeters, but they contained the same cultural expressions found on the talus (discussed at length below). The strata under the shelter were very uniform as to coior and varied subily in 
Figure 3. The stratigraphy at the Ashworth site. 


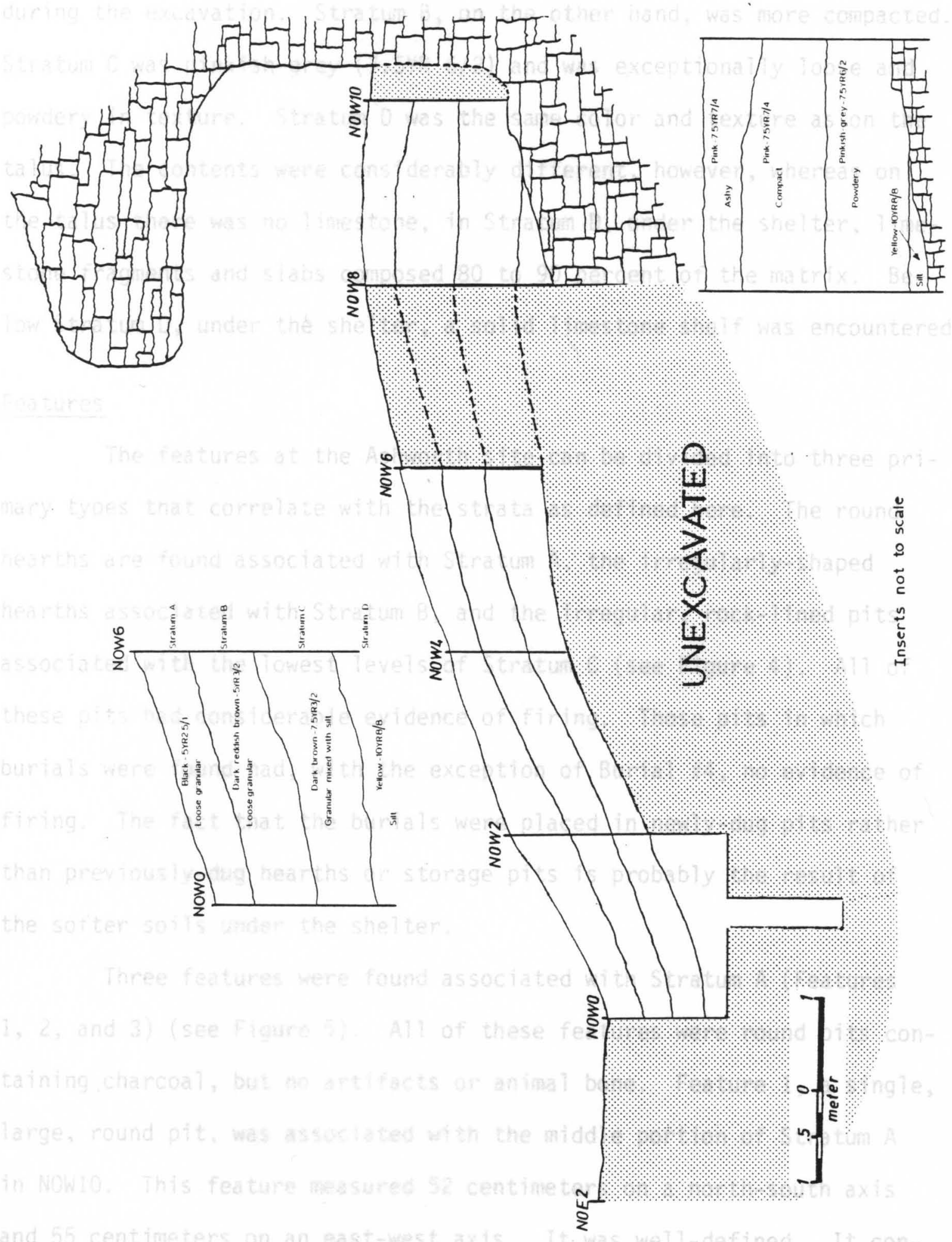


texture. Stratum $A$ and $B$ were both pink (7.5YR 7/4). The texture of Stratum A was very loose and "ashy" often forming choking dust clouds during the excavation. Stratum B, on the other hand, was more compacted. Stratum $C$ was pinkish-grey $(7.5 Y R$ 6/2) and was exceptionally loose and powdery in texture. Stratum D was the same color and texture as on the talus. The contents were considerably different, however, whereas on the talus there was no limestone, in Stratum $D$, under the shelter, limestone fragments and slabs composed 80 to 90 percent of the matrix. Below Stratum D, under the shelter, a solid limestone shelf was encountered.

\section{Features}

The features at the Ashworth site can be divided into three primary types that correlate with the strata as defined here. The round hearths are found associated with Stratum A, the irregularly-shaped hearths associated with Stratum B, and the irregular, rock-lined pits associated with the iowest levels of Stratum C (see Figure 4). All of these pits had considerable evidence of firing. Those pits in which burials were found had, with the exception of Burial \#4, no evidence of firing. The fact that the burials were placed in newly-dug pits rather than previously-dug hearths or storage pits is probably the result of the softer soils under the shelter.

Three features were found associated with Stratum A (Features 1, 2, and 3) (see Figure 5). All of these features were round pits containing charcoal, but no artifacts or animal bone. Feature 1, a singie, large, round pit, was associated with the middle portion of Stratum $A$ in NOW10. This feature measured 52 centimeters on a north-south axis and 55 centimeters on an east-west axis. It was well-defined. It consisted of approximately 7 centimeters of blackened earth and charcoal 
Figure 4. Feature locations at the Ashworth site. 

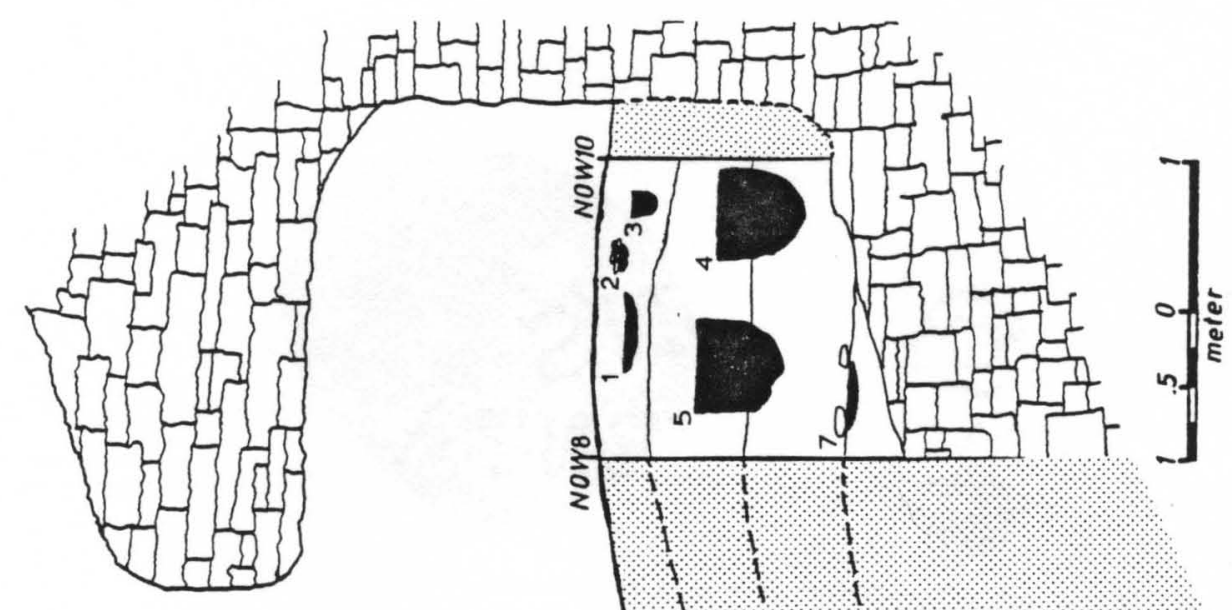
Figure 5. Woodland and Late Archaic features. 

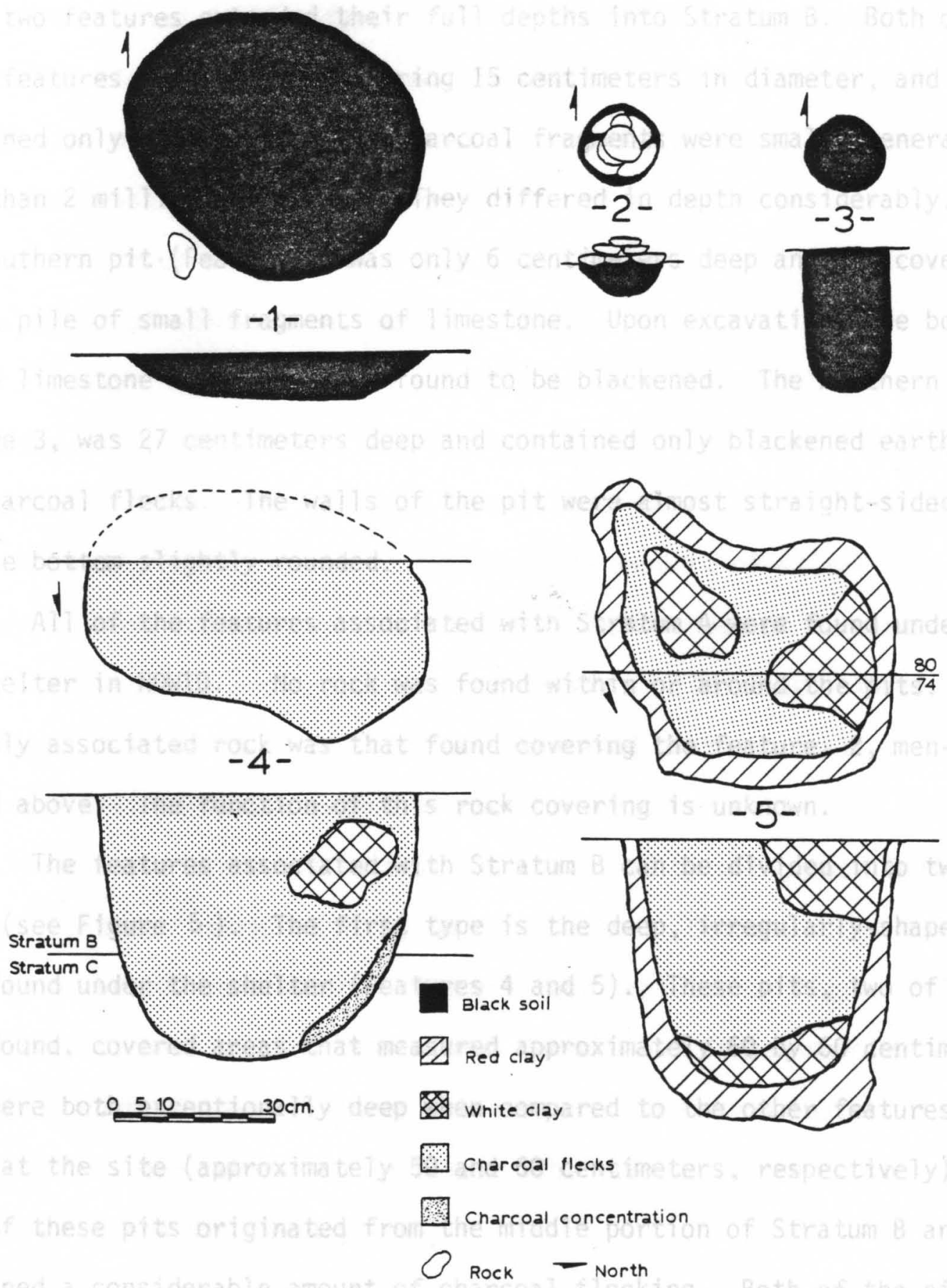
covered with approximately 3 centimeters of reddened earth. In cross section it was a broad, shallow bowl.

Two other features were associated with Stratum A (Features 2 and 3), however, they were found at the basai portion of that stratum. These two features extended their full depths into Stratum B. Both of these features were round, measuring 15 centimeters in diameter, and contained only biack soil. The charcoal fragments were small, generally less than 2 millimeters across. They differed in depth considerably. The southern pit (Feature 2) was only 6 centimeters deep and was covered with a pile of small fragments of 1 imestone. Upon excavation, the bottoms of the limestone fragments were found to be biackened. The northern pit, Feature 3, was 27 centimeters deep and contained only blackened earth and charcoal flecks. The walls of the pit were almost straight-sided and the bottom slightly rounded.

Ali of the features associated with Stratum $A$ were found under the shelter in Now10. No rock was found within or around the pits. The only associated rock was that found covering the feature, 2, mentioned above. The function of this rock covering is unknown.

The features associated with Stratum B can be divided into two types (see Figure 5 ). The first type is the deep, irregularly-shaped pits found under the shelter (Features 4 and 5). These pits, two of which were found, covered areas that measured approximately 60 by 60 centimeters. They were both exceptionally deep when compared to the other features found at the site (approximately 50 and 60 centimeters, respectively). Both of these pits originated from the middle portion of Stratum $B$ and contained a considerable amount of charcoal flecking. Both of the pits also contained a moderate amount of waste chippage, but no artifacts. 
The southernmost of these, feature 4 , was the pit that intruded upon Burial \#8 and contained the fragments of bone identified as Burial \#10. The northern portion of feature 5 was excavated during the 1974 test excavations (see Figure 5 ).

The second feature type found associated with Stratum B consisted of a semicircle of fired limestone, teature 6 . This feature appears to be a shallow pit ( 12 centimeters deep) surrounded by rock. It was open to the southeast. This feature was located at the basal portion of Stratum $B$ on the talus slope in unit NOW4 (see Figure 6 ). It contained a concentration of animal bone, but no chippage.

Stratum $C$ contained only a single feature type, with two representatives, features 7 and 8 (see Figure 6 ). Feature 7 was found under the shelter and the other, feature 8 , just outside of the dripline in Now6. Both of these features contained large amounts of animal bone and chippage. These features were irregularly-shaped areas of fire-reddened earth, surrounded by and containing many slabs of limestone. There was no evidence that a pit of any kind was excavated prehistorically. The areas were defined on the extent of the fire-reddened soil. The lack of a pit indicates a surface fire that was contained by using rock found nearby. Feature 7 measured 40 by 60 centimeters. Feature 8 , in NOW6, measured 90 by 100 centimeters. The artifact depicted in Figure $10 \mathrm{E}$ was recovered, both pieces, from within Feature 8. Carbon samples were taken from both of these features. The sample taken from Feature 7 has been sent to a gas laboratory in Texas. The results of the radiocarbon determination are discussed below.

\section{Culturally-diagnostic Objects}

Projectile points, knives and ceramics are being discussed in 
Figure 6. Early Archaic features. 

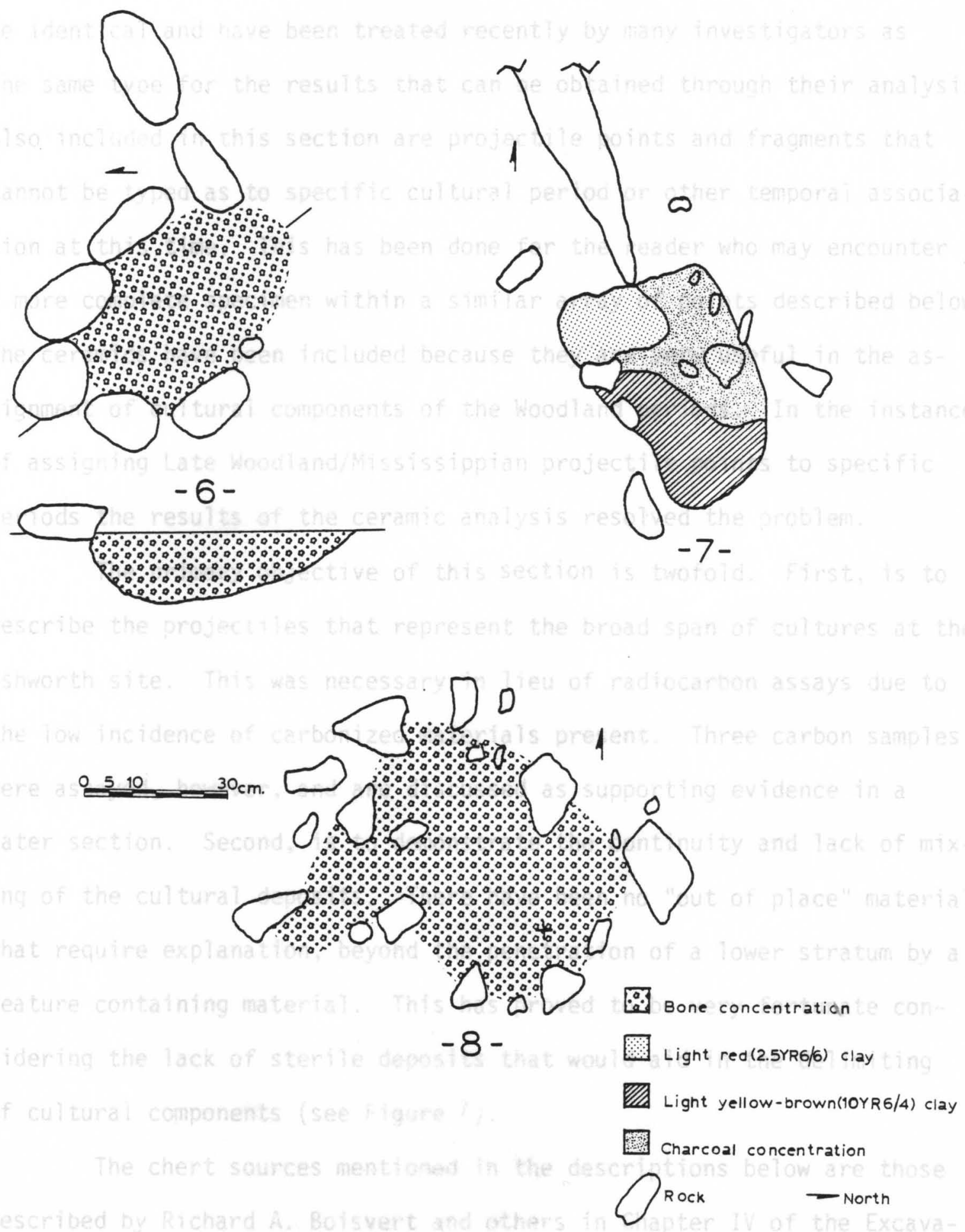
this section together for several reasons. Projectile points and knives in many cases can only be differentiated on the basis of wear patterns or a pronounced asymmetry of the blade. In every other respect they may be identical and have been treated recently by many investigators as the same type for the results that can be obtained through their analysis. Also included in this section are projectile points and fragments that cannot be typed as to specific cultural period or other temporai association at this time. This has been done for the reader who may encounter a more complete specimen within a similar array of points described below. The ceramics have been included because they are very useful in the assignment of culturai components of the Woodland periods. In the instance of assigning Late Woodland/Mississippian projectile points to specific periods the results of the ceramic analysis resolved the problem.

The primary objective of this section is twofold. First, is to describe the projectiles that represent the broad span of cultures at the Ashworth site. This was necessary in lieu of radiocarbon assays due to the low incidence of carbonized materials present. Three carbon samples were assayed, however, and are discussed as supporting evidence in a later section. Second, is to demonstrate the continuity and lack of mixing of the culturai deposits. There have been no "out of place" materials that require explanation, beyond the penetration of a lower stratum by a feature containing material. This has proved to be very fortunate considering the lack of sterile deposits that would aid in the delimiting of cultural components (see figure 7 ).

The chert sources mentioned in the descriptions below are those described by Richard A. Boisvert and others in Chapter IV of the Excavations at Four Archaic Sites in the Lower Ohio Valley, Jefferson County, 
Figure 7. Temporal and stratigraphic position of projectile points at the Ashworth Site. 


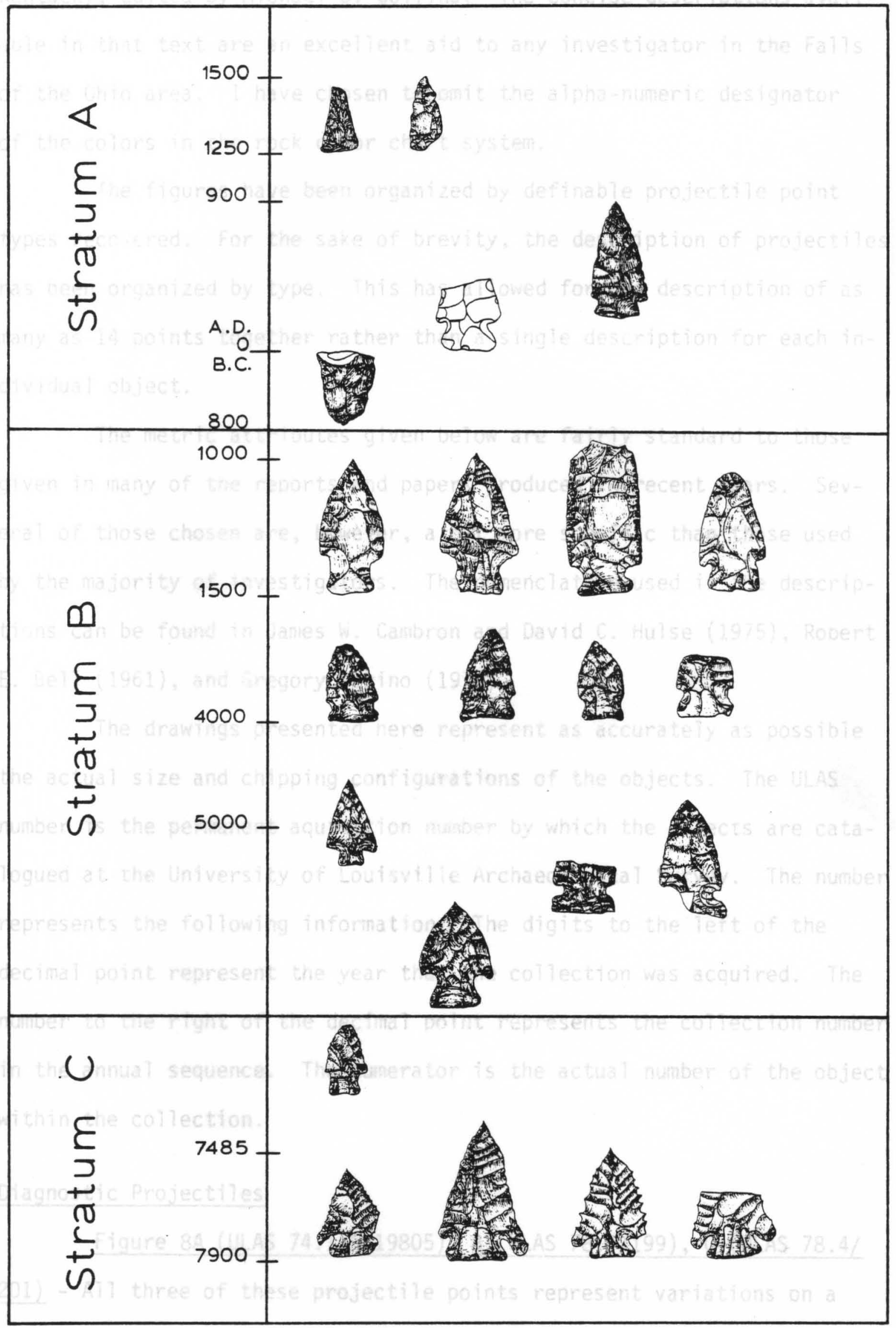


Kentucky, edited by Michael B. Collins. The concise descriptions avai1able in that text are an excellent aid to any investigator in the Falls of the Ohio area. I have chosen to omit the alpha-numeric designator of the colors in the rock color chart system.

The figures have been organized by definable projectile point types recovered. For the sake of brevity, the description of projectiles has been organized by type. This has aliowed for the description of as many as 14 points together rather than a single description for each individual object.

The metric attributes given below are fairly standard to those given in many of the reports and papers produced in recent years. Several of those chosen are, however, a bit more specific than those used by the majority of investigators. The nomenclature used in the descriptions can be found in Jamies $W$. Cambron and David C. Hulse (1975), Robert E. Beli (1961), and Gregory Perino (1971).

The drawings presented here represent as accurately as possibie the actual size and chipping configurations of the objects. The ULAS number is the permanent aquisition number by which the objects are catalogued at the University of Louisville Archaeological Survey. The number represents the following information. The digits to the left of the decimal point represent the year that the collection was acquired. The number to the right of the decimal point represents the collection number in the annual sequence. The numerator is the actual number of the object within the collection.

Diagnostic Projectiles

Figure 8A (ULAS 74.119/19805), B (ULAS 78.4/199), C (ULAS 78.4/ 201) - Ail three of these projectile points represent variations on a 
Figure 8. Woodland projectile points recovered from Stratum A. 

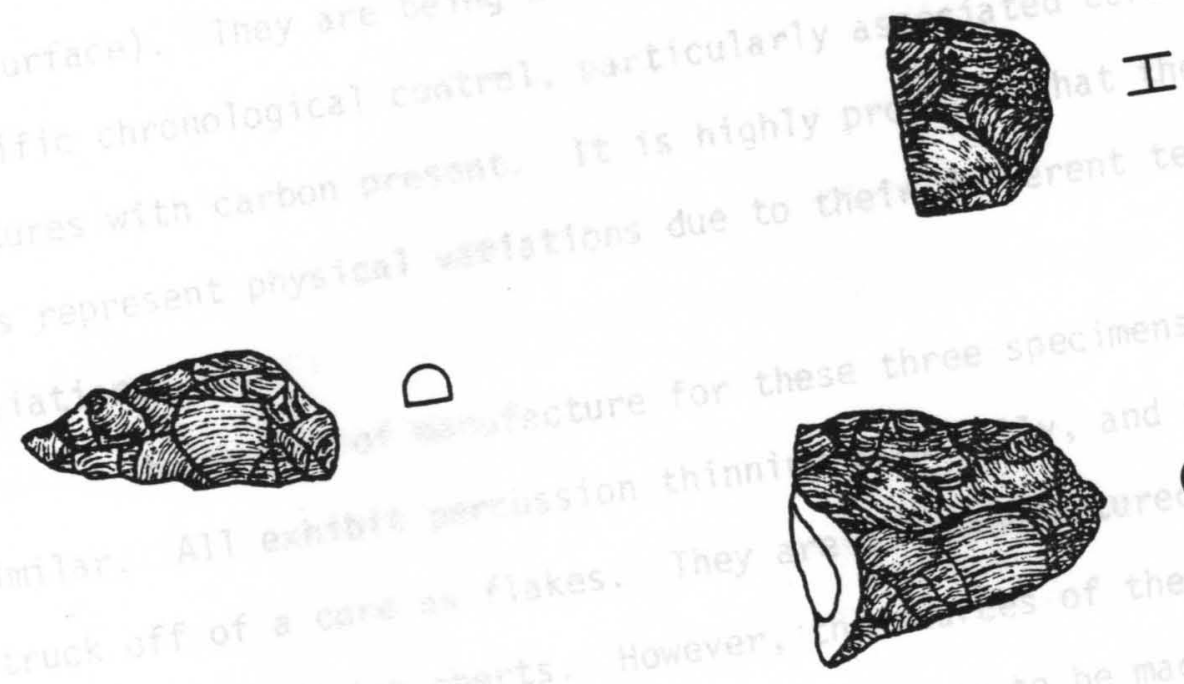

0
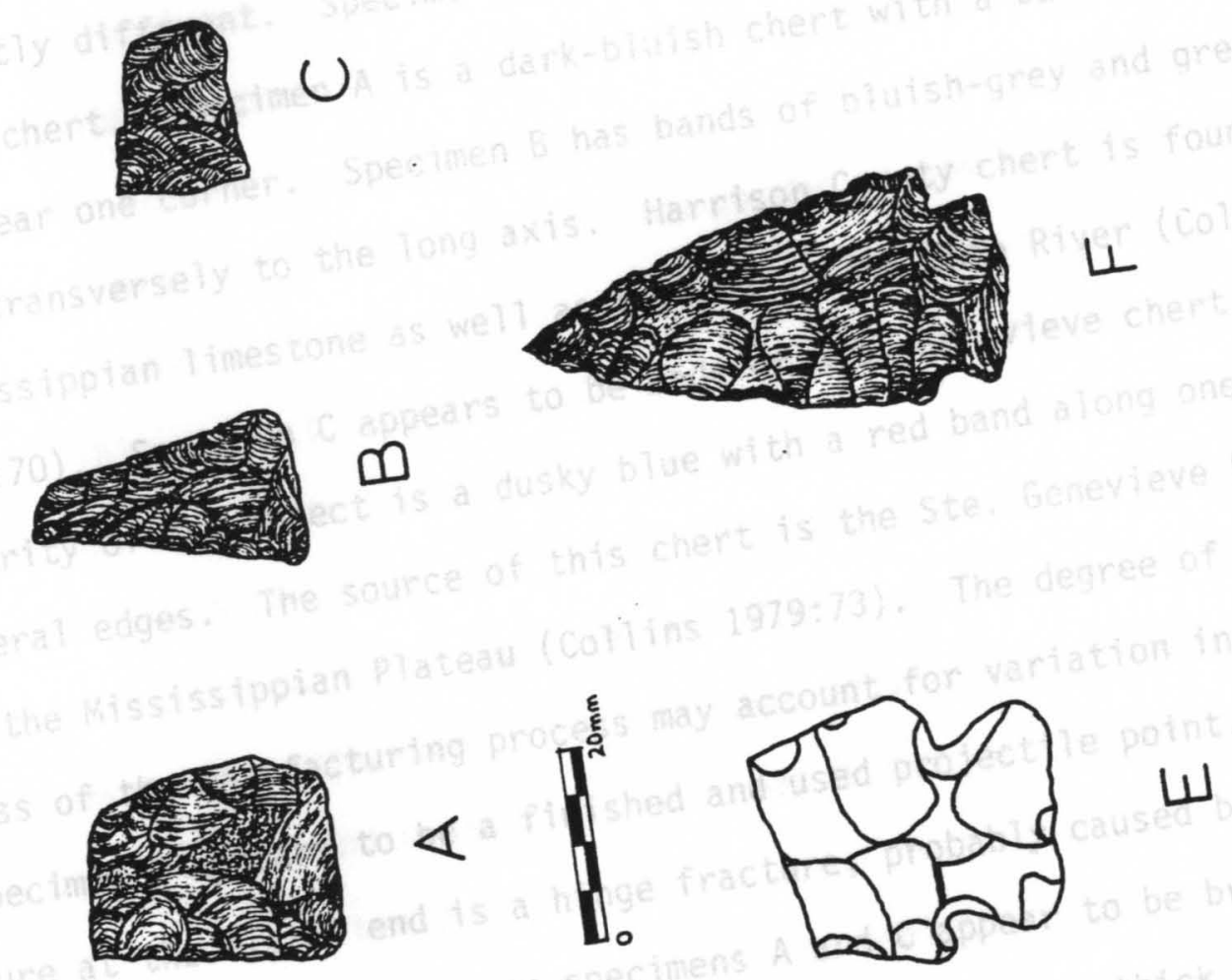
Late Woodland through Historic period type. They were recovered from the upper portion of Stratum $A$ in NOW1O $(A-4 \mathrm{~cm} ; B-8 \mathrm{~cm} ; C-7 \mathrm{~cm}$ below the surface). They are being discussed together because of the lack of specific chronological control, particularly associated ceramics or features with carbon present. It is highly probable that these specimens represent physical variations due to their different temporal affiliations.

The method of manufacture for these three specimens is very similar. All exhibit percussion thinning bifacially, and were initially struck off of a core as flakes. They are all manufactured from finegrained, grey-bluish cherts. However, the sources of the cherts are apparently different. Specimens $A$ and $B$ appear to be made from Harrison County chert. Specimen $A$ is a dark-bluish chert with a band of light grey near one corner. Specimen B has bands of bluish-grey and grey running transverseiy to the long axis. Harrison County chert is found in Mississippian limestone as well as gravels in the Ohio River (Collins 1979:70). Specimen C appears to be made of Ste. Genevieve chert. The majority of the object is a dusky biue with a red band along one of the Tateral edges. The source of this chert is the Ste. Genevieve Limestone in the Mississippian Plateau (Collins 1979:73). The degree of completeness of the manufacturing process may account for variation in shape. Specimen $B$ appears to be a finished and used projectile point. The fracture at the distal end is a hinge fracture, probabiy caused by impact. The transverse fractures on specimens $A$ and $C$ appear to be breaks caused by abortive attempts at thinning. Specimen $B$ is $4 \mathrm{~mm}$ thick and Specimens $A$ and $C$ are $5.5 \mathrm{~mm}$ and $6.5 \mathrm{~mm}$ thick, respectively. The base of Specimen $B$ is $15.0 \mathrm{~mm}$ wide where $A$ and $C$ are greater (18.5 and $16.0 \mathrm{~mm}$, respectively) 
Figure 8D (ULAS $78.4 / 125)$ - This smal1 triangular projectile point was recovered from the upper portion ( $8 \mathrm{~cm}$ below the surface) of Stratum $A$ in Now6. At the same level further down the slope a small fragment of sheli-tempered plainware (ULAS 78.4/68) was recovered. This projectile was manufactured from a single flake of chert. The color is light pink with darker pink striations that run diagonally through the object. The pink cast to the object indicates that it had been fired (Collins 1979:70-71). The chert source for this object is the Muldraugh Escarpment.

This projectile point has had a corner broken off, diagonally to the long axis, at a $90^{\circ}$ angle to the lines of inciusions. The presence of several hinge fractures, emanating from flakes removed from the base, indicated a "knot" had developed. A knot represents the culmination of several unsuccessful attempts to eliminate a section of material (Collins 1979:57). The broken corner is the result of an attempt to remove this knot.

This projectile point is $30.0 \mathrm{~mm}$ long and is widest $(13.0 \mathrm{~mm})$ approximately $8.0 \mathrm{~mm}$ distally from the base. Its maximum thickness $(5.5 \mathrm{~mm})$ was recorded at a $90^{\circ}$ angie at a point along its maximum width. Flaking patterns indicate that direct percussion was the primary means of manufacture. The fact that no secondary fiaking patterns are present also indicates the object was broken during the early thinning stage of manufacture.

Several investigators in Kentucky feel this small triangular projectile point type developed during the Late Woodland period (ca. 900 A.D.) and continued to be used through the Mississippian period and into Historic times (ca. 1700 A.D.) (R. B. Clay: personal communication). 
However, the association of the shell-tempered ceramics mentioned above, and described in more detail below, indicate that this point dates from approximately 1250 A.D. to 1500 A.D. Three other projectile point fragments of this type were recovered from the upper portion of Stratum A and are described above $(74.119 / 19805,78.4 / 199,201)$.

Figure 8E (ULAS 78.4/197) - This projectile point fragment was recovered from the middie portion of Stratum $A(19 \mathrm{~cm}$ below the surface) in the southern part of NOW10. It is covered with calcium carbonate deposits, therefore little can be said about its method of manufacture or the reason that it is broken. A small area of the carbonate deposits was removed in an attempt to establish the chert type and source. The chert is a very dark bluish-black, however, it cannot be determined whether it is Ste. Genevieve or Harrison County chert.

The entire point has an asymmetric appearance. The shoulders are moderately barbed and the base is expanding. The incomplete length is $30 \mathrm{~mm}$ (maximum). The width at the shoulders is $26 \mathrm{~mm}$. The stem is narrowest distally, $16 \mathrm{~mm}$, and widest proximaily, $22 \mathrm{~mm}$. The base is straight, and unground.

This point falis within the ranges of variation of the Lowe and Baker's Creek projectile point types. Both types are expanded stem projectile points. Baker's Creek points are generally associated with Copena occupations and have been alternately named "stemmed copena" points (Perino 1971:6 and Cambron and Hulse 1975:8). Lowe points are generally associated with the Middle Woodland Allison Complex of southern Illinois and Indiana (Perino 1971:60). Both projectile point types have been reported from various areas of Kentucky. Temporally Perino places the Baker's Creek point somewhat earlier (200 B.C. -600 A.D.) 
than the Lowe (1 A.D.-900 A.D.). Cambron and Hulse, however, place the Baker's Creek projectile point type at 1500 B.C. to the early centuries A.D. Locally a point of this type was recovered from 15Jf268 Feature 3 with an associated carbon sample. Dates for this sampie (UGa-1259) were $2300 \pm 350$ B.P. yielding a date of 350 B.C.

Figure $8 F$ (ULAS 78.4/61) - This entire projectile point was recovered from the middle portion of Stratum $A$ in unit NOW4. The blade is an elongated triangle having a distal end angle of $42^{\circ}$. The stem is expanding and has an incurvate base. The shoulders are moderately barbed and somewhat asymmetrical. It was manufactured from a yellowish-orange chert that contains very small $(0.25 \mathrm{~mm})$ pink-red inclusions. Several large ovate inclusions, of the same color, are $5 \mathrm{~mm}$ by $2 \mathrm{~mm}$ and are oriented paraliel to the long axis of the point.

This projectile point appears to have been produced from a larger biface rather than a flake. Large random percussion flake scars are present on both faces. Secondary flaking appears to be a combination of fortuitous percussion and pressure flaking. The lack of wear patterns on the blade's lateral edges confirm its use as a projectile point rather than a knife.

The object is $46.7 \mathrm{~mm}$ long. The maximum width (at the shoulders) is $22.6 \mathrm{~mm}$. The stem is $8.9 \mathrm{~mm}$ long and measures $14.5 \mathrm{~mm}$ wide below the shoulders as well as $17.0 \mathrm{~mm}$ wide proximally.

This point resembles the Baker's Creek projectile point (Perino 1971:6) except that the stem is somewhat shorter than points of that particular type. A further discussion of stemmed points of this type can be found above (ULAS 78.4/197).

Figure 8G (ULAS 74.119/19809), H (ULAS 78.4/204) - Both of these objects appear to be the rounded stems of projectile points. Specimen $G$ 
was recovered from the middle portion of Stratum A (14 cm below the surface). Specimen $H$ was recovered somewhat deeper within Stratum $A$ at a depth of $18 \mathrm{~cm}$ below the surface. Both specimens are made from fine-grained, grey cherts and both have cortex at the proximal ends.

The method of manufacture appears to be similar. The presence of cortex proximally indicates flakes struck from a nodule of chert. Percussion flaking was used for both bifacial thinning and shaping. The reason for the breakage appears to be the result of use especially the hinge fracture of Specimen $G$. Specimen $H$ may have been broken during the manufacturing process.

Specimen $G$ is $28.5 \mathrm{~mm}$ long, $21.6 \mathrm{~mm}$ wide, and $7.8 \mathrm{~mm}$ thick. Specimen $H$ is $15.0 \mathrm{~mm}$ iong, $19.0 \mathrm{~mm}$ wide, and $6.0 \mathrm{~mm}$ thick. A11 of these measurements are incomplete.

Projectile points with rounded bases have been dated at the Late Archaic-Early Woodland transition. It should be mentioned that three ceramic fragments were recovered from the middle and iower portions of Stratum A. These sherds were either chert-tempered (78.4/215) or limestone-tempered $(74.119 / 19813$ and $78.4 / 200)$. Ceramics with this temper type (discussed below) have been placed in the Early Woodland period and described as Fayette Thick-like (Clay 1980:175).

Figure 9A (ULAS 78.4/98), B (ULAS 78.4/135), C (ULAS 78.4/232), D (ULAS 78.4/154), E (ULAS 78.4/237), F (ULAS 78.4/260), G (ULAS 78.4/ 263) - This cluster of Late Archaic stemmed projectile points was recovered throughout Stratum B in units NOW4, NOW6, and NOW10. Individuals were recovered from as shallow as 8 centimeters below the contact of Stratum $A$ and $B$, and as deep as 55 centimeters below the contact. Six of the seven objects were of fine-grained chert sources (see table below). 
Figure 9. Late Archaic stemmed projectile points recovered from Stratum B. 


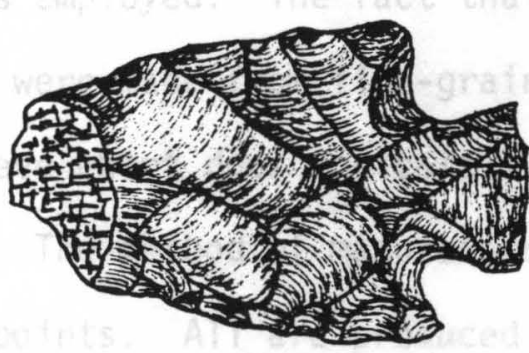

$\triangle$
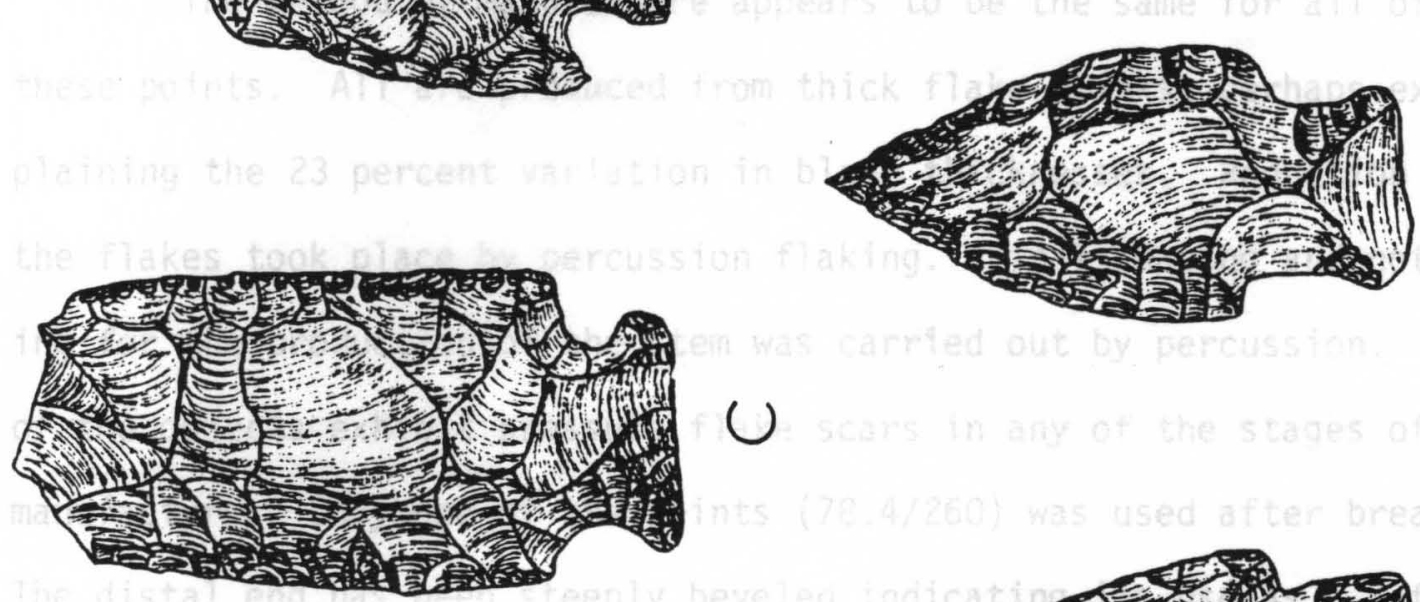

0
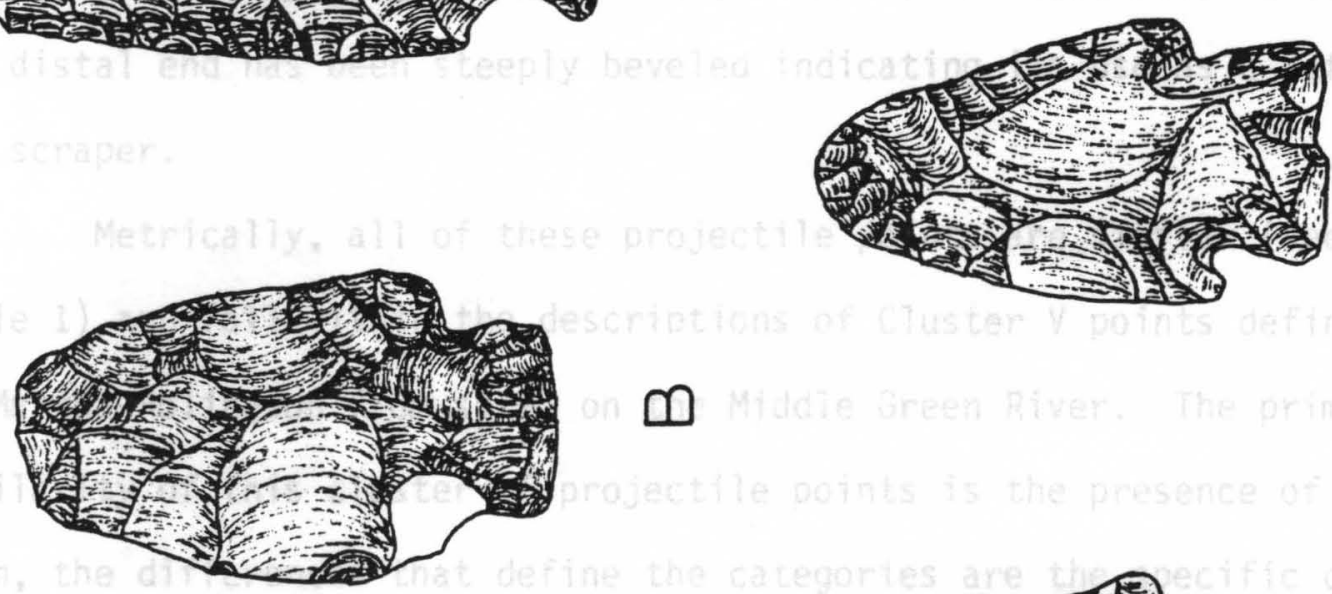

$\infty$
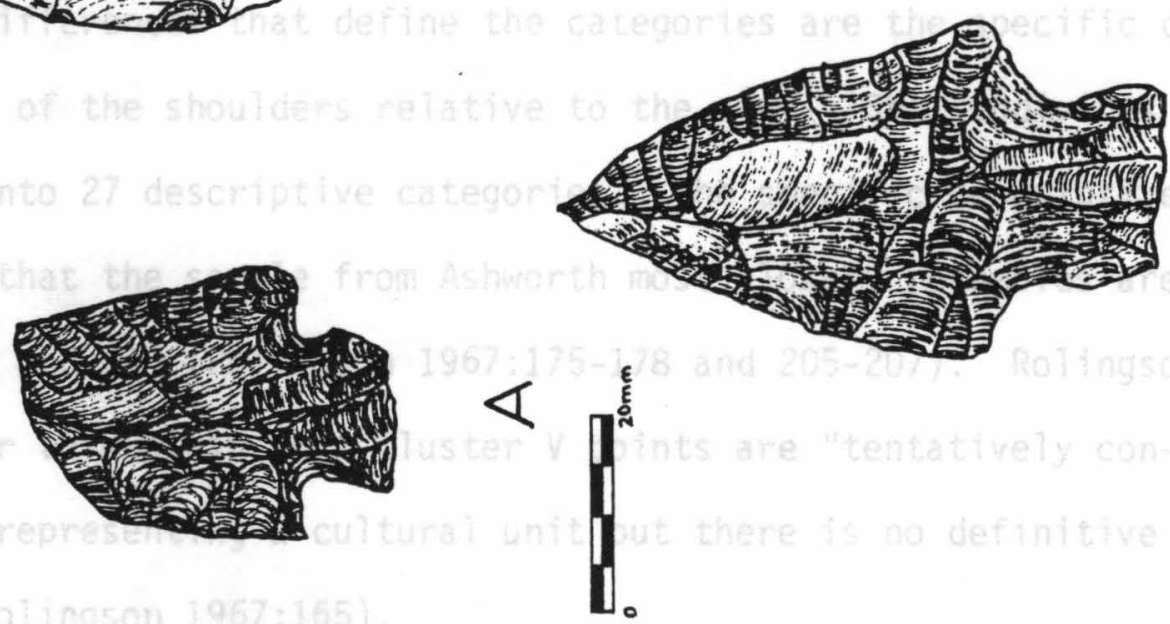

ш 
Only one object was made from the moderate- to coarse-grained Muldraugh chert. The type of chert did not apparently affect the manufacturing methods employed. The fact that approximately 85 percent of these points were made from fine-grained Harrison County, Indiana, or Ste. Genevieve chert does indicate a selectivity of material.

The method of manufacture appears to be the same for all of these points. All are produced from thick flake blanks, perhaps explaining the 23 percent variation in blade thicknesses. Reduction of the flakes took place by percussion flaking. Final shaping and notching for the production of the stem was carried out by percussion. None of the objects exhibit pressure flake scars in any of the stages of manufacture. Only one of the points $(78.4 / 260)$ was used after breakage. The distal end has been steeply beveled indicating its use as a hafted end scraper.

Metrically, all of these projectile points are similar (see Table 1) and fall within the descriptions of Cluster $V$ points defined by Martha Rolingson from sites on the Middie Green River. The primary similarity of this cluster of projectile points is the presence of the stem, the differences that define the categories are the specific configurations of the shoulders reiative to the stem. She subdivides Cluster $V$ into 27 descriptive categories. The specific descriptive categories that the sample from Ashworth most closely resembles are D7, D10, C9 and C10 (Roiringson 1967:175-178 and 205-207). Rolingson goes further to explain that Cluster $V$ points are "tentatively considered as representing a cultural unit but there is no definitive proof of this" (Rolingson 1967:165). 
Table 1. Late Archaic Stemmed Projectiles.

\begin{tabular}{|c|c|c|c|c|c|c|c|c|c|}
\hline & $\begin{array}{c}\text { width } \\
\text { at } \\
\text { shoulders }\end{array}$ & $\begin{array}{l}\text { width } \\
\text { of stem } \\
\text { below } \\
\text { shoulders }\end{array}$ & $\begin{array}{l}\text { width } \\
\text { of } \\
\text { stem } \\
\text { prox. }\end{array}$ & $\begin{array}{l}\text { length } \\
\text { of } \\
\text { stem }\end{array}$ & $\begin{array}{c}\text { thick } \\
\text { at } \\
\text { shoulder }\end{array}$ & $\begin{array}{l}\text { thick } \\
\text { at } \\
\text { blade }\end{array}$ & $\begin{array}{c}\text { thick } \\
\text { at } \\
\text { base }\end{array}$ & $\begin{array}{r}\text { overall } \\
\text { length }\end{array}$ & Chert Source \\
\hline $78.4 / 98$ & 26.0 & 12.4 & - & 8.5 & 7.0 & 6.5 & 5.0 & 35.0 & Harrison County \\
\hline $78.4 / 135$ & 29.0 & 17.0 & 18.0 & 10.0 & 6.0 & 5.0 & 4.2 & 52.0 & Ste. Genevieve \\
\hline $78.4 / 154$ & 30.5 & 13.0 & 15.5 & 10.5 & 6.2 & 6.0 & 4.0 & 49.0 & Harrison County \\
\hline $78.4 / 232$ & $2 \dot{9} .5$ & 16.0 & 22.0 & 11.5 & 8.0 & 8.5 & 5.0 & 62.2 & Ste. Genevieve \\
\hline $78.4 / 237$ & 31.5 & 16.5 & 19.5 & 15.5 & 8.8 & 8.5 & 5.2 & $56.5^{*}$ & Harrison County \\
\hline $78.4 / 260$ & 26.5 & 17.1 & 19.5 & 12.0 & 6.0 & 5.5 & 5.5 & 48.5 & Muldraugh \\
\hline $78.4 / 263$ & 26.0 & 15.5 & 17.0 & 15.2 & 8.1 & 6.1 & 6.6 & $54.9^{x}$ & Harrison County \\
\hline (2) Minimum & 26.0 & 12.4 & 15.5 & 8.5 & 6.0 & 5.0 & 4.0 & 35.0 & \\
\hline (3) Maximum & 30.5 & 17.1 & 22.0 & 15.5 & 8.8 & 8.5 & 6.6 & 62.2 & \\
\hline (4) Mean & 29.0 & 16.0 & 18.75 & 11.5 & 7.0 & 6.1 & 5.0 & 51.0 & \\
\hline (5) Stan. Dev. & 2.26 & 1.91 & 2.27 & 2.62 & 1.15 & $1.3 \hat{9}$ & 0.86 & 8.54 & \\
\hline $\begin{array}{l}\text { Coefficient } \\
\text { of Variance }\end{array}$ & 0.08 & 0.12 & 0.12 & 0.23 & 0.16 & 0.23 & 0.17 & 0.16 & \\
\hline
\end{tabular}


Spacially, Rolingson considers this type cluster to be broadly distributed drawing associations based upon physical characteristics from as far away as New York State. Similar point types are listed as Savannah River, Macon, Steubenville, Little Bear Creek, and Ellis, probably dating from 2000 B.C. to 1000 B.C. Culturally, she concludes that this cluster is the point type characterized with Webb's Indian Knoll Focus (Rolingson 1967:313, 404).

Figure 10A (ULAS 78.4/11), B (ULAS 78.4/16), C (ULAS 78.4/20), D (ULAS 78.4/18), E (ULAS 78.4/88), F (ULAS 78.4/79), G (ULAS 78.4/280), H (ULAS 74.119/19833), I (ULAS 78.4/293), J (ULAS 78.4/255) - These ten Salt River Side Notched projectile points represent a single projectile point type variously known in the eastern United States as Trimble Side Notched (Winters 1969:152-154, Plate 14), Brewerton Side Notched (Ritchie 1961:19,72), and the generalized "side notched" types excavated from Modoc Rockshelter, Randolph County, Iilinois. All of these previously established types date from the Middle Archaic to the Late. Archaic periods (ca. 4000 B.C. to 1500 B.C.). The Trimble Side Notched points recovered by Winters were recovered from open sites in the lower Wabash River Valley, Illinois, while the Brewerton site is located in New York. Locally, these projectile points have been recovered from open sites along the Salt River upstream of Taylorsvilie, Kentucky (Ball 1978) and in southwest Jefferson County, Kentucky along the Ohio River (Collins 1979). They have also been recovered from a site (15Jf267) in the central lowlands of Jefferson County in large numbers. Granger considers this site to date to the Late Archaic, however, no carbon dates are known from this site (Granger n.d.: 18). Clearly this kind of areal distribution indicates a broadly-based projectile point type. The broad 

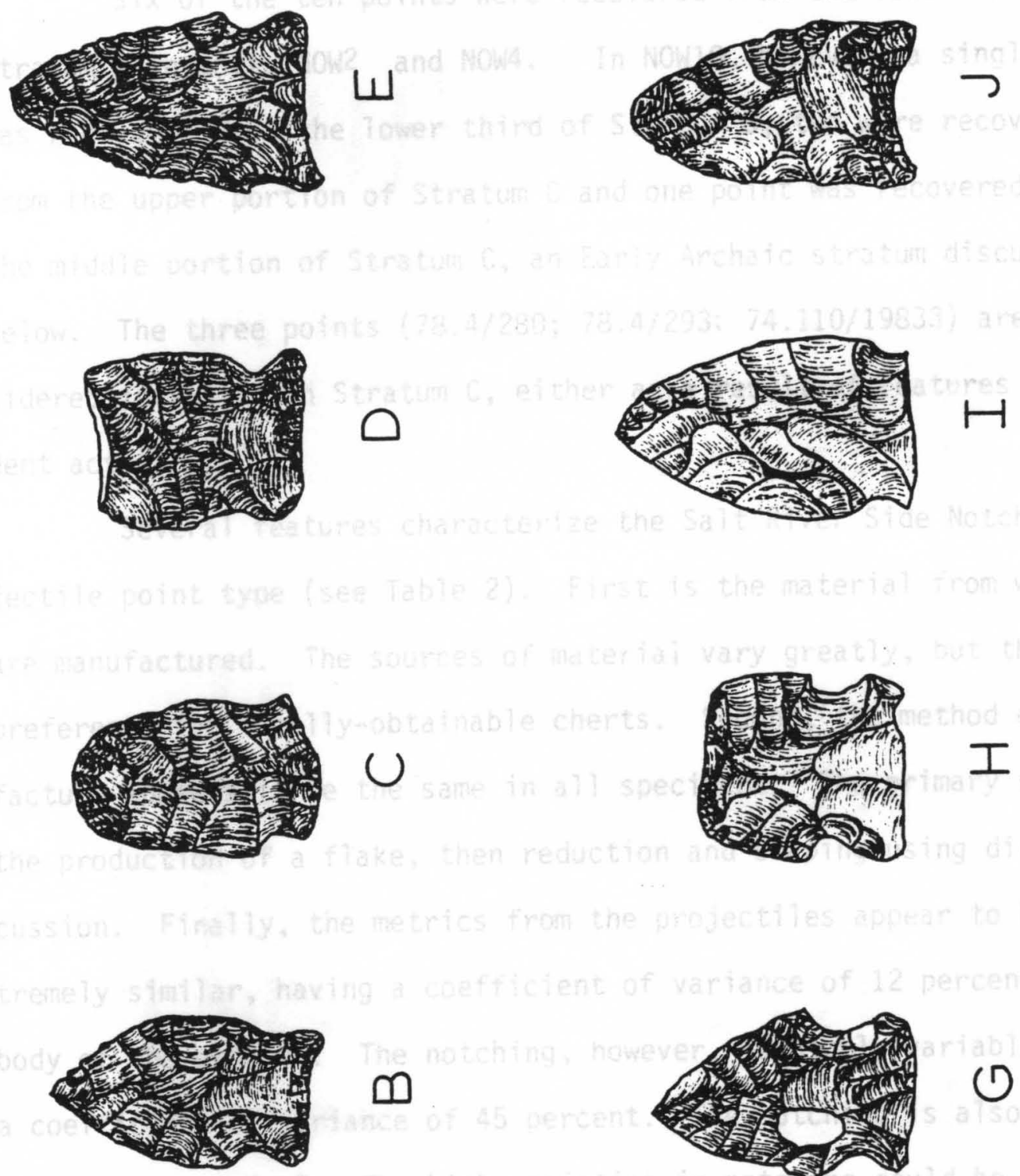

$\infty$

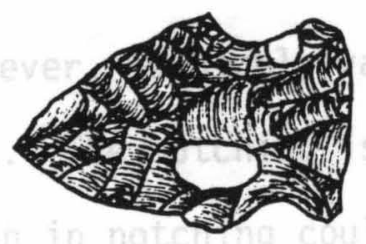

0

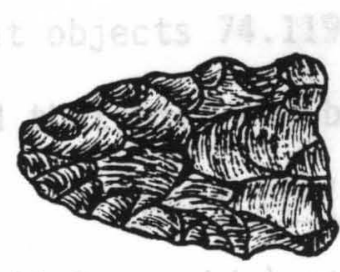

$<\overbrace{0}^{\varepsilon}$

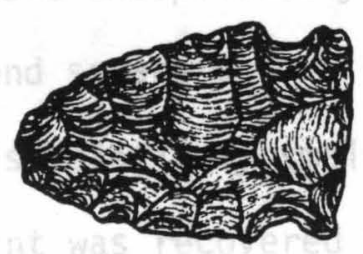

ᄂ 
range of ecozone and site types represents a diverse use of environment and can probably be related to Middle-Late Archaic Regional settiement patterns.

Six of the ten points were recovered from the lower third of Stratum B in units NOW2 and NOW4. In NOW10, however, a single point was recovered from the lower third of Stratum B, two were recovered from the upper portion of Stratum $C$ and one point was recovered from the middle portion of Stratum C, an Early Archaic stratum discussed below. The three points $(78.4 / 280 ; 78.4 / 293 ; 74.110 / 19833)$ are considered intrusive in Stratum $C$, either as a result of features or rodent activity.

Several features characterize the Salt River Side Notched projectile point type (see Table 2). First is the material from which they are manufactured. The sources of materiai vary greatiy, but there is a preference for locally-obtainable cherts. Second, the method of manufacture appears to be the same in all specimens. The primary stage is the production of a fiake, then reduction and shaping using direct percussion. Finally, the metrics from the projectiies appear to be extremely similar, having a coefficient of variance of 12 percent on the body of the objects. The notching, however, is highly variable having a coefficient of variance of 45 percent. The notching is also almost always asymmetrical. The high variation in notching could be a result of the function of the object. It should be noted in the table below that objects $74.119 / 19833$ and $78.4 / 18$ have exceptionally large notches and that both had been used as hafted end scrapers.

Figure 11A (ULAS 78.4/147) - This relatively small $(34.0 \mathrm{~mm}$ long by $20.5 \mathrm{~mm}$ wide) stemmed projectile point was recovered from the middle 
Table 2. Salt River Side Notched Projectiles.

\begin{tabular}{|c|c|c|c|c|c|c|c|c|c|c|c|c|}
\hline U.L.A.S.\# & $\begin{array}{l}\text { Overall } \\
\text { Length }\end{array}$ & $\begin{array}{c}\text { Width } \\
\text { at } \\
\text { Shoulders }\end{array}$ & $\begin{array}{l}\text { Body } \\
\text { Width } \\
\text { at } \\
\text { Notches }\end{array}$ & $\begin{array}{l}\text { and Blad } \\
\text { Width } \\
\text { of } \\
\text { Base }\end{array}$ & $\begin{array}{l}\text { Thickness } \\
\text { Between } \\
\text { liotches }\end{array}$ & $\begin{array}{c}\text { Thickness } \\
\text { of } \\
\text { Blade }\end{array}$ & $\begin{array}{c}\text { Thickness } \\
\text { of } \\
\text { Base }\end{array}$ & $\begin{array}{l}\text { Width } \\
\text { of } \\
\text { Notch }\end{array}$ & $\begin{array}{l}\text { Notch } \\
\text { Width } \\
\text { of } \\
\text { Notch }\end{array}$ & $\begin{array}{l}\text { ing } \\
\text { Depth } \\
\text { of } \\
\text { Notch }\end{array}$ & $\begin{array}{l}\text { Depth } \\
\text { of } \\
\text { Notch }\end{array}$ & Chert Source \\
\hline $78.4 / 11$ & 31.0 & 19.4 & 16.6 & 18.8 & 7.6 & 6.5 & 4.0 & 5.5 & 4.5 & 1.5 & 1.0 & Muldraugh \\
\hline $78.4 / 16$ & 32.2 & 18.5 & 14.1 & 16.3 & 8.0 & 6.0 & 4.2 & 6.5 & 6.5 & 2.0 & 1.0 & Muldraugh \\
\hline $78.4 / 20$ & 29.7 & 19.3 & 15.5 & 16.8 & 7.0 & 5.5 & 4.0 & 6.5 & 5.0 & 1.8 & 0.8 & Muldraugh \\
\hline $78.4 / 18$ & $26.5^{\star}$ & 21.9 & 17.5 & 21.0 & 8.5 & 8.0 & 4.5 & 9.0 & 6.2 & 2.3 & 1.2 & Gerkin-Like \\
\hline $78.4 / 88$ & $36.7^{\star}$ & 22.5 & 19.0 & 22.1 & 5.5 & 6.0 & 4.5 & 7.2 & 5.9 & 1.9 & 1.2 & Muldraugh \\
\hline $78.4 / 79$ & 32.3 & 21.3 & 16.4 & 19.4 & 7.5 & 7.2 & 4.0 & 6.8 & 6.2 & 1.8 & 1.8 & Muldraugh brown \\
\hline $78.4 / 255$ & 34.5 & 20.5 & 16.7 & 19.5 & 7.3 & 7.3 & 4.0 & $\cdots$ & - & - & - & Brassfield \\
\hline $74.119 / 19833$ & $25.0^{*}$ & 23.0 & 17.5 & 22.0 & 6.3 & 7.8 & 5.0 & 7.8 & 7.5 & 2.5 & 2.3 & Coquina Muldraugh \\
\hline $78.4 / 280$ & 32.0 & 20.5 & 15.0 & 19.5 & 8.0 & 7.5 & 4.0 & 8.0 & 8.0 & 2.3 & 2.0 & Boyle \\
\hline $78.4 / 293$ & 37.0 & 21.5 & 17.7 & 20.0 & 7.0 & 5.0 & 5.0 & 6.5 & 5.5 & 1.5 & 1.0 & Gerkin-Like \\
\hline Minimum & $29.7+$ & 18.5 & 14.1 & 16.3 & 5.5 & 5.0 & 4.0 & 5.5 & 4.5 & 1.5 & 0.8 & \\
\hline Maximum & 33.2 & 23.0 & 19.0 & 22.1 & 8.5 & 8.0 & 5.0 & 9.0 & 8.0 & 2.5 & 2.3 & \\
\hline Mean & $31.70+$ & 20.90 & 16.65 & 19.50 & 7.40 & 6.85 & 4.10 & 7.10 & 5.30 & 1.80 & 1.40 & \\
\hline Stan. Dev. & 2.63 & 1.47 & 1.44 & 1.93 & 0.88 & 1.03 & 0.41 & 2.74 & 2.47 & 0.79 & 0.74 & \\
\hline $\begin{array}{l}\text { Coefficient } \\
\text { of Variance }\end{array}$ & $\begin{array}{l}0.201 \\
\text { Ave }\end{array}$ & $\begin{array}{c}0.070 \\
\text { rage Coeffi }\end{array}$ & $\begin{array}{r}0.080 \\
\text { cient of }\end{array}$ & $\begin{array}{c}0.099 \\
\text { Variance }\end{array}$ & $\begin{array}{l}0.119 \\
=0.119 \\
\end{array}$ & $0.150 \overline{0}$ & 0.100 & $\begin{array}{l}0.386 \\
\text { Aver }\end{array}$ & $\begin{array}{r}0.466 \\
\text { age loe }\end{array}$ & $\begin{array}{r}0.439 \\
\text { fficien }\end{array}$ & $\begin{array}{l}0.529 \\
t \text { of } \operatorname{Var}\end{array}$ & iance $=0.455$ \\
\hline
\end{tabular}

* Indicates incomplete object

+ Indicates incomplete objects not considered 
Figure 11. Middle and late Early Archaic projectile points recovered from Stratum B. 

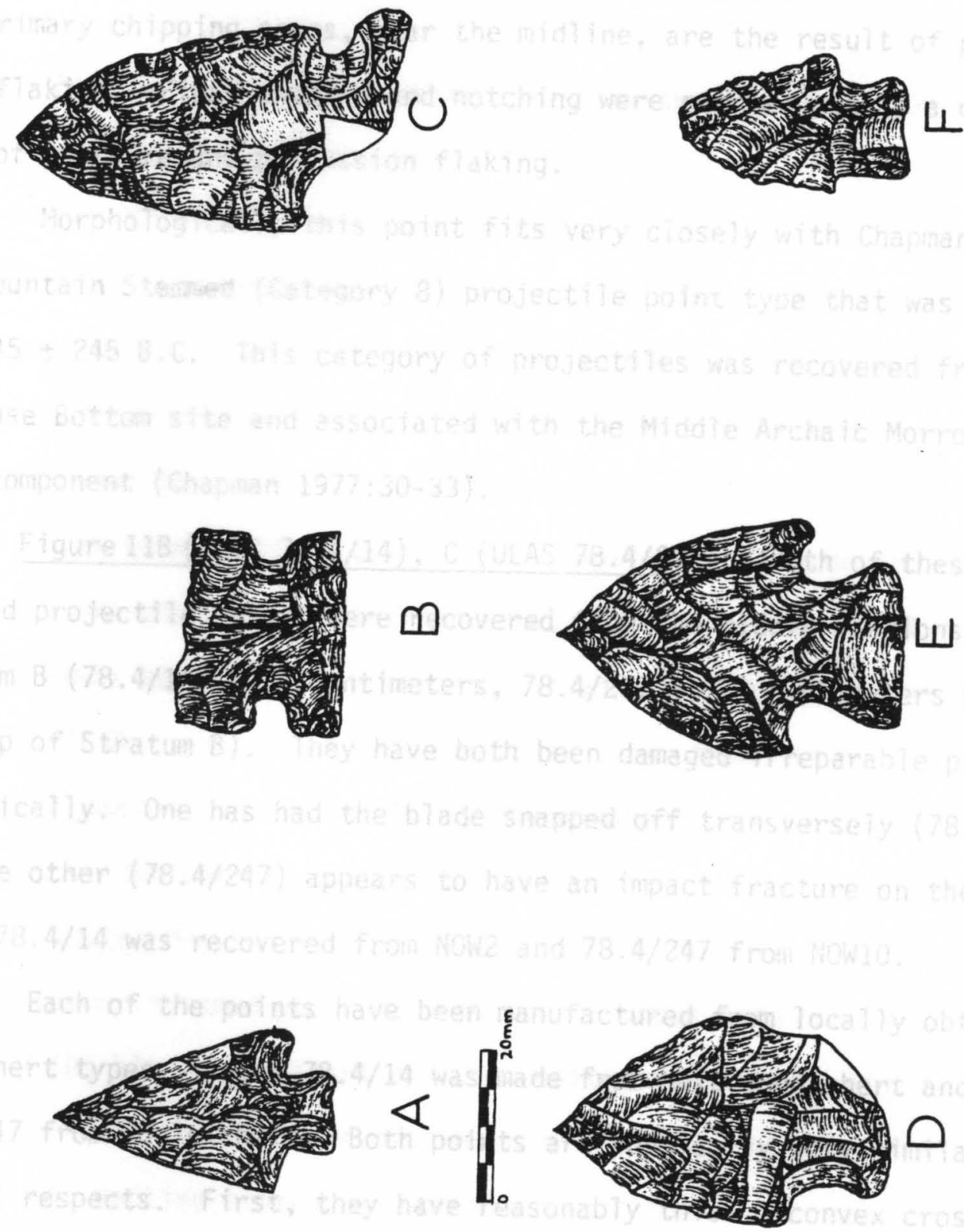
portion of Stratum B (32 centimeters below the contact of Strata A and B). This point is made of Harrison County chert. The stem is short $(7.5 \mathrm{~mm})$ and expands slightly $(9.0 \mathrm{~mm}$ distally to $10.3 \mathrm{~mm}$ proximaliy). The maximum thickness is $6.0 \mathrm{~mm}$. The cross section is planoconvex. The primary chipping scars, near the midline, are the result of percussion flaking. Final shaping and notching were carried out by a combination of pressure and percussion flaking.

Morphologicaily this point fits very ciosely with Chapman's Morrow Mountain Stermed (Category 8) projectile point type that was dated at $5045 \pm 245$ B.C. This category of projectiles was recovered from the Icehouse Bottom site and associated with the Middle Archaic Morrow Mountain component (Chapman 1977:30-33).

Figure 11B (ULAS 78.4/14), C (ULAS 78.4/247) - Boich of these side notched projectile points were recovered from the middle portions of Stratum B (78.4/14 at 37 centimeters, $78.4 / 247$ at 28 centimeters below the top of Stratum B). They have both been damaged irreparable prehistorically. One has had the blade snapped off transversely $(78.4 / 14)$ and the other (78.4/247) appears to have an impact fracture on the base. Point 78.4/14 was recovered from NOW2 and 78.4/247 from NOW10.

Each of the points have been manufactured from locally obtainable chert types. Point $78.4 / 14$ was made from Muldraugh chert and $78.4 / 247$ from Boyle chert. Both points are physically very similar in several respects. First, they have reasonably thick biconvex cross sections, $7 \mathrm{~mm}$, and broad deep side notching (a) 11 notches $6 \mathrm{~mm}$ wide and $4 \mathrm{~mm}$ deep). Both have slightly ground bases. The blade of $78.4 / 247$ is alnost imperceptabiy serrated, of course little can be said of the biade of 78.4/14. The method of manufacture appears to be simiiar with both 
points thinned by percussion flaking, notched by pressure flake removal, and then basally ground. The tang of $78.4 / 247$ extends beyond the width of the biade somewhat, indicating that the blade has been reduced by resharpening. The base of $78.4 / 247$ is incurvate as opposed to the straight base of $78.4 / 14$.

Typologically these points fall into the Big Sandy projectile point type. Point 78.4/247, however, falls within a subtype defined by Cambron as a Big Sandy Broad Base (Cambron and Hulse 1975:16). Temporally these points are poor indicators. Points of this type have been dated as early as the Early Archaic (7922 B.C. \pm 392) at Modoc Rock Shelter (Lewis and Lewis 1961:37) and as late as the beginning of the Christian era (Bell 1960:8). Some investigators have even suggested a Transitional Paleo Indian-Early Archaic placement (Cambron and Hulse 1975:16). At the Eva site in Tennessee, Lewis and Lewis conclude that the Big Sandy point type appeared most frequently in levels dating from 4000-3000 B.C. (Lewis and Lewis 1961:37). This type has been found in infrequent numbers in the Big Sandy phase dating from 1200 B.C. to the beginning of the Christian era (Bell 1960:8).

Figure 11D (ULAS 74.119/19840), E (ULAS 78.4/21) - Both of these broadly corner notched projectile points are made from Harrison County cherts. The blades are short and ovate with moderate to well defined shoulders. The broad corner notches form an expanding stem. No portion of the hafting element has been ground. Both appear to be manufactured in much the same way. Primary reduction and thinning took place by using percussion. Shaping was carried out by using a combination of percussion and pressure flaking. Notching was executed by pressure flake removal. 
Both of the points were associated with Stratum B. Point $78.4 / 21$ was recovered from the lower portion of Stratum B in unit NOW2. Point $74.119 / 19840$ was recovered from the third thoracic vertebra of Burial 4, discussed in more detail below. This burial is considered intrusive into Stratum $C$.

Metrically these projectiles are very similar. Projectile point $74.119 / 19840$ is $41.0 \mathrm{~mm}$ long and $26.0 \mathrm{~mm}$ wide. The stem is 8.2 $\mathrm{mm}$ long. The stem is $19.0 \mathrm{~mm}$ wide just proximally of the shoulders. Projectile point $78.4 / 21$ is $42.6 \mathrm{~mm}$ long and $28.9 \mathrm{~mm}$ wide. The stem is $15.1 \mathrm{~mm}$ wide, proximal to the shoulders, and $19.5 \mathrm{~mm}$ wide at the base. The maximum thickness is $7.0 \mathrm{~mm}$. Point $74.119 / 19840$, on the other hand, is $10.0 \mathrm{~mm}$ thick giving it an unfinished appearance. The bases are slightly excurvate. Both of these points are morphologically similar to Chapman's defined Category 30, a small excurvate corner notched point type. However, metrically they are somewhat larger (Chap$\operatorname{man} 1977: 40-47)$.

Chapman has recovered only 9 specimens of this type from the Icehouse Bottom site in the lower Little Tennessee River Valley. They were recovered from the upper half of the Early Archaic Kirk projectile point-bearing strata (Chapman 1977:47). As mentioned before, projectile point $74.119 / 19840$ was recovered in association with Burial 4 , intruding into Stratum C. Stratum $C$ was found to contain almost exclusively Early Archaic type projectile points at the Ashworth site.

Figure I1F (ULAS 78.4/27) - This small, slightly-serrated projectile point was recovered from the upper portion of Stratum $C$ (11 centimeters below the contact of Strata $B$ and $C$ ) in unit NOW2. It was manufactured from Harrison County chert. The stem is broad relative to the 
width of the blade forming weak shoulders. The cross section is planoconvex. It was manufactured using a combination of percussion and pressure flaking techniques. The base is straight to slightly incurvate. The base has been thinned, but is unground.

This point is $29.0 \mathrm{~mm}$ long and $6.0 \mathrm{~mm}$ thick. The maximum width measured at the shoulders is $16.8 \mathrm{~mm}$. The stem is $8.8 \mathrm{~mm}$ iong. The width of the stem measured below the shoulders is $11.5 \mathrm{~mm}$ and is 12.2 mm wide proximally.

Morphologically this projectile point falls in the Kirk Serrated/ Kirk Stemmed type (Category 18) defined by Jefferson Chapman (1977). This type is believed by Chapman to be a variant of the "classic" Kirk type defined by Coe and Broyles (Chapman 1977:37). Cultural1y, this point would fall toward the latter portion of the Early Archaic period. Figure 12A (ULAS 78.4/30), B (ULAS 78.4/52), C (ULAS 78.4/56), D (ULAS 78.4/50), E (ULAS 78.4/102), F (ULAS 78.4/184), G (ULAS 78.4/167 and Figure 13A (ULAS 78.4/240), B (ULAS 78.4/299), C (ULAS 78.4/308), D (ULAS 78.4/309), E (ULAS 78.4/157), F (ULAS 78.4/173), G (ULAS 78.4/158), H (ULAS 78.4/182) - This cluster of Ashworth Corner Notched projectile points/knives was found throughout and only within Stratum C. They were found within 3 centimeters of the contact zone of Strata $B$ and $C$ and on the contact zone of Strata $C$ and $D$ in all of the test units.

A11 of these projectiles exhibit the same method of manufacture; initially struck from a nodule as a flake, then thinned by percussion flaking. Shaping, in all cases, was completed by pressure flaking. Once the blade was shaped the base was thinned by pressure flaking as we11. This is apparently due to the fact that the flake scars emanating from the base override flake scars along the blade. In every example 
Figure 12. Ashworth Corner Notched projectile points recovered from Stratum $C$. 

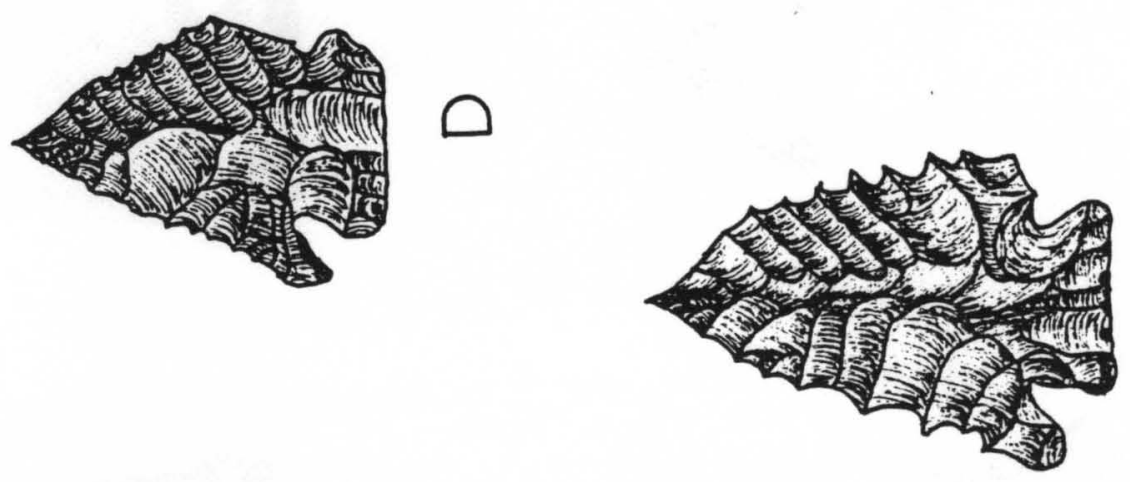

0

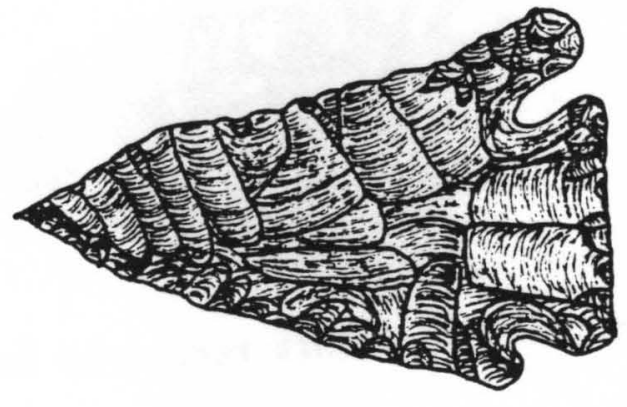

U

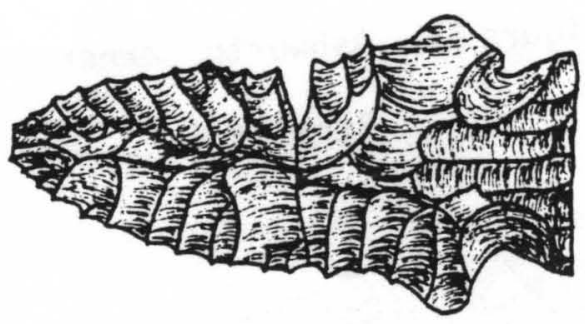

ᄂ

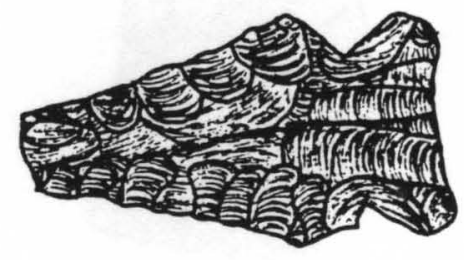

$\infty$

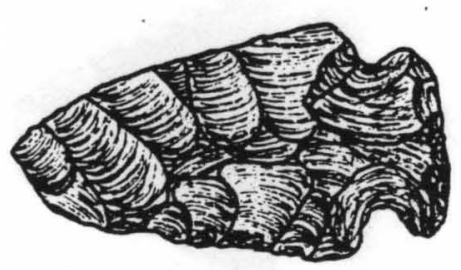

4

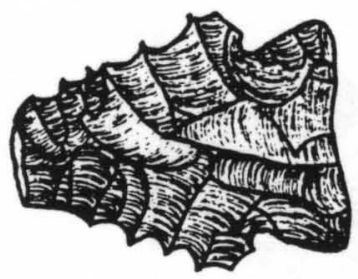

山 
Figure 13. Ashworth Corner Notched projectile points recovered from Stratum C. 

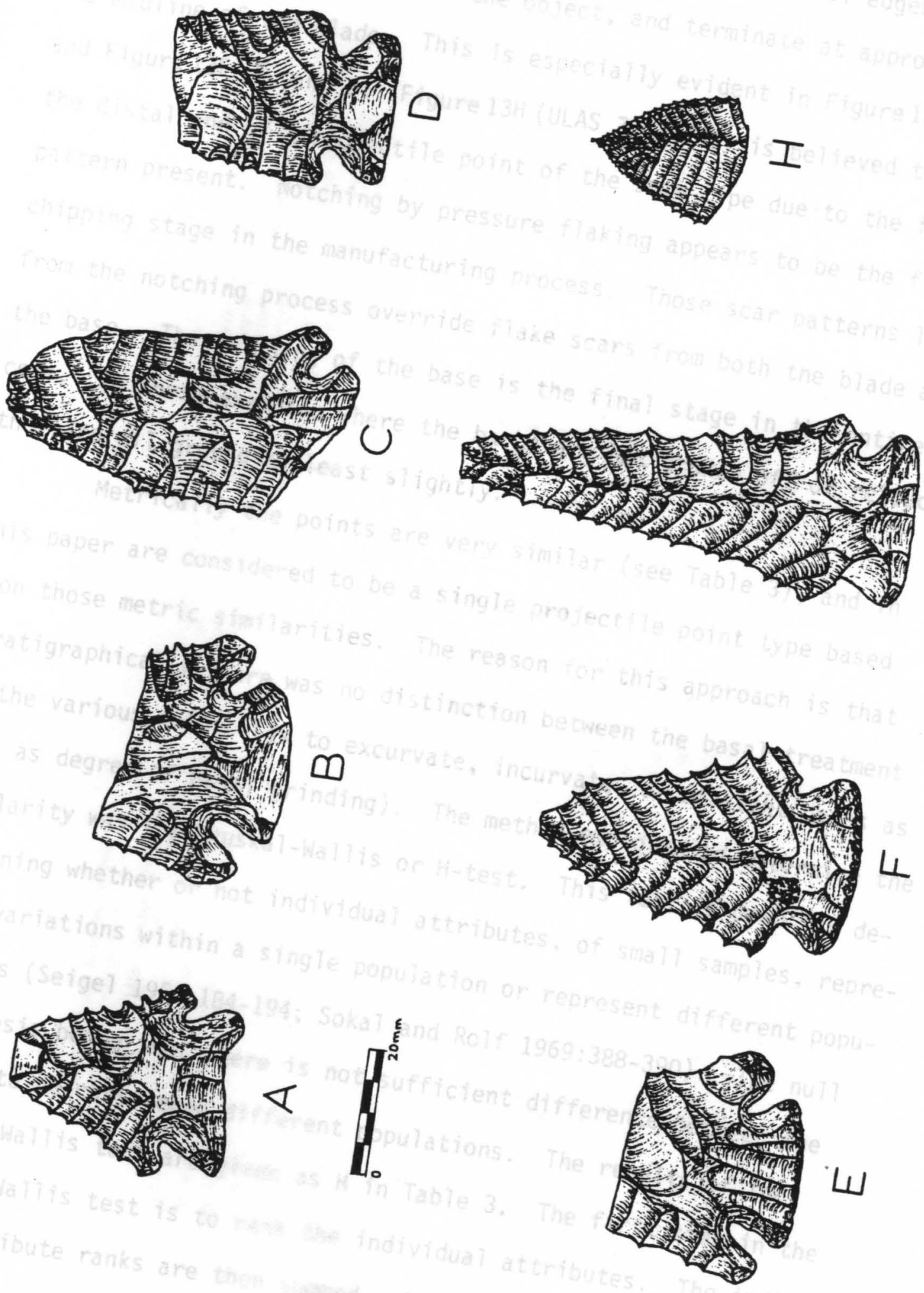
where the blade is present the flake scars on the blade are distributed transversely. That is, the scars emanate from the lateral edges, run diagonally across the face of the object, and terminate at approximately the midline of the blade. This is especially evident in Figure $12 F$ and $G$ and Figure $13 F$ G, and $H$. Figure $13 H$ (ULAS 78.4/182) is believed to be the distal end of a projectile point of the same type due to the flaking pattern present. Notcining by pressure flaking appears to be the final chipping stage in the manufacturing process. Those scar patterns left from the notching process override flake scars from both the blade and the base. The grinding of the base is the final stage in the entire process. In those examples where the barbs are not broken off or retouched they are all ground as least slightly.

Metrically the points are very similar (see Table 3 ), and in this paper are considered to be a single projectile point type based upon those metric similarities. The reason for this approach is that stratigraphically there was no distinction between the basal treatment of the various points (as to excurvate, incurvate, or straight bases as well as degree of basal grinding). The method employed to determine the similarity was the Kruskal-Wallis or $\mathrm{H}$-test. This test is used for determining whether or not individual attributes, of small samples, represent variations within a single population or represent different populations (Seigel 1956:184-194; Sokal and Rolf 1969:388-390). The null hypothesis being that there is not sufficient difference between the groups to be considered different populations. The results of the Kruskal-Wallis test are given as $H$ in Table 3 . The first step in the Kruskal-Wallis test is to rank the individual attributes. The individual attribute ranks are then summed. In this case the base shape was 
Table 3. Ashworth Corner Notched Projectiles

\begin{tabular}{|c|c|c|c|c|c|c|c|c|c|c|c|c|}
\hline & $\begin{array}{l}\text { Width } \\
\text { at } \\
\text { Notch }\end{array}$ & $\begin{array}{l}\text { Width } \\
\text { of } \\
\text { Base }\end{array}$ & $\begin{array}{l}\text { Length } \\
\text { of } \\
\text { Base }\end{array}$ & $\begin{array}{l}\text { Thickness } \\
\text { at } \\
\text { Notch }\end{array}$ & $\begin{array}{l}\text { Depth } \\
\text { of } \\
\text { Notch }\end{array}$ & $\begin{array}{l}\text { Depth } \\
\text { of } \\
\text { Notch }\end{array}$ & $\begin{array}{c}\text { Thickness } \\
\text { of } \\
\text { Base }\end{array}$ & $\begin{array}{l}\text { Width } \\
\text { of } \\
\text { Blade }\end{array}$ & $\begin{array}{c}\text { Thickness } \\
\text { of } \\
\text { Blade }\end{array}$ & $\begin{array}{l}\text { Base } \\
\text { Shape }\end{array}$ & $\begin{array}{l}\text { Relative } \\
\text { Degree of } \\
\text { Grinding }\end{array}$ & Material Source \\
\hline $78.4 / 56$ & 19.3 & 24.3 & 8.0 & 8.0 & 6.4 & 8.0 & 3.5 & 29.8 & 5.5 & $s$ & L & Harrison County \\
\hline $78.4 / 50$ & 15.0 & 19.5 & 7.5 & 5.1 & 6.0 & - & 4.0 & - & 2.0 & S & M & Harrison County \\
\hline $78.4 / 158$ & 17.5 & 24.0 & 9.2 & 7.8 & 5.9 & 7.5 & 4.8 & 27.9 & 3.5 & s & $H$ & Muldraugh Brown \\
\hline $78.4 / 167$ & 14.8 & 17.5 & 7.5 & 5.7 & 5.0 & 5.3 & 4.0 & 25.5 & 4.0 & s & $\mathrm{L}$ & Muldraugh \\
\hline $78.4 / 184$ & 17.0 & 21.0 & 7.4 & 6.5 & 5.3 & 6.8 & 4.0 & 28.2 & 4.0 & $S$ & M & Muldraugh \\
\hline $78.4 / 309$ & 14.0 & 22.8 & 8.8 & 4.5 & 6.8 & 8.5 & 3.0 & 26,5 & 5.0 & s & H & Harrison County \\
\hline $78.4 / 240$ & 18.0 & 25.5 & 9.5 & 6.5 & 8.5 & 10.0 & 6.5 & 28.5 & 4.5 & $s$ & H & Muldraugh \\
\hline $78.4 / 157$ & 16.0 & 21.5 & 9.0 & 6.3 & 6.0 & 6.5 & 4.0 & 27.5 & 5.5 & E & M & Harrison County \\
\hline $78.4 / 299$ & 19.5 & 24.0 & 9.7 & 7.0 & 7.0 & 6.3 & 4,0 & 33.0 & 8.3 & E & H & Muldraugh \\
\hline $78.4 / 30$ & 13.7 & 17.4 & 6.0 & 5.2 & 5.4 & - & 3.8 & 22.0 & 3.5 & E & $H$ & Paoli Chert \\
\hline $78.4 / 173$ & 18.0 & 25.3 & 9.5 & 6.5 & 5.8 & 6.5 & 3.8 & 30.1 & 3.8 & E & M & Gerkin-Like \\
\hline $78.4 / 308$ & 14.0 & - & 7.5 & 6.3 & 5.3 & - & 4,5 & 26.0 & 2.8 & 1 & H & Muldraugh \\
\hline $78.4 / 52$ & 14.4 & 21.1 & 8.5 & 6.3 & 6.3 & 6.8 & 3.5 & 22.0 & 3.8 & I & M & Brassfield \\
\hline $78.4 / 102$ & 16.9 & 21.9 & 7.5 & 7.0 & 7.6 & 7.6 & 4.0 & 24.8 & 2.9 & I & H & Harrison County \\
\hline Mininum & 13.7 & 17.4 & 6.0 & 4.5 & 5.0 & 5.3 & 3.0 & 22.0 & 2.0 & & & \\
\hline Maximum & 19.5 & 25.5 & 9.7 & 8.0 & 8.5 & 10.0 & 6.5 & 33.0 & 8.3 & & & \\
\hline Mean & 16.45 & 21.90 & 8.25 & 6.40 & 6.00 & 6.80 & 4.00 & 27.50 & 3.90 & & & \\
\hline Stan. Dev. & 2.01 & 2.69 & 1.08 & 0.98 & 0.97 & 1.27 & 0.81 & 3.12 & 1.54 & & & \\
\hline$H$ & 1.559 & 0.157 & 1.412 & 0.026 & 0.110 & 3.409 & 0.333 & 0.380 & 3.208 & & & \\
\hline
\end{tabular}

Base Shape $-S=$ straight, $E=$ Excurvate, $I=$ Incurvate

Degree of Grinding $-\mathrm{L}=1 \mathrm{ight}, \mathrm{m}=$ moderate, $\mathrm{H}=$ heavy 
the method employed for the subdivision of the population. The sum of the ranks are then inserted in the following formula:

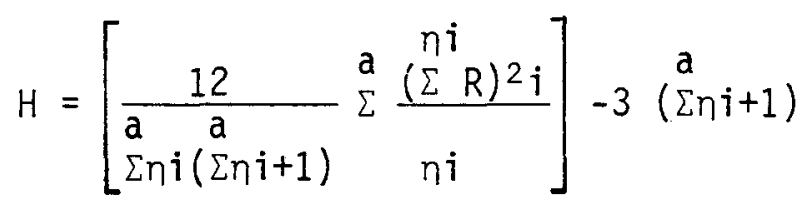

The resulting $H$ value is then compared with an established critical value depending upon population size. If $H$ is below the critical value the null hypothesis is accepted. In this case, Siegel's Table 0 was used (Seigel 1956:282-283). The critical value at the 0.049 confidence level was 5.6564. The results of the $H$ test, found in Table 3 , clearly demonstrate that no matter what form the base takes all of the specimens are from the same population. There is, however, some variation within the population. The notch depth (the greater of the two notches) and the thickness of the blade are the most variable. There is a possible explanation for both variations. First, the blade thickness could be highly variable due to the number of times that resharpening has been carried out. The high degree of variation in the notching could be the result of the fact that several of the objects have functioned as projectile points or knives or both. This could result in the requirement of greater notch depth for greater hafting stability, for those objects used as knives.

Morphologically these projectile point/knives fall within several defined corner notched types. The type that the Ashworth Corner Notched points most closely resemble is the Charlestown Corner Notched point type recovered from the St. Albans site, in Kanawah County, West Virginia (Broyles 1971:56-57). They aiso resemble Categories 28, 29, and 38 of 
deeply corner notched points recovered at the Icehouse Bottom site, on the lower Little Tennessee River. The radiocarbon dates given for the Charlestown Corner Notched points recovered at St. Albans are 7900 B.C. \pm 500 years (Broyles 1971:57). The radiocarbon date for the stratum from which the Category 38 projectile points were recovered are 7485 B.C. \pm 270 years (Chapman 1977:51). Chapman, in his summary of corner notched projectiles, considers those categories mentioned above as part of the broad Kirk Corner Notched cluster (Chapman 1977:53).

\section{Non-diagnostic Projectiles and Fragments}

Figure 14A (ULAS 78.4/130) - This expanding stem projectile point is made from Ste. Genevieve chert. Minor amounts of fire pocking indicate that is has been slightly heated. The blade is broken transversely and has not been reworked into a scraper. One of the corners of the base has also been broken off. It is $9.0 \mathrm{~mm}$ thick and biconvex in cross section. The shoulders are weak and are $22.0 \mathrm{~mm}$ wide. The stem is 15.5 $\mathrm{mm}$ long and $13.8 \mathrm{~mm}$ wide. The flaking pattern indicates that percussion flaking was employed in the manufacture of this object. It was recovered from the upper portion of Stratum A (9 centimeters below the surface) in NOW6.

Figure 14B (ULAS 78.4/89) - This projectile point was recovered from NOW4 in the lower portion of Stratum B (37 centimeters below the contact zone of Strata $A$ and $B$ ). It is planoconvex in cross section and manufactured from Muldraugh chert. This point has been fired. On the convex side the color is a deep, purplish-grey, on the flat side it is a dark pink. The blade is ovate $(21.0 \mathrm{~mm}$ at $i$ is widest) and has been shaped by percussion flaking. The stem has been broken and cannot be measured with confidence. The stem is $12.0 \mathrm{~mm}$ at its narrowest. 
Figure 14. Non-diagnostic projectile points and fragments. 

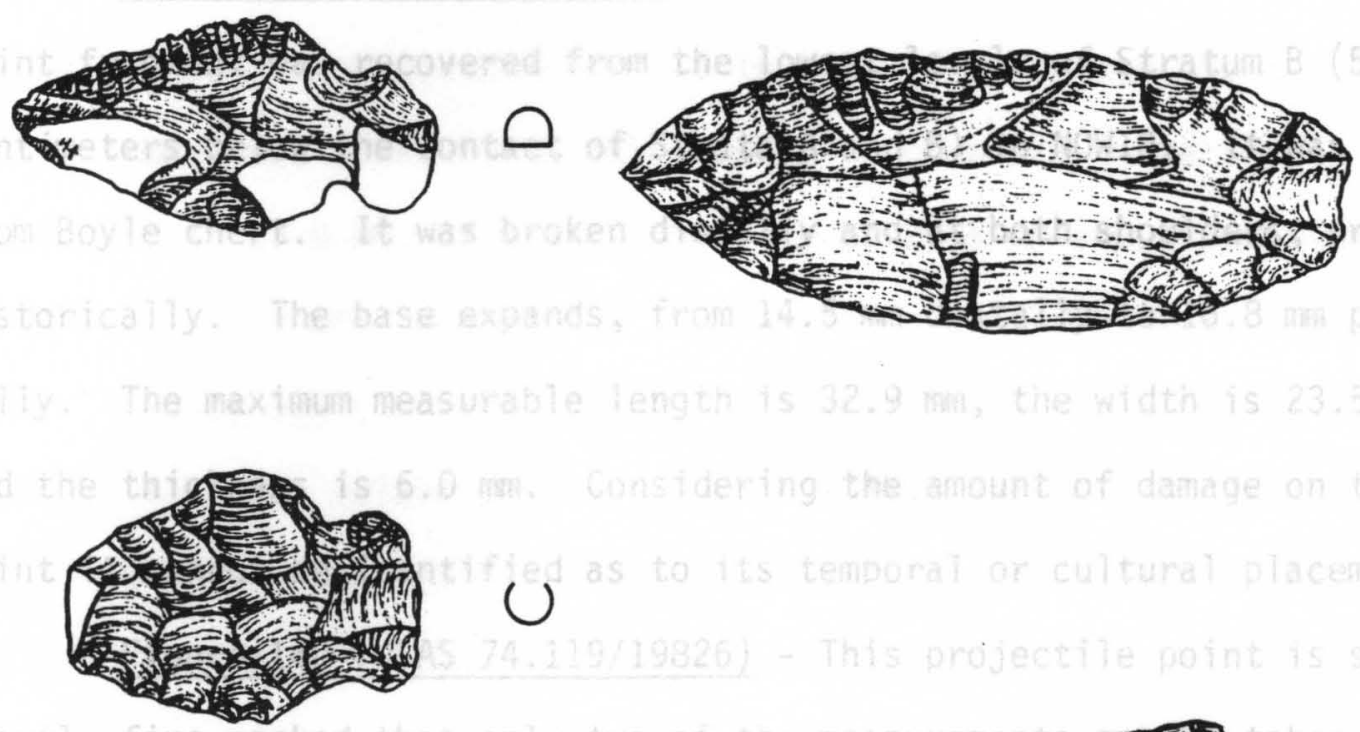

U
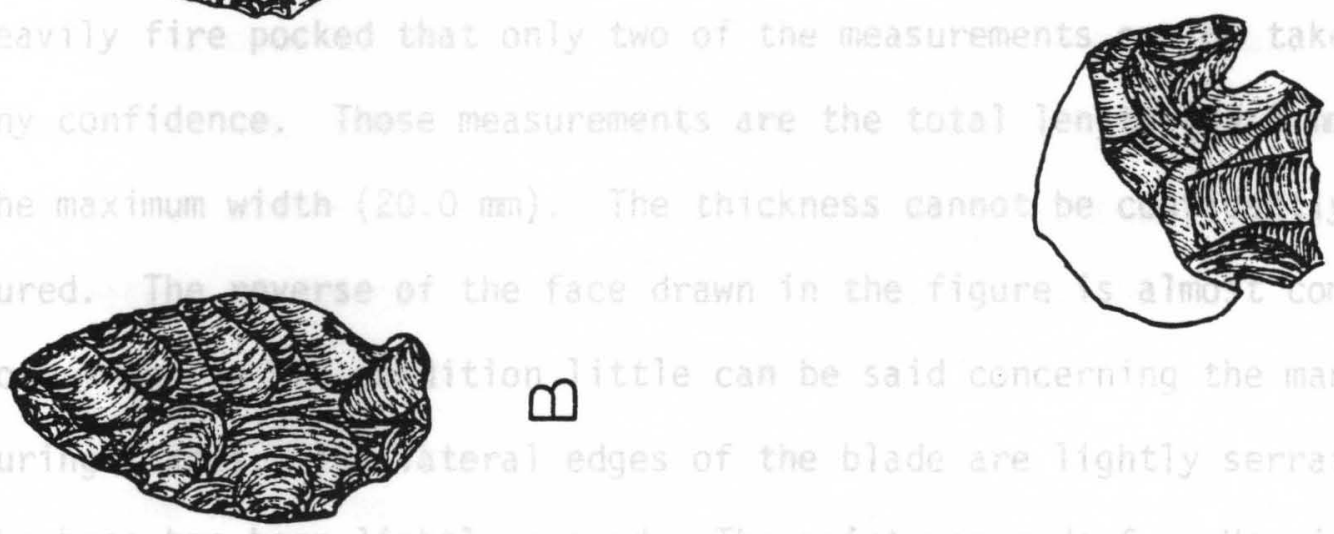

Ф
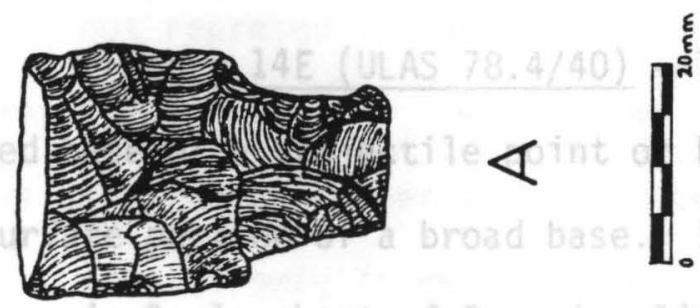
The entire point is $40.5 \mathrm{~mm}$ long and $7.1 \mathrm{~mm}$ thick. It is possible that this point may be a variant of the Sait River Side Notched points discussed above. Its stratigraphic position and morphology tend to support this belief.

\section{Figure 14C (ULAS 78.4/256) - This expanding stem projectile} point fragment was recovered from the lowest levels of Stratum B (50 centimeters below the contact of Strata A and B) in NOW10. It was made from Boyle chert. It was broken distally and at both shoulders, prehistoricaily. The base expands, from $14.5 \mathrm{~mm}$ distally to $16.8 \mathrm{~mm}$ proximally. The maximum measurable length is $32.9 \mathrm{mrn}$, the width is $23.5 \mathrm{~mm}$, and the thickness is $6.0 \mathrm{~mm}$. Considering the amount of damage on this point it cannot be identified as to its temporal or cultural placement. Figure 14D (ULAS 74.119/19826) - This projectile point is so heavily fire pocked that only two of the measurements can be taken with any confidence. Those measurements are the total iength $(39.2 \mathrm{~mm})$ and the maximum width $(20.0 \mathrm{~mm})$. The thickness cannot be confidently measured. The reverse of the face drawn in the figure is almost completely gone. Due to the condition little can be said concerning the manufacturing stages. The lateral edges of the blade are lightly serrated and the base has been lightly ground. The point was made from Harrison County chert. It was found in the middle portion of Stratum B, 34 centimeters below the contact of Strata $A$ and $B$, in NOW10.

Figure 14E (ULAS 78.4/40) - This object appears to be a bifurcated base of a projectile point or knife. It could, however, be an incurvate portion of a broad base. It is heavily ground. The chert source is Boyle chert of Devonian 7 imestones found in the Outer Bluegrass. It was recovered from the upper portion of Stratum C, 8 centimeters below 
the contact of Strata B and C, in NOW2.

Figure 14F (ULAS 78.4/97) - This object appears to be an abortive attempt at the manufacture of a corner notched projectile point such as those described as Ashworth Corner Notched above. This object was recovered in the upper portion of Stratum C, 8 centimeters below the contact of Strata B and C, in NOW4. It is made of Muldraugh chert. None of the dimensions present are believed to be complete. The length of the object is $27.0 \mathrm{~mm}$. Its maximum width is $29.5 \mathrm{~mm}$ and its maximum thickness is $7.0 \mathrm{~mm}$. The edge that appears to be the base is unground. Figure 14G (ULAS 78.4/218) - This object is not a projectile point or a knife. Flake patterns indicate that this object is a blank. All of the flake scars present are the result of percussion flaking. The object is fairly thick $10.5 \mathrm{~mm}$ and there are no wear patterns present to indicate its use as a knife. The overall length is $67.0 \mathrm{~mm}$. This object was made from Muldraugh chert and appears to have been fired to red. It was recovered from the upper level of Stratum B, within 5 centimeters of the contact of Strata A and B, in unit NOW10.

\section{Ceramic and Fired Clay}

The following discussion of ceramics recovered from the Ashworth site includes fired clay fragments. The fragments of fired clay, when initially recovered in the field, were believed to be vessei fragments. Though not representing an actual vessel, one of the clay fragments was impressed with fabric. Two similar instances, one relating to the actual weave pattern, the other to this type of impressions, are discussed below.

The ceramic fragments recovered from the Ashworth site are exceptionally smal1, the iargest measures 47.0 by $48.0 \mathrm{~mm}$. The majority of the other sherds were so small that they can only be described by the 
temper. The vessel fragments can be classified broadly into three temper types: grit and limestone, chert, and she11. The colors of the objects are given in Munsell values (Munsell Color 1975). The fragments of fired clay have no temper incorporated into the matrix. Another identifying characteristic of the fired clay fragments is that only the "interior" exhibits any surface treatment. The "exteriors" are rough.

The she11-tempered ceramic fragments were all recovered in the upper portion of soil stratum $A$ and were found at depths ranging from 7 to 10 centimeters below the surface. In ali, three sherds were recovered (ULAS 78.4/62, 68, and 202). Sherds $78.4 / 62$ and 78.4/68 were recovered from NOW4 and are believed to be from the same vessel. The sherds measure 16.3 by $13.1 \mathrm{~mm}$ and 46.5 by $39.9 \mathrm{~mm}$, respectively. Both are tempered with finely-crushed fragments of shell (averaging $1.2 \mathrm{~mm}$ ). The interiors and exteriors have been smoothed. The interior color is brown (10YR 5/3) and the exterior color is light yellowish-brown (10YR 6/4). The thicknesses are fairly uniform varying from $4.5 \mathrm{~mm}$ to $5.0 \mathrm{~mm}$.

The third sheil-tempered fragment (ULAS 78.4/202) was recovered from NOW10 in Stratum $A$ at a depth of 7 centimeters below the surface. The fragments of crushed shell are also very smal1 (averaging $1.2 \mathrm{~mm}$ ). The interior and exterior of this sherd are also smoothed. The thickness of this sherd also varies from $4.5 \mathrm{~mm}$ to $5.0 \mathrm{~mm}$.

A11 three she11-tempered sherds are very similar as to size of temper, exterior and interior treatment, and color. They were also recovered within the same relative stratigraphic position of one another. Though it is doubtfur that they are sherds from the same vessel, it is obvious that they represent the same ceramic type. Shell-tempered plainware is known throughout the Ohio Valley and is associated with 
both Mississippian and Fort Ancient Cultures. The small size of the fragments precludes a specific association such as those based upon rim decoration or vessel form. Therefore, the only temporal association that can be made at this point is that the ceramics date post-1250 A.D. to the period of contact with Europeans.

Two fragments of grit-tempered ceramics were recovered from the Ashworth site (ULAS 74.119/19813 and 78.4/200). Both of these fragments were found in NOW10. The specific location of 74.119/19813 can accurately be ascertained at 24 centimeters below the surface. The depth of the second sherd is 17 centimeters below the surface. Both of the sherds have an exterior surface treatment of cord-wrapped paddle impressions, and the sherds vary greatiy in thickness and temper size.

The smaller of the sherds (ULAS 78.4/200) measures 24.5 by 27.5 $\mathrm{mm}$ and is 7.0 to $10.0 \mathrm{~mm}$ thick. The temper consists of fired fragments of 1 imestone (average size $2.5 \mathrm{~mm}$ ) and smal1 quartz crystals (average size $2.0 \mathrm{~mm})$. The color of this sherd is a light red $(2.5 Y R 6 / 8)$. The interior is smooth but the exterior is covered by cord-wrapped paddle impressions. These impressions are of a twisted fiber running parallel to one another and though not very distinct had not been smoothed over. The diameter of the impressions are all very uniform at $2.0 \mathrm{~mm}$. The depth of the impressions varies along the length of the cord impression from $0.9 \mathrm{~mm}$ to $1.1 \mathrm{~mm}$ all in the same direction. The cord impressions are $2.2 \mathrm{~mm}$ apart.

The larger of the sherds (ULAS 74.119/19813) measured 47.0 by $48.0 \mathrm{~mm}$ and is between 11.0 and $15.0 \mathrm{~mm}$ thick. The interior is black $(N 2.5 / 0)$. The exterior is reddish-brown (2.5YR 4/4) and has several very weak ( $0.3 \mathrm{~mm}$ deep) cord marks distributed on the surface. The 
exterior appears to have been smoothed after malleation with a cordwrapped paddle. The cord impressions appear to be those of a twisted fiber. The temper consists of fired and unfired limestone fragments averaging 2.0 by $4.0 \mathrm{~mm}$ in size.

Limestone-tempered ceramics have been found in association with lobe base type projectile points and are together referred to as "Adena". However, the term Adena is based upon specific burial and mound buiiding practices (Clay 1980). The extent of the Adena culture beyond central Kentucky is poorly known. Limestone-tempered ceramics that are cordmarked as those described above can be considered Fayette thick-iike ceramics and would be considered to have an Early woodland association (ca. 800 B.C. -1 B.C.).

Two fragments of chert chip-tempered ceramic were recovered from the Ashworth site. One cord-marked body sherd (78.4/131) was found in Stratum A 32 centimeters below the surface in NOW6. The other sherd is a small rim fragment $(78.4 / 215)$ found in NOWi0. The rim fragment was identified in the iaboratory, not in the field, therefore it couid only be isolated to the daity level. The level for the day this sherd was recovered was between 23 to 40 centimeters below the surface.

The body sherd measured 38.5 by $40 \mathrm{~mm}$ and is 8.0 to $9.0 \mathrm{~mm}$ thick. The color is a uniform red (2.5YR 5/8) throughout. The temper consists of chert chips that vary from 1.5 to 4.5 min and a fossil crinoid stem $5.0 \mathrm{~mm}$ in diameter. The chert chips are Harrison County chert. The interior has been smoothed, the exterior had been cordmarked. The cord impressions are clustered in three groups of two cords each. Two other cord imporssions cross the clusters diagonally. These two cord impressions are $13.0 \mathrm{~mm}$ apart. The clusters of cords are 7.0 to $7.6 \mathrm{~mm}$ 
apart (measured from edge to edge). Within the ciusters the two cord impressions are approximately $2.0 \mathrm{~mm}$ apart. A7i of the cord impressions are of twisted fibers approximately $2.0 \mathrm{~mm}$ in diameter, and are approximately $1.0 \mathrm{~mm}$ deep.

The rim sherd recovered is very smal1. Measured along the circumference of the iip it is $20.5 \mathrm{~mm}$ 1ong. Mieasured from the inside of the lip to the outside it varies in thickness from 5.4 to $7.5 \mathrm{~mm}$ thick. The iip has been flattened at a right angle to the interior of the vessel and rolled outward to the exterior. The measurement taken from the edge of the lip to the bottom of the rim present is $8.5 \mathrm{~mm}$. The temper consists of Boyle chert (very fossiliferous) and a single chip was 8.0 by 4.5 by $3.0 \mathrm{~mm}$. The color of this rim was black (N2/0) throughout, as if it has been fired very heavily after breakage.

Chert-tempered ceramics have been found in association with limestone-tempered ware and have been ciassified as Fayette Thick. As noted above, recent investigators feei that Fayette Thick represents a specific type associated with the Adena in central Kentucky (Clay 1980: 171). Since specific culture traits, normally associated with Adena, are to date unknown from the Asiworth site, these ceramic fragments can be tentatively classified as Fayette Thick-like. Culturally, this would piace this levei, the lower portions of Stratum A, in the Early Woodland. Nine fired clay fragments were recovered from two isolated areas in the ievel between 23 and 40 centimeters below the surface in NOw10 (ULAS 78.4/219 and 221). They are all undifferentiated from one another except by size and, in one instance, by "interior" treatment. A11 of the fragments have rough "exteriors" and smoothed "interiors" except a singie example that is net-impressed (described below). A similar situation is 
known to have occurred at the Icehouse Bottoms site in the lower Little Tennessee River valley. Twenty-nine examples of prepared clay hearths in which fabrics had been impressed had been found in strata dating from 7500-6900 B.C. Chapman has postulated two functions of the textiles used to create the impressions, a net used for trapping, fishing, fowling (subsistence activity) or for the transportation of the clay to the site (Chapman 1977:108-112). Another aspect to this fabric-impressed fragment is that the weaving pattern is unlike those described by Chapman, but almost exactly like an actual fabric found lining a pit found on the Baldwin site in Fairfield County, Ohio. The impression found at Ashworth consists of two different cordages. The warp consists of 5 impressions $3.0 \mathrm{~mm}$ wide and $4.0 \mathrm{~mm}$ apart composed of individual clusters of untwined fibers. The weft consists of a single twined cord that is interwoven with the warp. This twined cord is $3.5 \mathrm{~mm}$ wide. This corresponds with the description given by James Griffin "A coarse woven matting of plain twining lined the bottom of a pit... The warp was composed of a bundle of grasslike fiber; the weft was a twisted cord." (Griffin 1966:55).

A11 of the undifferentiated fragments and the fabric-impressed fragment have no tempering material incorporated into the matrix. They are 211 red (2.5YR 5/8) in color. Unfortunately, the areas in which this material was recovered were very poorly defined and had no vertical depth. It is conceivable that they are the result of a prehistoricaliy damaged pit located outside the parameters of the test units. Analysis of ceramic vessel fragments and projectile points recovered from this level of Stratum A date this level to the Early Woodland. 
Table 4. Nondiagnostic Material Culture,

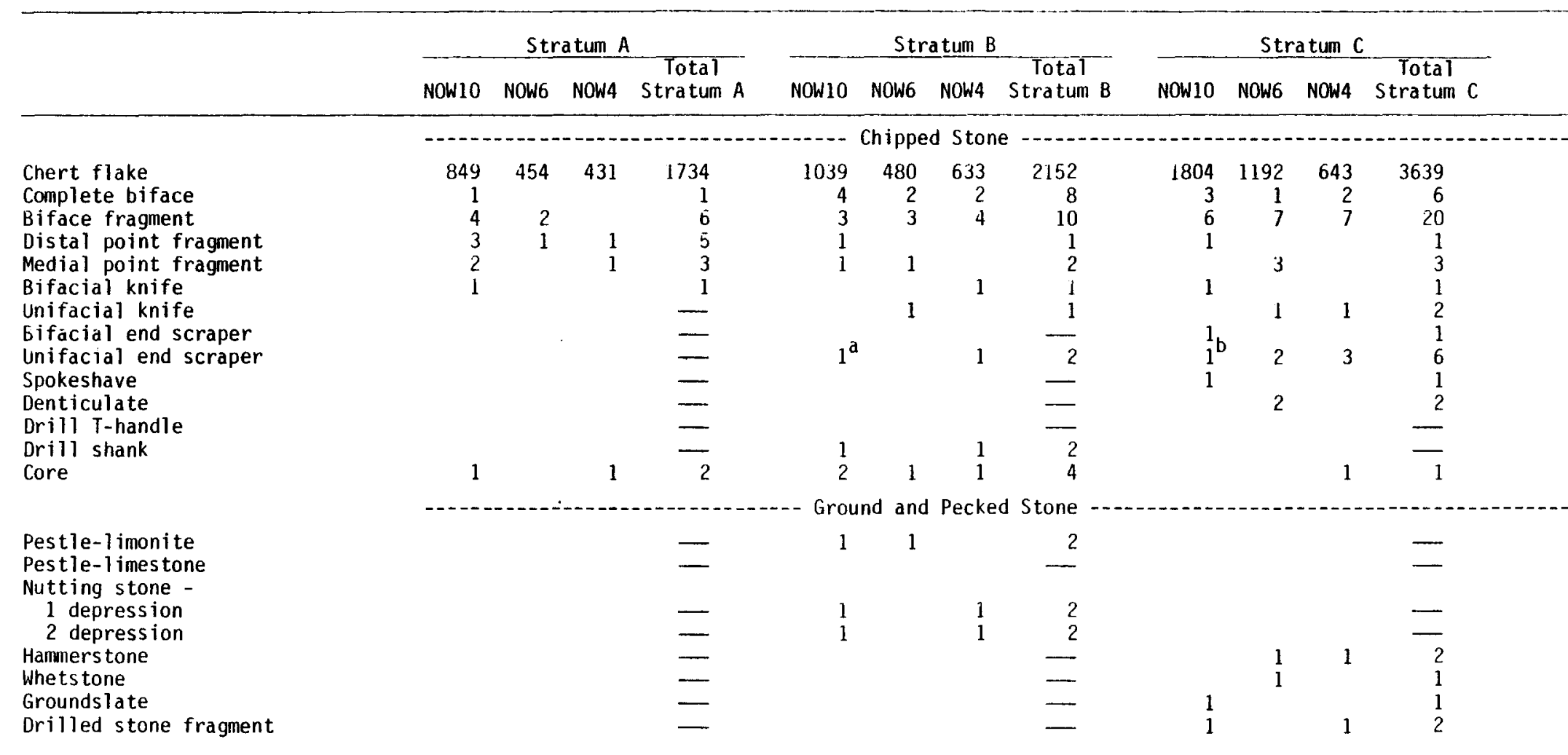


Table 4. (cont.)

\begin{tabular}{|c|c|c|c|c|c|c|c|c|c|c|c|c|}
\hline & \multicolumn{4}{|c|}{ Stratum A } & \multicolumn{4}{|c|}{ Stratum B } & \multicolumn{4}{|c|}{ Stratum C } \\
\hline & NOW10 & NOW6 & NOW4 & $\begin{array}{l}\text { Total } \\
\text { Stratum } \bar{A}\end{array}$ & NOW10 & NOW6 & NOW4 & $\begin{array}{c}\text { Total } \\
\text { Stratum B }\end{array}$ & NOW 10 & NOW6 & NOW4 & $\begin{array}{c}\text { Total } \\
\text { Stratum } C\end{array}$ \\
\hline & ---- & -- & - & -- & $\cdots$ & one at & d Ant & er -..... & & & 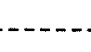 & \\
\hline Proximal drilled needle & & & & - & & & & - & 1 & & & 1 \\
\hline Proximal ground grooved needle & & 1 & & 1 & & & & - & & & & - \\
\hline Midshaft of needle & & & & - & 1 & & & 1 & 1 & 1 & & 2 \\
\hline Entire drilled needle & & & & - & & & & - & 1 & & & 1 \\
\hline Entire grooved needle & 1 & & & 1 & & & & - & & & & - \\
\hline Distal needle & & & & - & 2 & 2 & 2 & 6 & 5 & & & 5 \\
\hline Bone pin, ungrooved-drilled & 2 & & & 2 & 4 & 1 & & 5 & & & 2 & 2 \\
\hline Distal antler-flaker & 1 & & & 1 & 1 & & & 1 & & & 1 & 1 \\
\hline Distal antler-sharpened & 1 & & & 1 & & & & - & & & & - \\
\hline Grooved antler & 1 & & & 1 & & & & - & & & & - \\
\hline Fish hook & & & 1 & 1 & & & & - & & & & - \\
\hline Engraved bone fragment & & & & - & 1 & & & 1 & & & & - \\
\hline Drilled canine & & & & - & 1 & & & 1 & & & & - \\
\hline Bone bead & & & & - & & & & - & 1 & & & 1 \\
\hline Drilled mollusk, bivalve & & & & $\ldots$ & 1 & & & 1 & & & & - \\
\hline Drilled mollusk, snail & & & & - & 2 & & & 2 & & & & - \\
\hline
\end{tabular}

\section{and knife \\ beared}


Table 5. Nondiagnostic Material Culture - NOW2 (Profile Control Unit).

\begin{tabular}{|c|c|c|c|c|c|c|c|c|c|c|c|c|c|c|}
\hline & $\frac{78.4}{1}$ & $\frac{78.4}{3}$ & $\frac{78.4}{5}$ & $\frac{78.4}{6}$ & $\frac{78.4}{7}$ & $\frac{78.4}{10}$ & $\frac{78.4}{13}$ & $\frac{78.4}{25}$ & $\frac{78.4}{37}$ & $\frac{78.4}{39}$ & $\frac{78.4}{47}$ & $\frac{78.4}{55}$ & $\frac{78.4}{58}$ & $\frac{78.4}{59}$ \\
\hline Chert flake & 26 & 16 & 47 & 42 & 48 & 127 & 382 & 400 & 374 & 690 & 706 & 299 & 54 & 2 \\
\hline Complete biface & & & & & & & 2 & 1 & & & 1 & 1 & & \\
\hline Biface fragmeni & & & & & & & & 4 & & 3 & $\overline{1}$ & & & \\
\hline Distai point fragment & & & & & & 1 & & & & & & & & \\
\hline Bifacial endscraper & & & & & 1 & & & 2 & & & & & & \\
\hline Unifacial endscraper & & & & & & & & & & 1 & & & & \\
\hline Denticulate & & & & & & & I & & & & & & & \\
\hline Drill - T-handle & & & & & & & & & 1 & & & & & \\
\hline Drill shank & & & & & & & & & & 1 & & & & \\
\hline Core & & 1 & & & 1 & & & & & & & & & \\
\hline $\begin{array}{l}\text { Nutting stone } \\
1 \text { depression }\end{array}$ & & & & & & & & & & & 1 & & & \\
\hline Hammers tone & & & & & & & & & & & 1 & & & \\
\hline $\begin{array}{l}\text { Proximal portion } \\
\text { bone pin }\end{array}$ & & & & & & & 1 & & & & & & & \\
\hline Distal antler-flaker & & & & & & & 1 & & & & & & & \\
\hline
\end{tabular}


Burials and Human Remains

At the Ashworth site a total of 10 individuals were recovered from rockshelter \#7 (see Figure 15). However, several of the individuals represented consist of scattered remains found within excavated levels. All human bone recovered was assigned a burial number in the field. The burials reported below and in Appendix A are listed as they were recorded in the field. The primary reason for this recording method is due to the excavation procedure described below as weil as the fact that the bulk of the burials were recovered during the second testing of the site. In several instances portions of burials not recovered during the 1974 testing were recovered during the later-test excavation. As a resuit of this subsequent excavation, additional partial burials were recovered. Those portions extending beyond the parameters of the units were left in situ.

The methods employed for the excavation of a burial have three stages. First, a burial is encountered and identified as numan, then it is cleared of earth. This process is executed with extreme caution so as to not move or damage the bone. Once the bone is totally exposed (if the burial did not extend into the wall of a test unit) the position of the body, associated artifacts, and burial pit is recorded by drawing and then photographed. Samples of the burial pit matrix were bagged and labeled for flotation. Finally, the removal process was carried out. Since all of the burials encountered during this excavation were very we11 preserved a separate plastic bag was made up for each bone. The exterior of the bag was labeled with indelible marker. A separate card was also labeled and inserted in the bag witn each bone. Both the exterior label and card contained the following information: site number, 
Figure 15. Burial locations. 

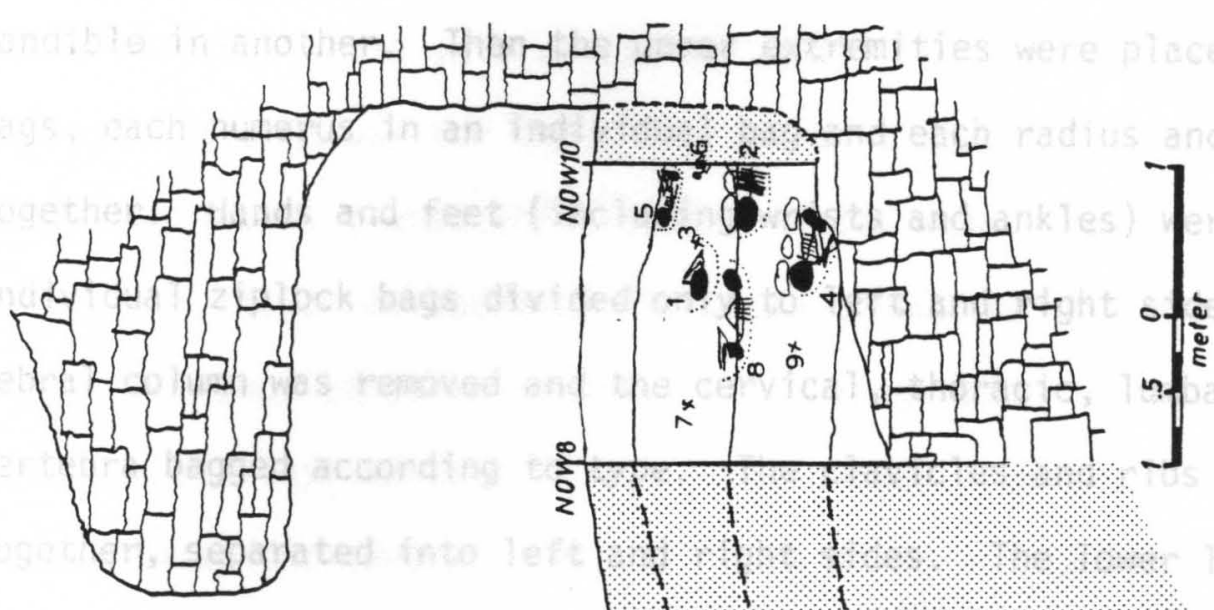
unit number, date, burial number, element, and side. The normal removal sequence and bagging consisted of placing the skult in one bag and the mandible in another. Then the upper extremities were placed in four bags, each humerus in an individual bag and each radius and ulna bagged together. Hands and feet (including wrists and ankles) were placed in individual ziplock bags divided only to left and right sides. The vertebral column was removed and the cervical, thoracic, lumbar, and sacral vertebra bagged according to type. The clavicles and ribs were bagged tugether, separated into left and right sides. The lower limbs were then bagged with the femurs and patellas bagged separately by side and the tibiae and fibulae bagged by side. Any additional elements, i.e., scapula, were bagged separately. The use of plastic bags worked better than paper bags in two ways. First, small animal bones adhering to the larger human bones were not lost in the creases at the botton of the paper bags. Second, the bones were damp when exposed and the sealed plastic bags allowed for more controi over the drying process.

In the lab the bones were laid out on paper and allowed to dry. This drying allowed the bone to harden before washing. The dry bones were then washed over fine screen $(0.00125 \mathrm{~mm})$. This allowed for the collection of smaller faunal and floral material and epiphyses from the burial. In every case at least one auditory ossicle was obtained from each complete burial, and on occasion all auditory ossicles except the stapies were recovered. The bones, once washed, were allowed to dry again before chemical stabilization.

Experience with human bone at the Archaeological Survey has shown that if human bone is left untreated, the variations in temperature and humidity will eventually lead to deterioration and damage. 
The damage is generally cracking and splitting along the long axis of longbones as well as the separation of the diploë from the tabula interna and the tabule externa of the skuli. Several chemical treatments are currentiy in use for the preservation of human oesteologicai remains, including animal glues, white glues, melted waxes, resins, wheat or rye paste, and filler compounds. All these compounds have drawbacks that range from poor adhesive properties to being rather expensive (Guldbeck 1972). Polyvinyl acetate (P.V.A.) was chosen from the array of materials in use today for several reasons. When mixed with a large percentage of acetone, the penetration is excellent and when mixed with a small amount of acetone it can be used as an adhesive to repair excavation-and/or transportation-induced breaks. The expense is fairly low and it is readily available locally. The compound does have several drawbacks. The main one is that once remains are treated with it they are rendered useless for carbon dating (Betty Lee Brandau, Geochronology Lab, Athens, Georgia: personal communication). P.V.A. also leaves a sheen on bone surfaces and if the solution is not prepared properly can leave small bubbles that can be mistaken for oesteoplasts.

Once the bones were soaked in a thin solution of polyvinyl acetate they were allowed to dry before reconstruction, measurement, and analysis. Each burial was reconstructed using a thickened soiution of P.V.A. taking great care to be sure all breaks were well mated. 01d breaks that exhibited chemical erosion and therefore did not fit well were not reconstructed. Measurements were taken using a GPM Swiss-made oesteological kit using the standards and points described in Bass (1971), Brothwe11 (1975) and Neumann (n.d.).

Upon completion of analys is the burials were catalogued, rebagged 
in various size plastic bags with seals, and boxed. They are currently stored at the University of Louisville Archaeological Survey. Acquisition number 78.4/Burial Number.

Burial \#1 (ULAS 78.4/B1) - Burial one is an adult male individual recovered during the 1974 test excavations. This individual was found in a tightly-flexed position laying on his right side. The top of the head was pointing north. The individual was facing the back wall of the shelter (west).

Analys is of the remains in the laboratory took place in March of 1981 (detailed resuits in Appendix A). A11 of the permanent dentition had erupted on this individual, however, the antremortim loss of several teeth caused considerable distortion in the facial area as weli as abnormal wear patterns. Sexing of the skull produced contradictory results with oniy the posterior end of the zygomatic process extending toward the external auditory meatus and larger mastoid processes indicating maie attributes. Other longbone and flat bone indices indicated maleness.

Examination of the pelvic area further substantiated the results of longbone indices. The sacrum was noted to be extremely arched, indicating maie. The width of the ala in scaral vertebrae also narrowed considerably from vertebrae one through five, again indicating male. Also of note in this individual, the first sacral vertebra was lumbardized, only the wings attached, and the anterior surface between sacral vertebrae two and three was partially iumbardized or unfused. The metric indices of the pelvis produced an indeterminate estimation of sex. But, all five subjective observations indicated the individual was male. In comparing the pubic symphysis with Todd's scale the observed fell between 
Stage I (18-19 yrs) and Stage II (20-21 yrs), indicating this individual was between 19-20 years of age at the time of death.

This individual was found in association with the middle portion of Stratum B (72.5 centimeters below the surface) in NOW10. This level has been dated to the Late Archaic period (ca. 3000-1000 B.C.) by projectile point association.

Burial \#2 (ULAS 78.4/B2) - This burial was found initially durin the 1974 excavations. What was recovered during this excavation was an articulated distal humerus, proximal radius, and proximal ulna. These were exposed in the north wall profile. During the expanded excavations of 1980 and 1981 the majority of this individual was recovered. The portions recovered during the later excavations consisted of the following: both upper extremities, the skull, the vertebral column (cervical and thoracic only), ribs, sternum, and scapula. The lumbar vertebrae, peivic area, and lower extremities were not recovered. This individual was interred in a shallow pit covered with limestone slabs. These slabs were from the same limestone from which the shelter is formed. The individual was placed chest down with the top of the skull pointing to the east and the face pointing south. From the amount of the individual exposed it is believed that he was placed in a semi- or loosely-flexed position. The right hand was placed under the skull. The left arm was under the torso with the hand at the upper abdominal region. The left radius and ulna were broken at midshaft post mortem, possibly during the placement of the slabs of limestone.

Analysis of the remains took place in March 1981. The sex of this individual is believed to be male based upon the robusticity indices of the long bones recovered and the observations of the cranium (Appendix A). The age is based upon the dentition. All of the permanent dentition 
had erupted and was well worn with the exception of the third molars of the mandible and maxilla. Estimate of age based upon wear pattern is approximately $45+$ years. Epiphysis closure only results in an age es timate of $24+$ years.

This individual was found to be associated with the lowest levels of Stratum B. The top of the burial pit was 100 centimeters beiow the surface. Analysis of projectile points indicate that this level dates as early as 4000 B.C. The middle level of Stratum B has produced projectile points that have been dated as early as 3000 B.C. in the Green River basin. Therefore it is estimated this individual was interred sometime in the period from $4000-3000$ B.C.

Burial \#3 (ULAS 78.4/B3) - This individual was recovered in a mixed association with Burial \#1, discussed earlier, during the 1974 test excavation. Those portions of Burial \#3 recovered consist of the following: proximal right femur, medial portion of a fibula, a humerus with the proximal portion missing, and a right mastoid process. Due to the fragmentary nature of this individual it could only be determined to be an infant less than six months of age.

During the later test excavations, Burial \#6 was recovered (discussed below). Those portions recovered in 1974 were believed to have been fragments of Burial \#6 until comparisons in the laboratory proved that to be incorrect. This was based on the fact that ihose portions of Burial \#3 were recovered from Burial \#6. Upon comparison of sizes of the elements recovered, this investigator feels that two individuals of the same age are represented. The age estimations and cultural affiliations for both burials are discussed below. 
Burial \#4 (ULAS 78.4/B4) - Burial \#4 was partially recovered during the 1974 test excavations. Those portions recovered consisted of the skull, pectoral girdle, left upper extremity, and thoracic area. During the 1980 test excavations the remaining portions were recovered. The body was laid chest down, with the top of the head pointing to the southeast. The face was straight down. The body was in a loosely-flexed position, the knees drawn up to the left of the chest. The left hand was raised, laying to the left of the face. The right arm was laying along the right side with the hand under the right half of the pelvis. The entire body was covered with large slabs of limestone. The slabs over the head and pelvic region were 30 centimeters thick and weighed approximately 20 kilograms. During the course of excavating the thoracic vertebrae, a projectile point (Figure 11D) was found imbedded in the bone.

Analys is of this individual took place in March 1981. The dentition was in an advanced state of deterioration. All of the teeth were extremely worn, from stage 4 to 6 (Brothwe11 1972:69). Abcesses were large and affected many of the teeth on the mandible and maxillae. On the mandible both the left and right first molars were affected and at the base of the left first molar both roots were exposed on the buccal side. The right first molar had shifted as a result of abcessing on the buccal side. The crown pointed lingualiy, the roots were pointing buccally. This molar had been worn to almost one-half its original diameter. On the buccal side of the right third molar was an abcess $8.0 \mathrm{~mm}$ in diameter. The maxillae were affected by abcessing almost as much as the mandible. On the left side the premolars and the first and second molars were affected by abcessing on both the mesial and buccal sides (diameters of the abcesses are as follows: PM1 - $12 \mathrm{~mm}$; 
PM2 - $9 \mathrm{~mm} ; \mathrm{M1}-12 \mathrm{~mm} ; \mathrm{M} 2-6 \mathrm{~mm}$ ). The abcess at the base of the first molar had caused the tooth to shift forward and had entered the left maxillary sinus. The resulting distortion had altered the infra-orbital foramen.

Post-cranially a number of abnormalities were noted. A small ridge of bone growth had formed on the semilunar arch of the right ulna ( $1 \mathrm{~mm}$ tal1 by $4 \mathrm{~mm}$ by $1.5 \mathrm{~mm}$ ). This had caused a smal1 pit to be eburnated into the trochlea of the right humerus. The eleventh thoracic vertebra had been crushed ventrally (thickness of body: ventrally 16.0 $\mathrm{mm}$, dorsally $23 \mathrm{~mm})$. Due to this variation in thickness, there was degeneration and lipping on the superior and inferior articular processes of thoracic vertebrae eight through twelve. Also noted on the superior vertral surface of thoracic vertebra eleven was a ridge of lipping $4.5 \mathrm{~mm}$ wide. A vestigial pair of ribs were attached to the twelfth thoracic vertebra. The costal pit arrangement on thoracic vertebrae eleven and twelve deviated from the norm.

Sex estimation based upon longbone indices indicated this individual was female. Observations of the skull and pelvic region also indicated the subject was female. All of the subjective observations of the pelvis such as broad subpubic angle, elevated ventral arc on pubis, presence of sub-pubic concavity, narrow medial aspect of ischiopubic ramus, a raised sacro-iliac articulation, and a broad siatic notch are all feminine traits. Age estimation, based upon Todd's scale of pubic symphisis (Krogman 1973:92-97), resulted in an age at death of 27-30 years.

As mentioned above, a projectile point was found imbedded in the body of the third thoracic vertebra. This projectile entered from the 
left rear of the individual splitting the neural arch between the left superior and inferior articulating surfaces and the spinous process. The extreme distal portion (tip) of the projectile entered the dorsal surface of the body of the vertebra with sufficient force to split the vertebra in half. The left superior articular surface of the fourth vertebra was also damaged (Gray 1977).

A wound of this type would have caused death almost immediately. The most apparent cause of death would have been hypotensive shock resulting from the direct reflex shock to the central nervous system caused by the impact and resulting rebound of the spinal cord. Hypotensive shock occurs when the blood vessels dilate causing a rapid drop in blood pressure, followed by a drop in puise (from the heart's inability to pump sufficient blood), and the eventual collapse of the entire circulatory system. If the individual was not killed immediately by reflex shock, hemorrhaging of the dorsi-spinal and longitudinal spinal veins would cause death in as little as five to fifteen minutes (DiBlasi: personal communication). Paralysis of the intercostal, abdominal, perineal, anal, and the muscles of the lower extremities is also a consideration (Ranson 1959:28). Paralysis of intercostal muscles would make breathing impossible, again causing death within a short period of time. The cultural affiliation of Burial \#4 is based upon artifact association of the projectile point embedded in the body. This projectile dates to the Early Archaic culture period. Another projectile point (Figure 13A) was recovered near the left patella. Unforturately, the burial pit was poorly defined and it is uncertain if this projectile was associated with the grave fill. A carbon sample taken from the peivic region (UGa.3945) yielded a date of 1454 B.C. \pm 3475 . This date is 
totally unacceptable for this burial due to the large standard deviation. The exceptionally large standard deviation probably is the result of the smal1 sample size (John Noakes, Geochronology Lab, Athens Georgia: personal communication).

Burial \#5 (ULAS 78.4/B5) - This individual was recovered on 22 May 1980 and analysed during March 1981. This child was placed on its back with the legs flexed to the right side. The arms were laid across the thoracic cavity, but not crossed. The skull faced right (north). The vertebral column was oriented on an east-west axis.

Estimation of age at the time of death is based upon dental eruption (Brothwe11 1975:59), the maximum lengths of the longbones, and fusion of the neural arch (Bass 1971). The longbone lengths indicate this individual was between 0.5 and 1.5 years of age. Estimate of age based on dental eruption indicates an age of less than 1.5 years. The sex of this individual could not be determined.

The first, third, and ungual phalangies of a wild turkey (Melagris gallopavo) were found associated with the right wrist of this individual. These were not altered by drilling or grooving and no cordage was found in the area that could have indicated a method of attachment.

This individual was associated with the upper portion of Stratum $B$ in NOW10 at a depth of 50 centimeters below the surface. Artifacts recovered from that level indicate an age of 3000 to 1000 B.C. for the time of interment, giving a cultural affiliation of Late Archaic. Burial \#6 (ULAS 78.4/B6) - This burial, excavated on 10 October 1980, was recovered from a depth of 70 centimeters in NOw10. The individual, an infant, was placed on its back and was articulated in a loosely-flexed position. The arms were laid at the side and the legs 
were flexed to the right. The specific orientation of the skull could not be determined. It was completely disarticulated and found iaying on the upper portion of the thoracic cavity. The vertebral column was oriented north and south with the peivis to the north. Several smail pieces of tabular limestone were placed over the body.

This burial was situated at approximately the same level and area as Burial \#1. It is possible the burial pits overlapped. As mentioned above, the fragments composing Burial \#3 were recovered from the matrix of Burial \#1. This investigator feeis that the individuais from Burials \#3 and \#6 were buried together and when Buriai \#1 was interred Burial \#3 was disturbed.

Burial \#6 was in excellent condition considering the age of the individual at the time of death. Measurements of longbones indicate that this individual died at the age of 300 to 355 days after conception (Stewart's table as presented in Bass 1971). It is possible that if Burials 3 and 6 represent twins they were stillborne. All other information such as dentition (no teeth erupted) and ossification indicate a newborn infant. Again, when the fragments of Buriai \#3 were compared with Burial \#6 all of the elements were found to be present in Burial \#6. When compared metricaily and visually the sizes were almost identical.

Burials 3 and 6 were found in the middle to upper portions of Stratum B. As mentioned above, this level has been dated by artifact association to the Late Archaic period. From the relative positions of Burials '1, 3, and 6 it is clear that Burial \#1 intruded on Burials 3 and 6 . 
Burial \#7 (ULAS 78.4/B7) - This burial consists of a left maxilla recovered from a depth of 79 centimeters in NOW10. This level has been dated to the Late Archaic. No other human remains were recovered in association with this fragment. The maxilla was compared to all of the other burials recovered and it was determined that it represented a separate individual.

From the evidence present an age of less than 0.5 years can be given for Burial \#7. This is based on the fact that the canine has not yet broken through the bone and the first and second premolar caps were in the sockets, but not yet erupied.

Buriais \#8 (ULAS 78.4/B8) and \#10 (ULAS 78.4/E10) - Burial \#8 was an articulated individual found 92 centimeters below the surface. The skull had, however, been damaged by the prehistoric excavation of a hearth. A single third cervical veriebra that had oesteo-arthritic 1 ipping on the superior articulating surface was recovered from the hearth. A maxillary right medial incisor of an adult was also found in the thoracic cavity of Burial \#8 but the wear pattern indicated an individual of greater age than Burial 8. This incisor and cervical vertebra have been assigned to Burial \#10. The only other evidence for Burial \#10 were several phalangies, that had completely fused epiphyses, which were larger than those associated with Burial 8. Burial \#10 can be classified as an adult based on the evidence present. No other fragments of Burial \#10 have been recovered.

Burial \#8 was found laying on its back with the vertebral column oriented on an east-west axis. The skull was situated toward the back wali of the sheiter (west). The arms were folded across the abdomen. The left illiac crest was visible in profile, but the remainder of the 
pelvis and legs were not. The clavicles and sternum had been disturbed prehistorically. The proximal portion of the left humerus and scapula had been damaged by heat.

Analysis of the remains indicate that Burial \#8 was between 15 and 17 years of age at the time of death. The age estimate is based upon dental eruption and epiphysis fusion. A tentative estimate of sex, based on the presence of a large septal aperture (Bass 1971:115), indicates this individual was female; however, with the lack of the pelvic region, the results are not conclusive.

This individual was situated in the middle and lower levels of Stratum B; however, the top of the grave pit indicates that this burial was actually associated with the upper portion of Stratum B. Projectile point analysis indicates that this level dates to the Late Archaic period (ca. 3000-1000 B.C.). A carbon sample (UGa3944) taken from the grave fill produced a date of 1900 B.C. \pm 165 . This date falls within the range established by projectile point analysis.

Burial \#9 (ULAS 78.4/B9) - This burial, recovered from a depth of 133 centimeters in NOW10, consists of a right and left patella and eight phalangies. These fragments were recovered from the centrai portion of the unit with no other human remains found in association. The only other individual recovered from a comparable depth is Burial \#4. These elements were compared to other burials and it was determined that, at least for the present, they represent a separate individual but due to the fragmentary nature of the remains this individual cannot be aged or sexed.

Culturaily, a tentative assignment of Early Archaic (ca. 75006900 B.C.) is the only conclusion that can be reached. This is based 
on the fact that Stratum $\mathcal{C}$ contains almost exclusively Early Archaic materials.

\section{Faunal Remains}

Vertebrates - The ideritification and analysis of the faunal remains was accomplished to produce general statements concerning subsistence activities. This preliminary assessment indicates that with refined recovery techniques and a larger sample further excavation will augment the conclusions.

Recovery methods are discussed in the Excavations Section and a table enumerating the species identified per level is provided in Appendix B. Flotation samples are not yet completed and may provide additional data. The sample represents 4.89 percent (23.63 cubic meters) of the total site. Fourteen cubic meters (4.65 percent of talus) represents talus deposits and 9.63 cubic meters (5.29 percent of undershelter) where taken from under the shelter. The individual strata were sampled in approximately equal volumes. The strata represent various depositional periods. Stratum A represents approximately 2300 years (ca. 800 B.C. to 1500 A.D.), Stratum B 4000 years (ca. 5000 B.C. to 1000 B.C.) and Stratum C approximately 2000 years (ca. 8000 B.C. to 6000 B.C.). No correction factor has been applied to the interpretation to account for the variations in deposition rates.

Preservation of the material is excellent. The effects of chemical degeneration are minimal. Objects such as delicate bird bones and fish scales have been preserved. Most of the unidentified material consisted of large-mammal bone fragments less than two centimeters long. This fragmentation is probably due to mechanical damage rather than an aspect of subsistence such as marrow extraction. 
The immediate area around the site is capable of supporting a typical Carolinian assemblage of fauna. One can assume that species present represent selections by the human population on the biotic community. This selection process is controlled by several factors, the season, the species available, and established prehistoric patterns of hunting and collection. In this preliminary assessment there is not sufficient data to draw specific inferences concerning the seasonal occupancy of the site. However, several general trends concerning selectivity can be inferred. During the Early Archaic period, represented by Stratum $C$, the selection of vertebrates consisted of animals from aquatic and forest communities. During the Middle, Late Archaic period and throughout the Woodland/Mississippian periods, represented by Stratum $B$ and $A$, respectively, the selection was from forest and forest edge communities. Table 6 of the ten most common vertebrates indicates the trends in seiection.

It can also be inferred that the human population was not necessarily occupying the Ashworth site as a specialized hunting camp since there is no dominant species represented. Rather than a focused hunting pattern it appears that a diffuse exploitation of local resources took place. Dependence on supplemental activities such as fishing and gathering of aquatic reptiles shifted through time. This shift in dependence is shown in Table 7. Throughout the periods represented mammals were the largest class of animals represented.

Table 7 presents the percentages by ciass of animal calculated using the total MNI obtained from the table in Appendix $B$. The percentages were calculated from the entire sample of 182 identified individuals. The percentage for Stratum $D$ and for the profile control unit $(P)$ are included for completeness. The percentage of mammals remains constant 
Table 6. The ten most common vertebrates from occupied strata.

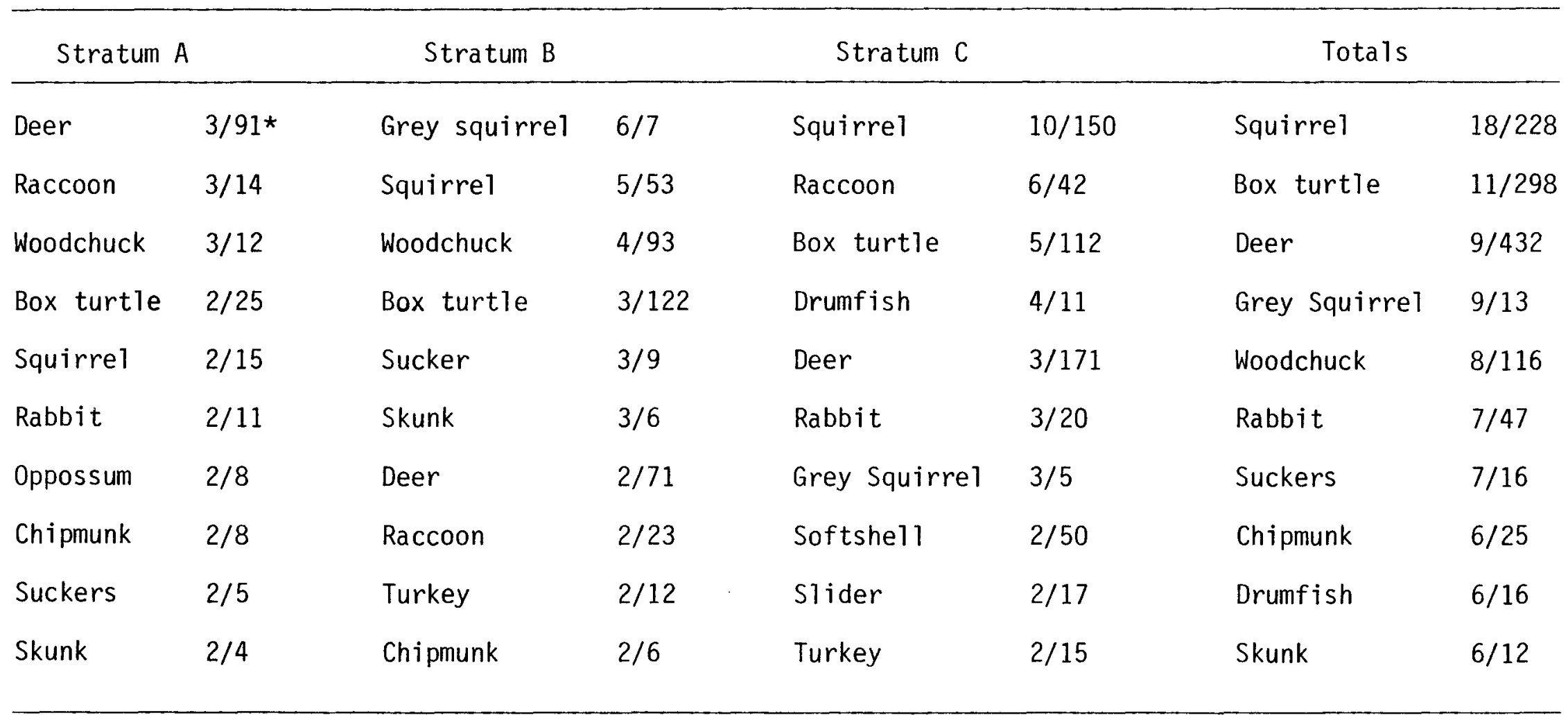

*MNI/fragments identified (numerator represents Minimum Number of Individuals, denominator represents the number of fragments identified) 
Table 7. Percentages of class of animals from all identified bone.

\begin{tabular}{lccccc}
\hline & A & B & C & D & $P$ \\
\hline Fishes & 2.20 & 3.85 & 4.95 & NiM & NM \\
Amphibians & NM & NM & 1.10 & NM & NM \\
Reptiles & 4.40 & 3.30 & 6.95 & 1.10 & 0.55 \\
Birds & 0.55 & 3.85 & 3.85 & NM & NM \\
Mammals & 15.93 & 21.98 & 21.98 & 1.65 & 2.20 \\
\hline
\end{tabular}

NM - no material of this class of vertebrates recovered 
in Strata $B$ and $C$ but drops in $A$. The cumulative percentages of aquatic species (fishes, amphibians, and reptiles) is nearly twice as high in Stratum $C$ than in $A$ and $B$. Reptiles are relatively abundant in Strata $A$ and $C$, but less common in $B$. Fishes decrease in abundance from Stratum $C$ to $A$. Overall a smaller percentage of the fauna was recovered from Stratum A. This could be related to an increased dependence on horticultural activities during the later periods.

The presence of the animal remains on the site is the result of human activity and the animals that died there. One immature woodchuck and several concentrations of chipmunk and mole bone apparently represent burrow deaths. The general lack of small nocturnal animals and immature squirrels indicates that raptor predation was not a major factor in the accumulation of the faunal deposits.

Mollusca - In order to determine the site's potential for yielding specific environmental and dietary information, an identification of molluscs was undertaken. The sample chosen consisted of all shell fragments recovered from NOW10. NOW10 was the primary area of occupation within the test sample as well as containing the largest number of shells and fragments. The exception to this is several individuais representing the genus Retinezla (Conkin, personal communication) which were taken from the culturaliy-sterile stratum in NOW2. The presence of Retinella is discussed in the Natural History section above.

The identified bivalves (see Table 8 ) represent species taken by the prehistoric inhabitants of this rockshelter and is simply a list of those species present. It does not take into account the period of time involved during which the site was occupied, since individuals of all species listed were found in almost every level in the occupation 
Bivaives:
Alasmidonta sp.
Amblema plicata (Say)
Fusconaia sp.
Lampsizis sp.
Lampsizis ovata Say
Lampsizis ovata form ventricosa
Ligumia recta
MegaZonaias gigantea
Pleurobema sp.
Tritogonia verrucosa (Raf.)

Aquatic Snails:

Goniobasis sp.

Lithasia obovata Say

Terrestrial Snails:

Angiospira altemata (Say)

Angiospira kochi (Pfeiffer)

Haplotrema concavum (Say)

Mesomphix sp.

Stenotrema hirsutum (Say)

Triodopsis albolabris (Say)

Triodopsis denotata (Ferussac) 
series. Also the fact that currently the sample is so small no trends in prehistoric selectivity through time can yet be determined.

When comparing the excavated sample of bivalves to modern local populations, several points become apparent. A11 of the species present from the excavated material are found in the area, either in Floyd's Fork (Taylor 1980) or the Salt River (Krumholz and Neff 1974), with the exception of Ligumia recta. The reason for the absence of this species in modern samples locally is not known. This area is within the modern range of the species that currently consists of almost al1 of eastern North America (Clench 1963:1145). Sampling error could account for this absence. Ralph Taylor, who sampled five stations in Jefferson County, identified twenty species of bivalves including Corbicula Zeana, the introduced Asian clam. However, he does not report having recovered any individuals of the species Megalonaias gigantea in Floyd's Fork. His study did include one station on the Salt River in Spencer County, Kentucky, where Megazonaias was recovered (Taylor 1980: 14). Krumholz and Neff do report the presence of Megalonaias gigantea in the Salt River (Krumholz and Neff 1974:30). The presence of $M$. gigontea at this site, 2.4 kilometers from the Salt River, in all occupation levels, indicates that the lower end of Floyd's Fork is capable of supporting large-river species. M. gigantea is considered to be a largeriver species (Goodrich et al. 1944:308).

The presence of both Lampsilis ovata Say and Lompsilis ovata form ventricosa in the excavated materials points to the transitional nature of the environs of this portion of Floyd's Fork. L. ovata is considered to be a large-river species that tends to grade into $L$. ovata form ventricosa toward headwaters (Goodrich et al. 1944:315). 
The terrestrial and aquatic snails recovered from the excavation are also all found locally and most likely represent natural intrusions on the site (Table 8). The presence of Goniobasis sp. (an aquatic snail) can be explained by flooding. According to the U.S.G.S. Floodprone 7.5' Brooks quadrangle, the site is inundated approximately every two years. (This investigator had to halt excavations twice due to flooding) The site lies well within the modern ranges of all the terrestrial species (Burch 1962). Discus cronkhitei (Newcomb) in fact is predominantly found in forests under logs and other floodplain debris (Goodrich et a1. 1944:274). Angiospira kochi (Pfeiffer) is considered a forest species that prefers shaded slopes and limestone bluffs. Also of note is the fact that $A$. kochi numbers are apparently decreasing in historic times (Goodrich et al. 1944:274 and Neff, personal comunication). Neff noted during the laboratory identification that there was an exceptionally large number of this species present in the prehistoric sample.

The two specimens of Lithasia obovata Say were recovered from the lower portions of Stratum B. These individuals were the only representatives of that species. Both of the shells had been altered by abrasion to produce beads. The alteration consisted of grinding the shell through the first body whorl on the plane of the operculum. One of the individuals had been ground so heavily that the umbilical chink had been smoothed away and the outer lip had been smoothed as well. The smaller of the specimens had been abraded only on the first body whorl. L. obovata Say has been found in the Salt River drainage basin on the Rolling Fork approximately one mile (0.62 kilimeter) southwest of Lebanon Junction, Kentucky. They are found on steep muddy banks and 
in large numbers (William Clench, personal communication). They are not known in Floyd's Fork now and it is believed that pollutants are the cause of their disappearance. Pleurocera canaliculatum, another aquatic snail, is also found under the same conditions; but no individuals of this species have been recovered from the Ashworth site to date.

\section{Radiocarbon Determinations}

Three samples of charcoal were sent to Geochronology Laboratories, University of Georgia, Athens, Georgia. After cleaning, all of the samples weighed less than ten grams. One sample weighed less than two grams and it was suggested that it be sent to Radiocarbon Ltd., a gas laboratory in Lampasas, Texas.

The sample taken from feature four (UGa.3944) produced a date of $3850 \pm 165$ radiocarbon years: 1900 B.C. This date fell well within the range of dates for the Late Archaic Stemed projectile points (Rolingson 1967) recovered near the surface of feature four.

The sample taken from the pelvic region of Burial \#4 (UGa.3945) produced a date of $3415 \pm 3475$ radiocarbon years: 1465 B.C. This date was much too late for the burial for two reasons. Stratigraphically, it was situated well below feature four and burial four had a projectile point located in the body that has been associated with late Early Archaic deposits (Chapman 1977). The large standard deviation of the results is felt to have been caused by the small sample size (less than three grams).

The third sample taken from feature eight (R.L.1552) produced a date of $5020 \pm 270$ radiocarbon years: MASCA corrected $3880 \pm 300$ B.C. This date was also too late for the stratigraphic location of this feature and the associated projectile points. This date should have fallen 
between approximately 7000 to 8000 B.C. Since feature eight was situated directly on Stratum D (an impermeable clay) at the mouth of a fissure in the limestone, it is possible that the material was contaminated with humic acid. 
SUMMARY OF EXCAVATIONS

Test excavations carried out under my direction have provided data that revealed many aspects of the site that were previousiy unknown. The earlier investigation, due to the limited scope of its sampling design combined with an incomplete analysis of recovered materials, did not recognize several categories of data necessary to the determination of the significance of the Ashworth site as a cultural resource. By employing a broader sampling design and thorough analysis, the position of the site relative to the culture history of the Floyd's Fork drainage system has been elucidated.

Each of the following categories of data, that have resulted from my excavations, demonstrate that the Ashworth site can provide important information relevent to a regional research design (Granger 1981). This information also demonstrates the significance of the site as a regional resource.

Previous investigations indicated that the Ashworth site contained only three cultural manifestations: Copena, Woodland, and Fort Ancient. These conclusions were based on the identification of two objects dating from "500 B.C. to A.D." and 1200 A.D. to 1600 A.D. (MCgraw 1975:102, 106). It is now known that the site contains deposits dating from approximately 7900 B.C. to 1500 A.D. (Figure 7). Analysis of nondiagnostic material culture indicates that a broad assemblage of lithic and bone tools are preserved in all levels (Table 4). The large quantity of blanks for point manufacture which were in various stages of completion, can produce information concerning the manufacturing 
sequence. The lithic resources at Ashworth are quite diverse and when combined with known chert sources (Collins 1979) prehistoric selection patterns can be defined. Bone tools preserved in Stratum $C$ can provide data on a previously unknown aspect of the Early Archaic tool kit.

The diversity of feature types through the established chronology and their distribution have provided additional data into intrasite activity areas (Figures 4, 5, and 6). Early Archaic activity tended to be outside the shelter whereas during the later periods the sheltered portion was the preferred location. Burial distribution and body position remained constant from late Early Archaic to the Late Archaic. Burial pits are clustered within one and one-half meter of the shelter's backwall (Figure 15). Body position in all instances is flexed. The sample is currentiy too small to determine preferred orientation of the burials by sex, age, or cultural affiliation.

The number of objects recovered from the small (4.89 percent) sample indicates the potential quantity of materials is very large. Since eight features, seven complete burials, 45 identifiable projectile points and 13,953 identifiable animal bone fragments were recovered in the sample, it can be postulated that total recovery can produce 160 features, 140 burials, 900 projectiles and 279,060 identifiable fragments of bone. From the sample two clusters of projectile points were recovered in sufficient quantity to describe new cotypes (Salt River Side Notched, Table 2 and Ashworth Corner Notched, Table 3).

Preliminary analysis of vertebrate remains indicates a shift in prehistoric selectivity as well as changes of subsistance dependence. Early Archaic populations appear to have been more dependent upon the aquatic and forest communities whereas the later populations depended 
upon forest and forest-edge communities. A decrease in vertebrates in general appears to have occurred during the Woodland/Mississippian periods, providing supporting evidence for their dependence on horticulture (Tables 6 and 7 ). Analysis of a larger faunal sample may produce statements of seasonal occupancy of the site during the culture periods present.

Ceramics are one of the poorest represented classes of objects present at the site with only seven fragments recovered. However, analysis of the ceramic and fired-clay fragments has provided comparative data on textiles and prepared clay hearths. Prepared clay hearths have been described from Early Archaic sites in Tennessee (Chapman 1977). Textiles, similar to impressions found at Ashworth, have been reported from Ohio (Griffin 1966).

The stratigraphy and current state of preservation are also very important properties of the deposits at Ashworth. The stratigraphy has been delineated vertically as well as horizontal distribution (Figure 3). Though the vertical stratigraphy is not segregated by sterile colluvial deposits, it has been delineated by three strata each containing a number of cultural manifestations (Figure 7). I feel that, with a large enough sample, the strata can be further subdivided into discrete cultural horizons. The horizontal distribution indicates that the deposits under the shelter were the area of primary activity and that the talus functioned as a trash heap. It has been noted that a number of rockshelters in the area have been extensively looted, however, the Ashworth site has yet to become the object of local collectors. The excellent conditions of burials (including infants), and faunal materials indicate that the site conditions are stable and preservation is good. 


\section{CULTURAL RESOURCE MANAGEMENT OVERVIEW}

It has been demonstrated that the Ashworth site is a significant regional resource. The previous assessment (McGraw 1975) has been handled inappropriately. As discussed in the Summary of Excavations, there are many properties of the site that the previous investigator, B. J. McGraw, did not realize. These properties are very important in determining a site's significance. When significance is not fulty assessed additional statements concerning impacts (primary, secondary, on-going, or potential) come into question. If impacts are not understood, mitigation alternatives become invalid. Every stage in the decision-making process is questionable as a result of inadequate assessment. The previous investigator produced a preliminary report of testing which was inadequately analyzed and lacked a statement of significance. Inadequate research design, by halting excavations "when a significant depth of cultural material was established" (McGraw 1975: 100-101) due to ignorance of laws and regulations is the crux of the cultural resource management problem.

There are several federal laws and associated regulations that guide the cultural resource manager involved in contract archaeology. The Historic Preservation Act of 1966 (Public Law 89-665, 80 Stat. 915, 15 USC470) or NHPA and Executive Order 11593 "Protection and Enhancement of the Cultural Environment" are the legal mandates that establish the Advisory Council on Historic Preservation (ACHP). These laws also direct the federal government to take a leadership role in preserving this nation's cultural heritage. The Department of Transportation Act 
of 1966 (Public Law 89-670, 90 Stat. 574, 23USC 1 et. seq.) is another legislative act that incorporated the concept of considering cultural resources during the planning stages of proposed projects to insure that destruction to sites was minimized. But, it was not until the passage of the National Environmental Policy Act of 1969 (Public Law 91-190, 83 Stat. 842,42 USC7321) or NEPA that outlined the procedures under which a federal agency was to function in preserving cultural resources. In effect NEPA required that federal agencies produce an environmental impact statement before funding, licensing, or proceeding with a project that would affect cultural resources. The regulations that are to be considered are: 36CFR800 and 40CFR1500. Regulation 36CFR800 details the function of the ACHP review process and establishes specific criterion for the nomination of properties to the National Register of Historic Places (NRHP). Regulation 40CFR1500 deals with the collection, analysis, and synthesis of cultural resources data relative to NEPA. The two main goals of this legislation and regulation are: 1) to preserve intact the maximum of significant resources and 2) or whenever there may be damage or destruction of these resources, as a result of competing national objectives, provide for a means to recover, record, and synthesize the data prior to loss (Scovill et al. 1977:44). These regulations cannot be implemented if the initial assessment made by an archaeological investigator is incorrect, because every step in the decision making process is a direct result of that assessment (Klinger and Raab 1980:556). There are many methods for assessing the significance of a cultural resource. These methods rely on: 1) National Register criteria; 2) the cost/benefit ratios concerning data recovery (or monetary value); 3) the unique characteristics present; and 4) how well the recovered 
data will aid an explicit problem-oriented research design (Raab and K1 inger 1977).

The monetary value or the unique characteristics present in a cultural resource are a poor criterion to be used by an archaeologist because they do not fully address the properties of the resource. By stating that the resource will aid in the resolution of an explicit problem-oriented research design is somewhat short-sighted because future research problems are not yet known (Sharrock and Grayson 1979). Those criteria established for determining eligibility to the NRHP appear best suited as a management tool. The primary reason being that the NRHP allows protection of resources that may potentially produce data. However, NRHP criteria as set forth by ACHP do, generally, require that a resource's properties be considered in a research design (Advisory Council on Historic Preservation 1976).

The criteria used for assessing significance should be clearly stated in the environmental impact assessment (Scovill et a1. 1977:56). Specifically, in a contract situation it is not the field archaeologist who actually makes the determination of a site's significance. The field archaeologist is to locate the resources, test them, and present the results as evidence for a determination of eligibility to the NRHP. In order to reach the NRHP these data must first be reviewed by the State Historic Preservation Officer. The final determination of eligibility is made by the NRHP and the Secretary of the Interior (Barnes et a1. 1980 and Advisory Council on Historic Preservation 1976). Once a site is "listed" or included in the NRHP the Archaeological and Historic Preservation Act of 1974 (Public Law 92-291,88 Stat. 174,16USC 469) or AHPA constrains federal agencies from adversely affecting the 
resource. The AHPA also allows the federal government to expend one percent of a project's cost on the preservation of significant cultural resources.

The incorrect assessment of significance of the Ashworth site has had a serious effect on the resource. The site was protected by being listed on the NRHP, but it was only assessed as a "well-known type" of site (Moratto and Kelly 1978:21-23) of which there are literally hundreds in the Falls of the Ohio region. Late Archaic sites, by the fact they are well known, rank rather low in regional priorities. Without this reassessment of the Ashworth's significance its potential might never have been determined. Because KYDOT was not provided with the necessary statement of significance to consider the impacts on the resource, this agency and ultimately the SHPO could not propose or implement viable mitigation alternatives.

The results of cultural resource management studies eventually effect all archaeology. This study has been an attempt to depict the Ashworth site as a cultural resource in its true perspective, to demonstrate its significance, and to integrate its environmental and cultural data potential into a regional research design. 


\section{REFERENCES CITED}

Advisory Council on Historic Preservation.

1976 The National Resister and Archaeology: Suggestions to Archaeologists Regarding Determinations of Eligibility. Paper presented at annual meeting of the Society of American Archaeologists, St. Louis.

Bal1, Donald B.

1978 Summary Report of Archaeological Survey: Taylorsville Lake, Salt River Basin, Spencer, Nelson and Anderson Counties, Kentucky. U. S. Army Engineer District Louisville. LouisvilTe, Kentucky.

Barbour, Roger W.

1971 Amphibians and Reptiles of Kentucky. The University Press of Kentucky. Lexington.

Barnes, Mark R., Alton K. Briggs and Jerry J. Neilson.

1980 A Response to Raab and Klinger on Archaeological Significance. American Antiquity 45:551-553.

Bass, William M.

1971 Human Osteology: A Laboratory and Field Manual of the Human Skeleton. Missouri Archaeological Society, Columbia.

Bell, Robert E.

1960 Guide to the identification of certain American Indian Projectile Points. Oklahoma Anthropological Society, Special Bulletin No. 2.

Braun, E. Lucy.

1972 Deciduous Forests of Eastern North America. Hafner Publishing, New York.

Brothwel1, Donald R.

1975 Digging up Bones, The Excavation, Treatment and Study of Human Skeletal Remains. Staples Printers Ltd, St. ATbans, Herts, England.

Broyles, Bettye J. (editor).

1971 The St. Albans Site, Kanawha County, West Virginia. West Virginia Geological and Economic Survey. Report of Investigations No. 3. Morgantown, West Virginia.

Burch, John B.

1962 The Eastern Land Snails. William C. Brown, Dubuque, Iowa. 
Burt, William Henry and Richard Philip Grossenheider.

1976 A Field Guide to the Mammals. Third Edition. Houghton Mifflin, Boston.

Cambron, James W. and David C. Hulse.

1975 Handbook of Alabama Archaeology Part I Point Types. ArchaeoTogical Research Association of Alabama.

Chapman, Jefferson.

1977 Archaic Period Research in the Lower Little Tennessee River Valley. University of Tennessee, Department of Anthropology Report of Investigations No. 18.

Clay, R. Berle.

1980 The Cultural Historical Placement of Fayette Thick Ceramics in Central Kentucky. Tennessee Anthropologist 5(2):166-178.

Clench, William J.

1963. Mollusca. In Freshwater Biology, edited by W. T. Edmondson, pp. 1117-1160. John Wiley \& Sons, New York.

Collins, Michael B. (editor).

1979 Excavations at Four Archaic Sites in the Lower Ohio Valley, Jefferson County, Kentucky, Volume I. University of Kentucky, Department of Anthropology, Occasional Papers in Anthropology No. 1.

Conkin, James E. and Barbara M. Conkin

1961 Fossil Land Snails from the Loess at Vicksburg, Mississippi. Transactions of the Kentucky Academy of Science 22(1-2):11-15.

Filson, John

1962 The Discovery, Settlement and Present State of Kentucke. Corinth Books, New York.

Goodrich, Calvin, et al.

1944 A revision of the Mollusca of Indiana. The American Midland Naturalist $32(2): 257-326$.

Granger, Joseph E.

n.d. A Study of Falls Region Archaeology. Ms. on file, University of Louisvilie, Archaeological Survey.

Granger, Joseph E.

1981 A current synthesis of Falls Region Prehistory. In Toward a Research and Management Design: Cultural Resources Studies in the Falls Region of Kentucky, Vol. 3. Kentucky Heritage Commission, Frankfort. In press.

Gray, Henry

1977 Gray's Anatomy, Descriptive and Surgical, Fifteenth English Edition, Bounty Books, New York. 
Griffin, James Bennett

1966 The Fort Ancient Aspect. Its Cultural and Chronological Position in Mississippi Valley Archaeology. University of Michigan, Museum of Anthropology, Anthropological Papers No. 28 .

Guldbeck, Per Ernst

1972 The Care of Historical Collections. American Association for State and Local History, Nashville.

Hoyt, Robert D., Stuart E. Neff and Vincent H. Resh

1979 Distribution, Abundance, and Species Diversity of the Upper Salt River Drainage, Kentucky. Transactions of the Kentucky Academy of Science $40(1-2): 1-20$.

Kentucky Department of Transportation, Bureau of Highways

1978 I-65 (Kentucky Turnpike) Final Environmental Impact Statement. Federal Highway Administration and Kentucky Department of Transportation, Frankfort.

Kepferle, Roy C.

1972 Geologic Map of the Brooks Quadrangle Bullitt and Jefferson Counties, Kentucky. The U. S. Geological Survey, Washington, D. C.

Klinger, Timothy $C$. and L. Mark Raab

1980 Archaeological Significance and the National Register: A Response to Barnes, Briggs and Nielson. American Antiquity 45:554-557.

Krogman, Wilton Marion

1973 The Human Skeleton in Forensic Medicine. Charles C. Thomas, Springfield, Illinois.

Krumholz, Louis A. and Stuart E. Neff

1974 Changes in the Economy and Ecology at Proposed Lake Sites in the Salt River Basin, Kentucky, During Early Construction of the Dam for Taylorsville Lake. University of Louisville Water Resources Laboratory, Research Report No. 78.

Lewis, Thomas M. N. and Madeline Kneberg Lewis

1961 Eva: An Archaic Site. University of Tennessee Press, Knoxville.

McGraw, Betty J.

1975 Archaeological Impact Assessment Kentucky Turnpike Project. In Kentucky Impact Assessment, pp. 75-131. Hazelett and Erda 7 Environmental Engineers, Louisville, Kentucky.

McGraw, Betty J.

1977 Archaeological Characteristics of the Project Area. In Draft Environmental Impact Statement, Jefferson-Bullitt-Hardin Counties, Kentucky Turnpike (I-65), pp. 22-41. FederaT Highway Administration and Kentucky Department of Transportation, Frankfort. 
Miller, Wihry, and Lee

1980 Draft Working Papers Floyd's Fork Management Plan. Prepared for Jefferson County Environmental Policy Office, Louisville, Kentucky.

Monroe, Burt L., Jr.

1976 Birds of the Louisville Region. The Kentucky Warbler 52(3): 27.

Moratto, Michael J. and Roger E. Kelly

1978 Optimizing Strategies for Evaluating Archaeological Significance. In Advances in Archaeological Theory and Method, Vol. I, edited by Michael B. Schiffer, pp. 1-30. Academic Press, New York.

Munse 11 Color

1975 Munsel1 Soil Color Charts. Kollmorgen, Baltimore

Neumann, Georg K.

n.d. Laboratory Manual, Bloomington, Indiana.

Perino, Gregory

1971 Guide to the Identification of Certain American Indian Projectile Points. Special Bulletin No. 4, Oklahoma Anthropological Society.

Raab, L. Mark and Timothy C. K1inger

1977 A Critical Appraisal of "Significance" in Contract Archaeology. American Antiquity 42:629-633.

Ranson, Stephen Walter

1959 The Anatomy of the Nervous System: Its Development and Function, Tenth Edition: Revised by Sam Lillard Clark, W. B. Sanders, Philadelphia.

Ritchie, William A.

1961 A Typology and Nomenclature for New York Projectile Points. New York State Museum and Science Bulletin No. 384.

Rollingson, Martha Ann

1967 Temporal Perspective on the Archaic Cultures of the Middle Green River Region, Kentucky. Ph.D. Dissertation, University of Michigan. University Microfilms, Ann Arbor.

Scovill, Douglas H., Garland J. Gordon and Keith M. Anderson

1977 Guidelines for the Preparation of Statements of Environmental Impact on Archaeological Resources. In Conservation Archaeology, edited by M. B. Schiffer and G. J. Gumerman, pp. 43-62. Academic Press, New York.

Sharrock, Floyd W. and Donald K. Grayson

1979 "Significance" in Contract Archaeology. American Antiquity $44: 327-328$. 
Siegel, Sidney

1956 Nonparametric Statistics for the Behavioral Sciences. McGrawHi17, New York.

Sokal, Robert R. and F. James Rohlf

1969 Biometry, The principles and practice of statistics in biological research. W. H. Freeman, San Francisco.

Taylor, Ralph W.

1980 Mussels of Floyd's Fork, a Small Northcentral Kentucky Stream (Unionidae). The Nautilus 94(1):13-15.

Walker, Eugene $\mathrm{H}$.

1957 The Deep Channel and Alluvial Deposits of the Ohio Valley in Kentucky. Geological Survey Water-Supply Paper 1411. United States Government Printing Office, Washington, D. C.

Winters, Howard D.

1969 The Riverton Culture: A Second Millenium Occupation in the Central Wabash Valley. Illinois State Museum, Reports of Investigation No. 13 . 
APPENDIX A

BURIAL DATA 
Appendix A. Ashworth Burials Dentition and Attrition Rates

\begin{tabular}{|c|c|c|c|c|c|c|c|c|}
\hline & \multicolumn{2}{|c|}{$\begin{array}{c}\text { Mandible } \\
\text { Left Right }\end{array}$} & \multicolumn{2}{|c|}{$\begin{array}{l}\text { Maxilla } \\
\text { Left Right }\end{array}$} & \multicolumn{2}{|c|}{$\begin{array}{c}\text { Mandible } \\
\text { Left Right }\end{array}$} & \multicolumn{2}{|c|}{$\begin{array}{l}\text { Maxilia } \\
\text { Left Righ }\end{array}$} \\
\hline & Burial & $\# 1$ & & & Buri & $\# 2$ & & \\
\hline \multirow[t]{2}{*}{$\begin{array}{l}\text { medial incisor } \\
\text { lateral incisor } \\
\text { canine } \\
\text { premolar } 1 \\
\text { premolar } 2 \\
\text { molar } 1 \\
\text { molar } 2 \\
\text { molar } 3\end{array}$} & $\begin{array}{l}3 \\
3 \\
\text { PM } \\
3 \\
3 \\
5++ \\
4 \\
2\end{array}$ & $\begin{array}{l}3 \\
3 \\
2 \\
2 \\
2 \\
2 \\
2 \\
\text { NO }\end{array}$ & $\begin{array}{l}3 \\
\mathrm{PM} \\
2 \\
5 \\
\mathrm{PM} \\
5+ \\
4 \\
2\end{array}$ & $\begin{array}{l}\text { PM } \\
\text { PM } \\
3 \\
2 \\
\text { AM } \\
\text { AM } \\
2 \\
2\end{array}$ & $\begin{array}{l}5 \\
5 \\
5 \\
5 \\
5+ \\
5+ \\
5+ \\
3\end{array}$ & $\begin{array}{l}5 \\
5 \\
5 \\
5 \\
5+ \\
5+ \\
5+ \\
3\end{array}$ & $\begin{array}{l}5 \\
5 \\
5 \\
5 \\
5+ \\
5+ \\
5+ \\
3\end{array}$ & $\begin{array}{l}5 \\
5 \\
P M \\
5 \\
5+ \\
5+ \\
5+ \\
3\end{array}$ \\
\hline & Burial & $\# 4$ & & & Buri & $\# 5$ & & \\
\hline \multirow[t]{2}{*}{$\begin{array}{l}\text { medial incisor } \\
\text { lateral incisor } \\
\text { canine } \\
\text { premolar } 1 \\
\text { premolar } 2 \\
\text { molar } 1 \\
\text { molar } 2 \\
\text { molar } 3\end{array}$} & $\begin{array}{l}4 \\
4 \\
4 \\
5 \\
5+ \\
5++ \\
5++ \\
5\end{array}$ & $\begin{array}{l}4 \\
4 \\
4 \\
5+ \\
5++ \\
5++ \\
5++ \\
5\end{array}$ & $\begin{array}{l}5 \\
5 \\
5 \\
5++ \\
5++ \\
6 \\
6 \\
5++\end{array}$ & $\begin{array}{l}5 \\
5 \\
5 \\
5++ \\
5++ \\
6 \\
6 \\
5+\end{array}$ & $\begin{array}{l}E \\
E \\
E \\
E \\
C P \\
C P\end{array}$ & $\begin{array}{l}E \\
E \\
E \\
E \\
C P \\
C P\end{array}$ & $\begin{array}{l}E \\
E \\
E \\
E \\
C P \\
C P\end{array}$ & $\begin{array}{l}E \\
E \\
E \\
E \\
C P \\
C P\end{array}$ \\
\hline & Burial & $\# 7$ & & & Buri & $\# 8$ & & \\
\hline $\begin{array}{l}\text { medial incisor } \\
\text { lateral incisor } \\
\text { canine } \\
\text { premolar } 1 \\
\text { premolar } 2 \\
\text { molar } 1 \\
\text { molar } 2 \\
\text { molar } 3\end{array}$ & $\begin{array}{l}- \\
\overline{-} \\
-\end{array}$ & $\begin{array}{l}\bar{Z} \\
\overline{-}\end{array}$ & $\begin{array}{l}- \\
\overline{C P} \\
C P \\
C P\end{array}$ & $\begin{array}{l}\overline{-} \\
\overline{-}\end{array}$ & $\begin{array}{l}2 \\
1 \\
1 \\
1 \\
2 \\
2+ \\
1 \\
\mathrm{CP}\end{array}$ & $\begin{array}{l}\text { PM } \\
2 \\
1 \\
2 \\
2 \\
2+ \\
1 \\
C P\end{array}$ & $\begin{array}{l}2 \\
1 \\
1 \\
1 \\
1 \\
3 \\
2 \\
C P\end{array}$ & $\begin{array}{l}2 \\
2 \\
1 \\
1 \\
2 \\
3 \\
2 \\
\mathrm{CP}\end{array}$ \\
\hline
\end{tabular}

Key to table for those codes not found in Brothwel1 1972:69.

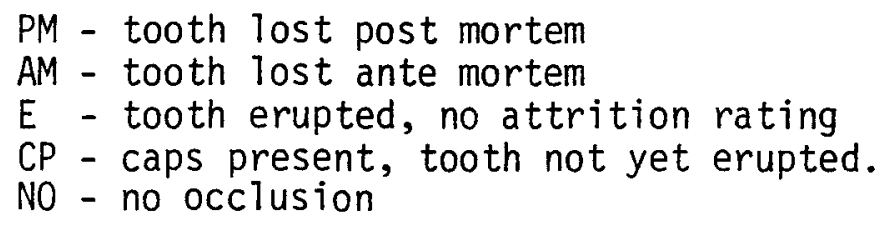


Ashworth Burials Metric Observations*

\begin{tabular}{|c|c|c|c|c|c|c|c|c|c|c|c|c|}
\hline \multirow[b]{2}{*}{ Cranial Vault } & \multicolumn{2}{|c|}{ Burial \#1 } & \multicolumn{2}{|c|}{ Burial \#2 } & \multicolumn{2}{|c|}{ Burial \#4 } & \multicolumn{2}{|c|}{ Burial \#5 } & \multicolumn{2}{|c|}{ Burial \#6 } & \multicolumn{2}{|c|}{ Burial \#8 } \\
\hline & Left & Right & Left & Right & Left & Right & Left & Right & Left & Right & Left & Right \\
\hline $\begin{array}{l}\text { Maximum length } \\
\text { Maximum breadth } \\
\text { Basion-bregma height } \\
\text { Cranial Index } \\
\text { Cranial Module } \\
\text { Cranial length-height } \\
\text { Cranial breadth-height } \\
\text { Mean Height Index } \\
\text { Mean Basion-height Index } \\
\text { Minimum Frontal Breadth }\end{array}$ & & $\begin{array}{l}174.0 \\
141.0 \\
\text { NA } \\
81.03 \\
\text { NA } \\
\text { NA } \\
\text { NA } \\
\text { NA } \\
\text { NA } \\
\text { NA }\end{array}$ & & $\begin{array}{l}180 \\
131 \\
\text { NA } \\
72.77 \\
\text { NA } \\
\text { NA } \\
\text { NA } \\
\text { NA } \\
\text { NA } \\
\text { NA }\end{array}$ & & $\begin{array}{l}184.0 \\
142.0 \\
134.0 \\
77.17 \\
153.33 \\
72.83 \\
94.37 \\
82.21 \\
82.21 \\
101.0\end{array}$ & & $\begin{array}{l}\text { NA } \\
\text { NA } \\
\text { NA } \\
\text { NA } \\
\text { NA } \\
\text { NA } \\
\text { NA } \\
\text { NA } \\
\text { NA } \\
\text { NA }\end{array}$ & & $\begin{array}{l}\text { NA } \\
\text { NA } \\
\text { NA } \\
\text { NA } \\
\text { NA } \\
\text { NA } \\
\text { NA } \\
\text { NA } \\
\text { NA } \\
\text { NA }\end{array}$ & & $\begin{array}{l}\text { NR } \\
\text { NR } \\
\text { NR } \\
\text { NR } \\
\text { NR } \\
\text { NR } \\
\text { NR } \\
\text { NR } \\
\text { NR } \\
\text { NR }\end{array}$ \\
\hline \multicolumn{13}{|l|}{ Mandible } \\
\hline $\begin{array}{l}\text { Bicondylar breadth } \\
\text { Symphys is height } \\
\text { Bigoinal breadth } \\
\text { Ramus height } \\
\text { Ramus minimum breadth } \\
\text { Gonial angle }\end{array}$ & $\begin{array}{l}66.0 \\
29.0 \\
107^{\circ}\end{array}$ & $\begin{array}{l}128.0 \\
32.0 \\
103.0 \\
64.0 \\
30.0 \\
108^{\circ}\end{array}$ & $\begin{array}{l}62.5 \\
31.75 \\
105^{\circ}\end{array}$ & $\begin{array}{l}126.5 \\
33.5 \\
100.5 \\
\text { NA } \\
\text { NA } \\
\text { NA }\end{array}$ & $\begin{array}{l}\text { NA } \\
\text { NA } \\
\text { NA }\end{array}$ & $\begin{array}{l}111.0 \\
37.0 \\
102.0 \\
57.5 \\
31.0 \\
119^{\circ}\end{array}$ & $\begin{array}{l}\text { NA } \\
\text { NA } \\
\text { NA }\end{array}$ & $\begin{array}{l}\text { NA } \\
\text { NA } \\
\text { NA } \\
\text { NA } \\
\text { NA } \\
\text { NA }\end{array}$ & $\begin{array}{l}\text { NA } \\
\text { NA } \\
\text { NA }\end{array}$ & $\begin{array}{l}\text { NA } \\
\text { NA } \\
\text { NA } \\
\text { NA } \\
\text { NA } \\
\text { NA }\end{array}$ & $\begin{array}{l}\text { NA } \\
\text { NA } \\
\text { NA }\end{array}$ & $\begin{array}{l}\text { NA } \\
29.0 \\
97.0 \\
55.5 \\
32.5 \\
+\end{array}$ \\
\hline \multicolumn{13}{|l|}{ Palate } \\
\hline $\begin{array}{l}\text { External } \\
\text { Maxillo-alveolar length } \\
\text { Maxillo-alveolar breadth } \\
\text { Maxillo-alveolar Index } \\
\text { Internal }\end{array}$ & & $\begin{array}{l}54.0 \\
55.0 \\
101.85\end{array}$ & & $\begin{array}{l}47.5 \\
68.0 \\
143.16\end{array}$ & & $\begin{array}{l}50.0 \\
61.0 \\
122.0\end{array}$ & & $\begin{array}{l}\text { NA } \\
\text { NA } \\
\text { NA }\end{array}$ & & $\begin{array}{l}\text { NA } \\
\text { NA } \\
\text { NA }\end{array}$ & & $\begin{array}{l}46.0 \\
39.0 \\
84.78\end{array}$ \\
\hline $\begin{array}{l}\text { Palatal length } \\
\text { Palatal ireadth } \\
\text { Palatal Index }\end{array}$ & & $\begin{array}{l}\text { NA } \\
36.0 \\
\text { INA }\end{array}$ & & $\begin{array}{l}47.0 \\
42.0 \\
89.36\end{array}$ & & $\begin{array}{l}47.5 \\
40.0 \\
84.21\end{array}$ & & $\begin{array}{l}\text { NA } \\
\text { NA } \\
\text { NA }\end{array}$ & & $\begin{array}{l}\text { NA } \\
\text { NA } \\
\text { NA }\end{array}$ & & $\begin{array}{l}54.0 \\
65.5 \\
121.30\end{array}$ \\
\hline
\end{tabular}


Ashworth Burials Metric Observations* (cont.)

\begin{tabular}{|c|c|c|c|c|c|c|c|c|c|c|c|c|}
\hline \multirow[b]{2}{*}{ Facial } & \multicolumn{2}{|c|}{ Burial \#1 } & \multicolumn{2}{|c|}{ Burial \#2 } & \multicolumn{2}{|c|}{ Burial \#4 } & \multirow{2}{*}{$\frac{\text { Burial }}{\text { Left }}$} & \multirow{2}{*}{$\frac{\# 5}{\text { Right }}$} & \multicolumn{2}{|c|}{ Burial \#6 } & \multicolumn{2}{|c|}{ Burial \#8 } \\
\hline & Left & Right & Left & Right & Left & Right & & & Left & Right & Left & Right \\
\hline $\begin{array}{l}\text { Total facial height } \\
\text { Upper facial height } \\
\text { Bizygomatic breadth } \\
\text { Total facial Index } \\
\text { Upper facial Index }\end{array}$ & & $\begin{array}{l}55.5 \\
\text { NA } \\
136.0 \\
40.80 \\
\text { NA }\end{array}$ & & $\begin{array}{l}59.0 \\
49.0 \\
140.0 \\
42.14 \\
35.0\end{array}$ & & $\begin{array}{l}114.5 \\
67.5 \\
126.5 \\
90.51 \\
53.36\end{array}$ & & $\begin{array}{l}\text { NA } \\
\text { NA } \\
\text { NA } \\
\text { NA } \\
\text { NA }\end{array}$ & & $\begin{array}{l}\text { NA } \\
\text { NA } \\
\text { NA } \\
\text { NA } \\
\text { NA }\end{array}$ & & $\begin{array}{l}\text { NA } \\
\text { NA } \\
\text { NA } \\
\text { NA } \\
\text { NA }\end{array}$ \\
\hline \multicolumn{13}{|l|}{ Nose } \\
\hline $\begin{array}{l}\text { Nasal height } \\
\text { Nasal breadth } \\
\text { Nasal Index }\end{array}$ & & $\begin{array}{l}\text { NA } \\
\text { NA } \\
\text { NA }\end{array}$ & & $\begin{array}{l}55.0 \\
20.25 \\
36.82\end{array}$ & & $\begin{array}{l}47.0 \\
24.5 \\
52.13\end{array}$ & & $\begin{array}{l}\text { NA } \\
\text { NA } \\
\text { NA }\end{array}$ & & $\begin{array}{l}\text { NA } \\
\text { NA } \\
\text { NA }\end{array}$ & & $\begin{array}{l}\text { NA } \\
\text { NA } \\
\text { NA }\end{array}$ \\
\hline \multicolumn{13}{|l|}{ Orbits } \\
\hline $\begin{array}{ll}\text { Orbital height } \\
\text { Orbital breadth } \\
\text { Orbital Index }\end{array}$ & $\begin{array}{l}35.0 \\
37.5 \\
93.33\end{array}$ & $\begin{array}{l}+ \\
+ \\
+\end{array}$ & $\begin{array}{l}36.0 \\
38.5 \\
93.51\end{array}$ & $\begin{array}{l}+ \\
+ \\
+\end{array}$ & $\begin{array}{l}33.5 \\
38.5 \\
87.01\end{array}$ & $\begin{array}{l}+ \\
+ \\
+\end{array}$ & $\begin{array}{l}\text { NA } \\
\text { NA } \\
\text { NA }\end{array}$ & $\begin{array}{l}\text { NA } \\
\text { NA } \\
\text { NA }\end{array}$ & $\begin{array}{l}\text { NA } \\
\text { NA } \\
\text { NA }\end{array}$ & $\begin{array}{l}\text { NA } \\
\text { NA } \\
\text { NA }\end{array}$ & $\begin{array}{l}\text { NA } \\
\text { NA } \\
\text { NA }\end{array}$ & $\begin{array}{l}\text { NA } \\
\text { NA } \\
\text { NA }\end{array}$ \\
\hline \multicolumn{13}{|l|}{ Sternum } \\
\hline $\begin{array}{l}\text { length-manubrium } \\
\text { length-body }\end{array}$ & & $\begin{array}{l}51.5 \\
104.5\end{array}$ & & $\begin{array}{l}45.0 \\
125.5\end{array}$ & & $\begin{array}{l}49.0 \\
82.0\end{array}$ & & $\begin{array}{l}\text { NO } \\
\text { NO }\end{array}$ & & $\begin{array}{l}\text { NO } \\
\text { NO }\end{array}$ & & $\begin{array}{l}39.0 \\
\text { NR }\end{array}$ \\
\hline \multicolumn{13}{|l|}{ Scapula } \\
\hline $\begin{array}{l}\text { Maximum length } \\
\text { Maximum breadth } \\
\text { Length of spine } \\
\text { Length-supra-spinous line } \\
\text { Length-infra-spinous line } \\
\text { Scapula index }\end{array}$ & $\begin{array}{l}\text { NA } \\
\text { NA } \\
\text { NA } \\
\text { NA } \\
\text { NA } \\
\text { NA }\end{array}$ & $\begin{array}{l}\text { NA } \\
94.5 \\
123.5 \\
74.5 \\
114.0 \\
\text { NA }\end{array}$ & $\begin{array}{l}\text { NA } \\
\text { NA } \\
\text { NA } \\
\text { NA } \\
\text { NA } \\
\text { NA }\end{array}$ & $\begin{array}{l}\text { NA } \\
\text { NA } \\
\text { NA } \\
\text { NA } \\
\text { NA } \\
\text { NA }\end{array}$ & $\begin{array}{l}\text { NA } \\
\text { NA } \\
\text { NA } \\
\text { NA } \\
\text { NA } \\
\text { NA }\end{array}$ & $\begin{array}{l}138.0 \\
90.5 \\
120.0 \\
47.0 \\
102.5 \\
65.58\end{array}$ & $\begin{array}{l}54.0 \\
42.0 \\
49.5 \\
23.5 \\
43.0 \\
77.78\end{array}$ & $\begin{array}{l}52.0 \\
N A \\
N A \\
N A \\
N A \\
\text { NA }\end{array}$ & $\begin{array}{l}31.0 \\
27.0 \\
29.0 \\
12.0 \\
26.5 \\
87.10\end{array}$ & $\begin{array}{l}31.0 \\
26.5 \\
27.0 \\
12.0 \\
24.5 \\
85.48\end{array}$ & $\begin{array}{l}\text { NA } \\
\text { NA } \\
\text { NA } \\
\text { NA } \\
\text { NA } \\
\text { NA }\end{array}$ & $\begin{array}{l}\text { NA } \\
\text { NA } \\
\text { NA } \\
\text { NA } \\
\text { NA } \\
\text { NA }\end{array}$ \\
\hline
\end{tabular}


Asnworth Burials Metric Observations* (cont.)

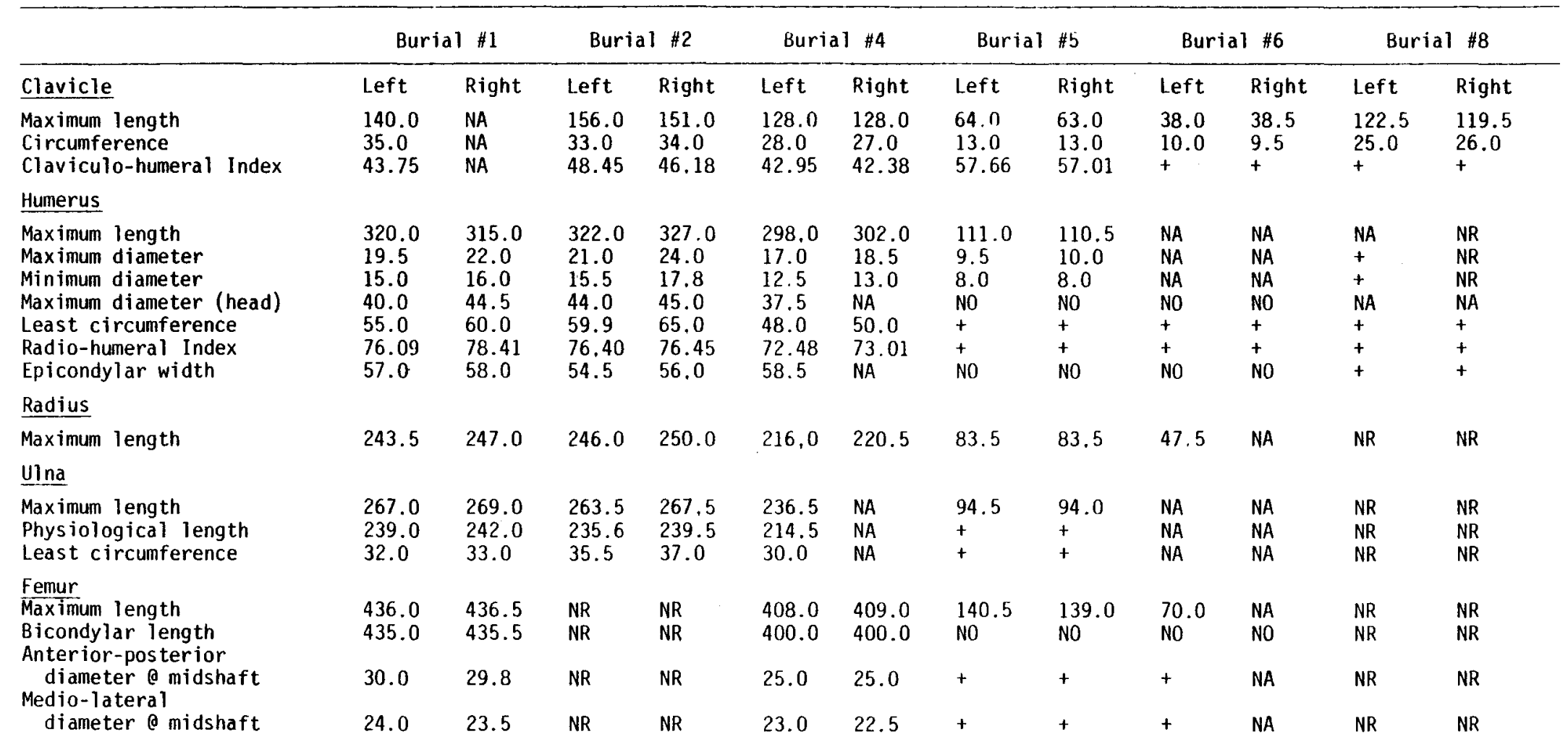


Ashworth Burials Metric Observations* (cont.)

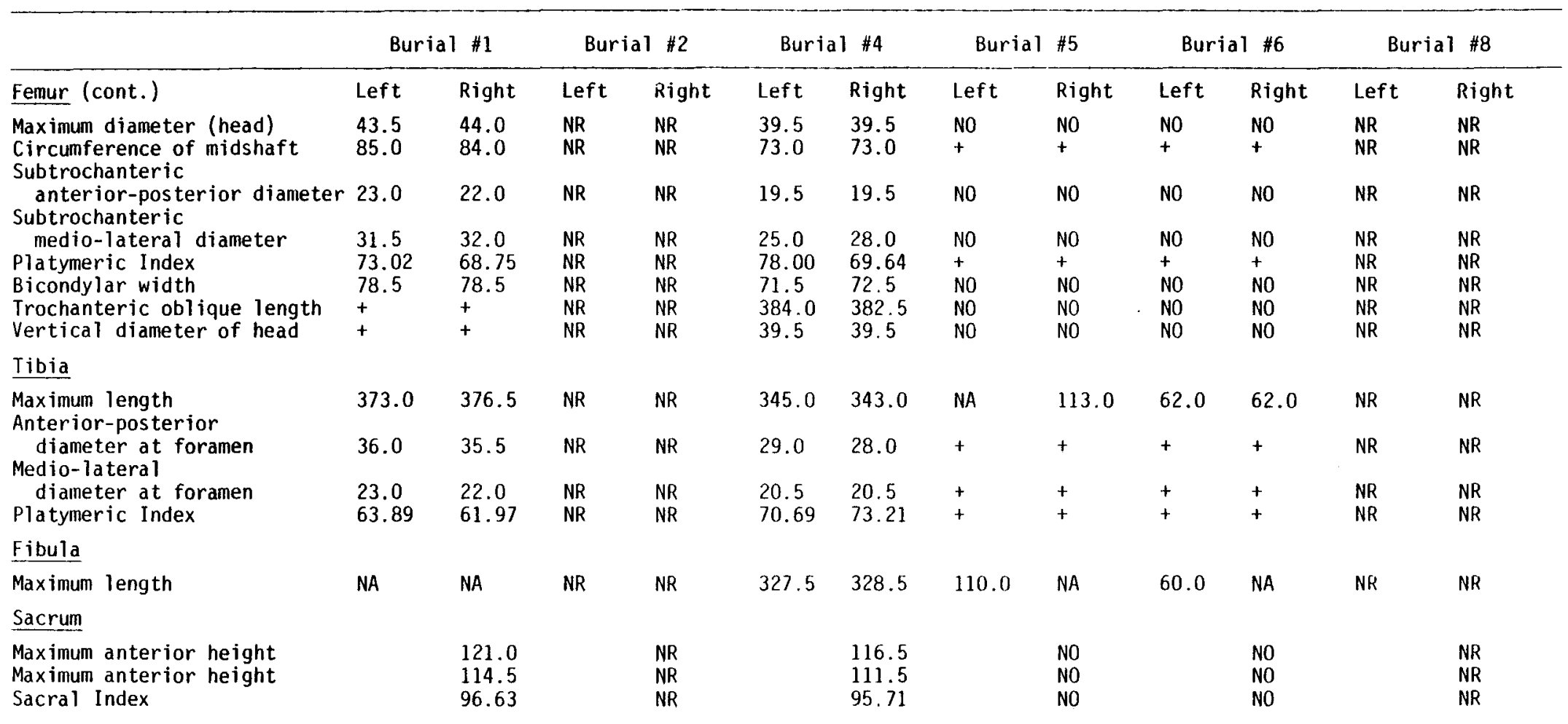


Ashworth Burials Metric Observations* (cont.)

\begin{tabular}{|c|c|c|c|c|c|c|c|c|c|c|c|c|}
\hline \multirow[b]{2}{*}{ Pelvis } & \multicolumn{2}{|c|}{ Buriai \#1 } & \multicolumn{2}{|c|}{ Burial \#2 } & \multicolumn{2}{|c|}{ Burial \#4 } & \multicolumn{2}{|c|}{ Burial \#5 } & \multicolumn{2}{|c|}{ Burial \#6 } & \multicolumn{2}{|c|}{ Burial \#8 } \\
\hline & Left & Right & Left & Right & Left & Right & Left & Right & Left & Right & Left & Right \\
\hline $\begin{array}{l}\text { Maximum height } \\
\text { Maximum breadth } \\
\text { lscnium-pubis Index } \\
\text { Pubis length } \\
\text { Ischium length }\end{array}$ & $\begin{array}{l}247.5 \\
\text { NA } \\
91.53 \\
81.0 \\
88.5\end{array}$ & $\begin{array}{l}245.5 \\
158.5 \\
84.38 \\
67.5 \\
80\end{array}$ & $\begin{array}{l}\text { NR } \\
\text { NR } \\
\text { NR } \\
\text { NR } \\
\text { NR }\end{array}$ & $\begin{array}{l}\text { NR } \\
\text { NR } \\
\text { NR } \\
\text { NR } \\
\text { NR }\end{array}$ & $\begin{array}{l}198.5 \\
150.0 \\
102.56 \\
80.0 \\
78.0\end{array}$ & $\begin{array}{l}195.0 \\
153.5 \\
153.50 \\
\text { NA } \\
\text { INA }\end{array}$ & $\begin{array}{l}\text { NO } \\
\text { NO } \\
\text { NO } \\
\text { NO } \\
\text { NO }\end{array}$ & $\begin{array}{l}\text { NO } \\
\text { NO } \\
\text { NO } \\
\text { NO } \\
\text { NO }\end{array}$ & $\begin{array}{l}\text { NO } \\
\text { NO } \\
\text { NO } \\
\text { NO } \\
\text { NO }\end{array}$ & $\begin{array}{l}\text { NO } \\
\text { NO } \\
\text { NO } \\
\text { NO } \\
\text { NO }\end{array}$ & $\begin{array}{l}\text { NR } \\
\text { NR } \\
\text { NR } \\
\text { NR } \\
\text { NR }\end{array}$ & $\begin{array}{l}N R \\
N R \\
N R \\
N R \\
N R\end{array}$ \\
\hline
\end{tabular}

*A11 measurements after Bass 1971

All measurements given in millimeters

NA - Elements present, accurate reconstruction impossible

NO - Elements not ossified, due to individual's age

NR - Elements not recovered (explained in text)

+ - Measurements not taken 
APPENDIX B

FAUNAL REMAINS 
Appendix B. Faunal Remains (MNI/number of fragments)

\begin{tabular}{|c|c|c|c|c|c|c|}
\hline & \multicolumn{4}{|c|}{ Strata } & \multirow[b]{2}{*}{$P \star$} & \multirow[b]{2}{*}{ Total } \\
\hline & $A$ & $\bar{B}$ & $\mathrm{C}$ & $\mathrm{D}$ & & \\
\hline \multicolumn{7}{|l|}{ Fishes - 250 fragments, 20 individuals } \\
\hline $\begin{array}{r}\text { Family: Lepisostidae - gars } \\
\text { Lepisosteus sp. (gars) }\end{array}$ & $1 / 1$ & $1 / 3$ & $1 / 5$ & & & $3(1) / 9$ \\
\hline Family: Catostomidae - suckers & $2 / 5$ & $3 / 9$ & $2 / 2$ & & & $7(4) / 16$ \\
\hline Family: Ictaluridae - catfishes & & & $1 / 2$ & & & $1 / 2$ \\
\hline $\begin{aligned} \text { Family: } & \text { Percidae - sauger } \\
& \text { Stizostedion sp. } \\
& \text { (sauger or walleye) }\end{aligned}$ & & $1 / 1$ & $1 / 1$ & & & $2(1) / 2$ \\
\hline Family: Centrarchidae - bass/sunfish & $1 / 1$ & & & & & $1 / 1$ \\
\hline $\begin{array}{c}\text { Family: Sciaenidae - drum } \\
\text { Aplodinotus gmmniens } \\
\text { (freshwater drum) }\end{array}$ & & $2 / 4$ & $4 / 11$ & & $/ 1$ & $6(6) / 16$ \\
\hline Fish sp. (unidentified) & $/ 12$ & $/ 55$ & $/ 137$ & & & $/ 204$ \\
\hline Total Fishes & $4 / 19$ & $7 / 72$ & $9 / 158$ & & $/ 1$ & $20(12) / 250$ \\
\hline \multicolumn{7}{|l|}{ Amphibians - 2 fragments, 2 individuals } \\
\hline $\begin{array}{l}\text { Family: Bufonidae - toads } \\
\text { Bufo comericanus or } \\
\text { B. woodhousei fowleri } \\
\text { (American or Fowler's toad) }\end{array}$ & & & $1 / 1$ & & & $1 / 1$ \\
\hline $\begin{aligned} \text { Family: } & \text { Ranidae - frogs } \\
& \text { Rona sp. (frog) }\end{aligned}$ & & & $1 / 1$ & & & $1 / 1$ \\
\hline Total Amphibians & & & $2 / 2$ & & & $2 / 2$ \\
\hline
\end{tabular}


Appendix B. (cont.)

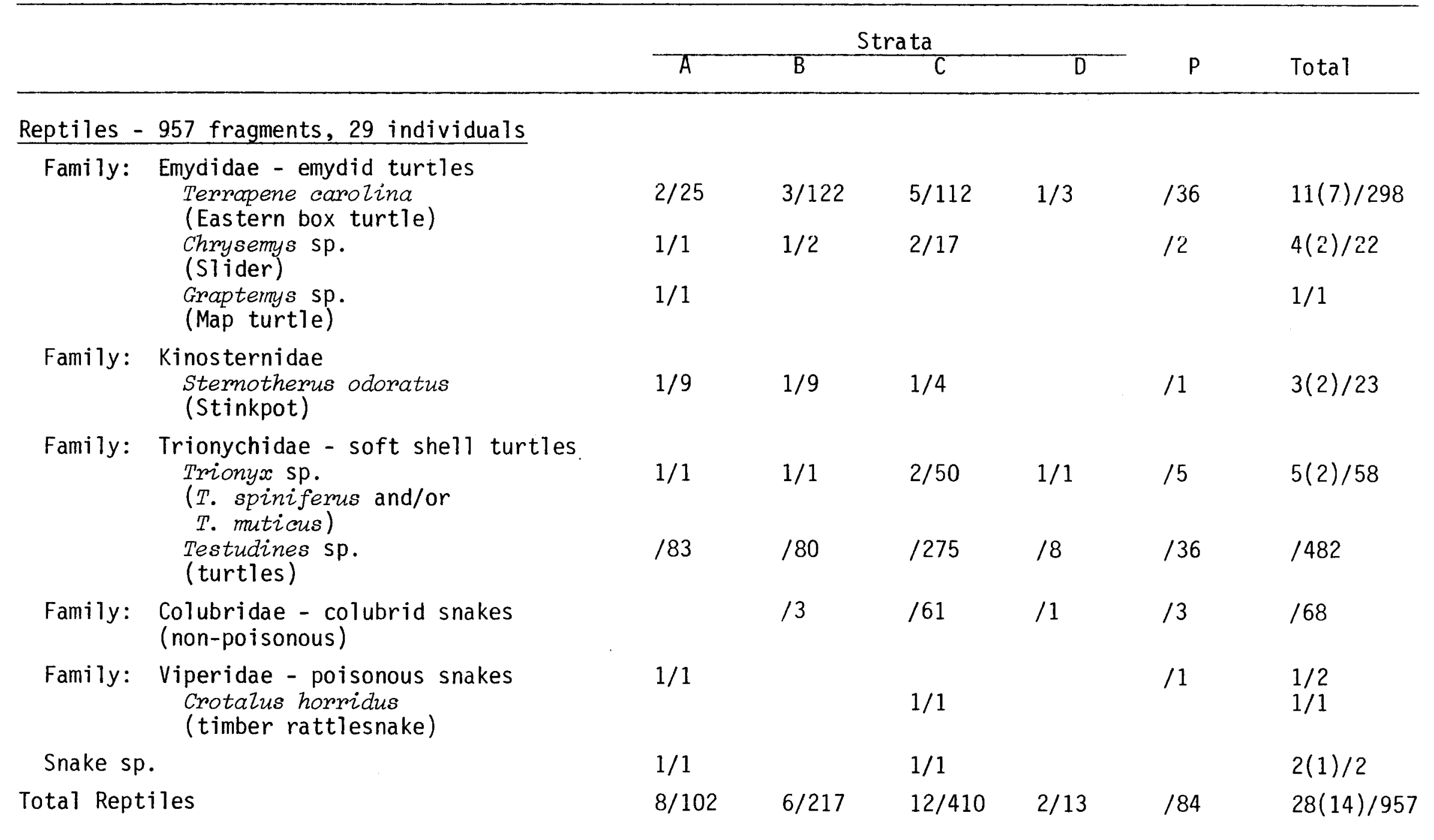




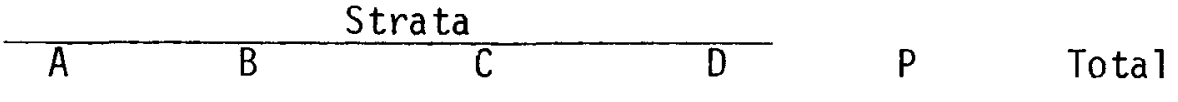

\section{Birds - 898 fragments, 16 individuals}

Family: Anatidae - ducks, etc.

cf. Branta sp.

(cf. Canada goose)

Anas sp.

(cf. Mailard or Black duck)

Anas sp.

(cf. Teal)

Duck sp.

Family: Accipitridae - hawks

Buteo Iineatus?

(Red-shouldered hawk?)

$1 / 1$

$1 / 1$

$1 / 3$

$2(1) / 4$

$1 / 1$

$1 / 1$

$1 / 1$

$1 / 1$

$1 / 1$

$1 / 1$

$1 / 1$

Family: Phasianidae - quail, etc.

cf. Colinus virginianus (cf. Bobwhite)

$1 / 1$

$1 / 1$

Family: Meleagrididae - turkeys Meleagris galzopavo (wild turkey)

$1 / 9$

$2 / 12$

$2 / 16$

$5(3) / 37$

Family: Columbidae - pigeons Ectopistes migratorius (Passenger pigeon)

$1 / 1$

$1 / 2$

$2(1) / 3$

Family: Strigidae - owls

Ow1 sp.

$1 / 1$

$1 / 1$

Family: Corvidae - jays, etc. Corvus brachyrhynchos (Common crow)

$1 / 1$

$1 / 1$

Bird sp. (unidentified)

Total Birds

$/ 132 \quad / 219 \quad / 393$

$\begin{array}{lll}1 / 141 & 7 / 236 & 7 / 417\end{array}$ 
Strata

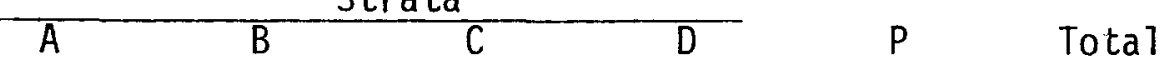

Mammals - 11,846 fragments, 116 individuals

Family: Didelphidae - opossum

Didelphis virginianus

(Opossum)

Family: Talpidae - moles

Scalopus aquaticus

(Eastern mole)

$2 / 8$

$\begin{array}{llll}1 / 1 & 1 / 5 & / 11 & 4(3) / 25\end{array}$

$\begin{array}{lllll}1 / 4 & 1 / 8 & 1 / 3 & 1 / 2 & 4(4) / 17\end{array}$

Family: Leporidae - rabbits

Sylvizagus cf. floridanus

(Eastern cottontail)

Syzvizagus sp.

(S. floridanus and/or

S. aquatious)

Family: Sciuridae - squirrels

Timias striatus

(Eastern chipmunk)

Marmota monax

(Woodchuck)

Sciums carolinensis

(Gray squirrel)

Sciumus niger

(Fox squirrel)

Sciurus sp.

(S. carolinensis and/or

$1 / 8$

\begin{tabular}{|c|c|c|c|}
\hline & $1 / 1$ & & \\
\hline$/ 11$ & $2 / 14$ & $3 / 20$ & 12 \\
\hline
\end{tabular}

S. niger)

Glaucomys volans

(Southern flying squirrel)

\begin{tabular}{|c|c|c|c|c|c|}
\hline $2 / 8$ & $2 / 6$ & $2 / 12$ & & & $6(4) / 26$ \\
\hline \multirow[t]{2}{*}{$3 / 12$} & $4 / 93$ & $1 / 7$ & & 14 & $8(5) / 116$ \\
\hline & $6 / 7$ & $3 / 5$ & & $/ 1$ & $9(9) / 13$ \\
\hline $1 / 1$ & $1 / 2$ & & & & $2(1) / 3$ \\
\hline $2 / 15$ & $5 / 53$ & $10 / 150$ & $1 / 1$ & $1 / 9$ & $19(13) / 228$ \\
\hline & $1 / 1$ & & & & $1 / 1$ \\
\hline
\end{tabular}


Appendix B. (cont.)

Strata
$\mathrm{A}$

\section{Mammals' (cont.)}

Family: Castoridae - beavers

Castor canadensis

(Beaver)

$1 / 2$

$1 / 5 \quad 1 / 4$

$1 / 4$

14

$3(3) / 15$

Family: Cricetidae - rats, mice

Peromyscus leucopus

(White-footed mouse)

Peromyscus sp.

( $P$. Zeucopus and/or

$P$. maniculatus)

Neotoma floridana

(Eastern woodrat)

Family: Arvicolidae - voles

Microtus sp.

(Meadow, Prairie, and/or

Woodland voles)

ondatra zibethicus

(Muskrat)

Family: Canidae - canids

Canis famiziarus

(Dog)

Urocyon cinereoargenteus

(Gray fox)

$1 / 2$

$2 / 2$

$1 / 1$

$1 / 1$

$1 / 2$

$1 / 1$

$2(1) / 3$

$1 / 1$

$1 / 1$

Procyonidae - raccoon

Procyon Zotor

(Raccoon) 
Appendix B. (cont.)

Strata

A $\frac{\text { Strata }}{C} \quad$ D $\quad P \quad$ Totals

Mamma 1s (cont.)

Family: Mustelidae - mustelids

Mustela frenata

(Long-tailed weasel)

Mustela vison

(Mink)

Mephitis mephitis

(Striped skunk)

\begin{tabular}{|c|c|c|c|c|}
\hline & $1 / 1$ & $1 / 1$ & & $2(1) / 2$ \\
\hline $1 / 1$ & $2 / 2$ & & & $3(2) / 3$ \\
\hline $2 / 4$ & $3 / 6$ & $2 / 2$ & $/ 1$ & $7(4) / 13$ \\
\hline
\end{tabular}

Family: Felidae - cats

Lynx rufus

(Bobcat)

Large carnivore

$1 / 2$

$1 / 2$

$1 / 1$

$1 / 1$

Family: Suidae - pigs

Sus scrofa

(Domestic pig)

1/1(surface)

$1 / 1$

Family: Cervidae - deer

odocoileus virginianus

$3 / 91$

$2 / 72$

$3 / 171$

$1 / 4$

196

$9(6) / 434$

Family: Bovidae - cows

cf. Bos taurus

(cow)

1/2(intrusion)

$1 / 2$

Mammal sp. (unidentified)

$\begin{array}{llllll}/ 1741 & / 1981 & / 5315 & / 71 & / 1964 & / 11,072\end{array}$

Total Mammals

$29 / 1953$

$40 / 2290$

$40 / 5804$

$3 / 77$

$4 / 2114116(78) / 12,238$ 
VITA

The author, Philip James DiBlasi, is the son of Philip A. DiBlasi and AnnMarie (Gorczyca) DiBlasi. He was born 6 May 1954, in Syracuse, New York.

During his father's service with the United States Air Force he attended many different elementary schools, completing his elementary education at John Glenn Elementary School, San Antonio, Texas. He completed his secondary education at Madisonville North Hopkins Senior High School, Madisonville, Kentucky, where he was graduated in 1972.

In August, 1972, he entered the University of Louisville, and in December 1976, received the degree of Bachelor of Arts with a major in Anthropology. He was married to Donna Gail Claytonin August 1974.

In August, 1976, he began graduate work in the Interdisciplinary program in Cultural Resource Management at the University of Louisville. While attending the University of Louisvilite he field-supervised twentyfour cultural resource management studies, resulting in the publication of twenty-nine technical reports. During the summer of 1977 he received a Smithsonian grant to assist in the excavation of a pre-medieval fortress in Mietlica, Poland under the direction of Stephanie Maloney (University of Louisville) and Alexander Dymaczewski (Zakład Archeologii Wielkopolski). He was elected Vice President of the Kentucky Archaeological Association in 1978. He also holds membership in the American Anthropological Association and the Society of American Archaeologists. In August, 1981, he was awarded the Master of Science in Cultural Resource Management. 